COMMUNITY COLLEGE REFORM: PLACING FOSTER YOUTH AT THE CENTER OF A MORE EQUITABLE VISION FOR SUCCESS

\author{
A dissertation submitted to the faculty of \\ San Francisco State University \\ In partial fulfillment of \\ The Requirements for \\ The Degree
}

Doctor of Education

In

Educational Leadership

\author{
by \\ Lauren Noelle Ford \\ San Francisco, California
}

May 2020 
Copyright by

Lauren Noelle Ford

2020 


\section{CERTIFICATION OF APPROVAL}

I certify that I have read Community College Reform: Placing Foster Youth at the Center of a More Equitable Reform by Lauren Noelle Ford, and that in my opinion this work meets the criteria for approving a dissertation submitted in partial fulfillment of the requirements for the degree: Doctor of Education in Educational Leadership at San Francisco State University.

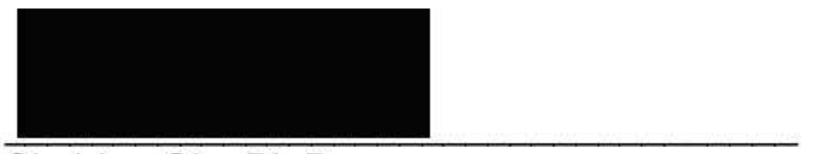

Sheldon Gin, Ph.D.

Associate Professor

School of Public Affairs \& Civic

Engagement

San Francisco State University

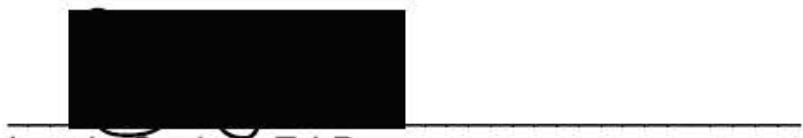

Laurie Scolari, Ed.D.

Assistant Vice President, Student

Services

Foothill College

Lecturer

San Francisco State University

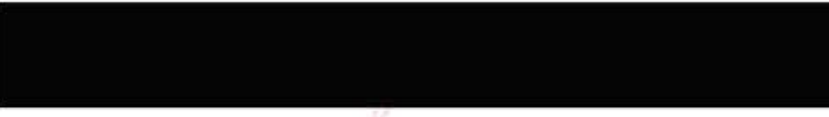

Michael Quiaoit, MPA

Dean of Educational Services \&

Support California Community Colleges

Chancellor's Office 


\title{
COMMUNITY COLLEGE REFORM: PLACING FOSTER YOUTH AT THE CENTER OF A MORE EQUITABLE VISION FOR SUCCESS
}

\author{
Lauren Noelle Ford \\ San Francisco State University \\ 2020
}

In 2016, the California Community Colleges Chancellor's Office launched the Vision for Success, a strategic plan focused on improving completion rates and closing equity gaps. This qualitative, cross case study explored the ways in which three community colleges were intending to implement Guided Pathways, a major component of the Vision for Success, specifically with equity in mind. Additionally, this study acknowledges the historically low completion rates of former foster youth. This study also explored the educational experiences for foster youth in an effort to provide recommendations to improve equitable outcomes for students. Through document analysis and practitioner interviews, findings highlighted the ways in which colleges understand equity, are approaching an equitable implementation of Guided Pathways, and how they have utilized student voice in their campus inquiry process. Additionally, foster youth shared their motivations for attending college, expressed an appreciation for support programs such as Guardian Scholars and EOPS, and provided recommendations for community college leaders on ways in which foster youth outcomes could be increased. Recommendations outline ways in which community college practitioners and policy makers can best support the needs of foster youth, and other vulnerable student populations, through current campus reform efforts in order to move the needle on student success.

\section{I certify that the Abstract is a correct representation of the content of this dissertation.}

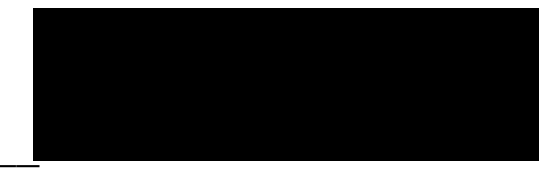

Chair, Dissertation Committee

Date 


\section{ACKNOWLEDGEMENTS}

There are not enough words to properly acknowledge and thank all of those that have helped me get to where I am today. Though, I will try. First and foremost, l'd like to thank God for allowing me to be here. To my family, Laura, Jeff, Joy, Jeffrey, and Onxy, thank you for giving me purpose, support, and a foundation of advocacy. Mommie, you are gracefully triumphant and steadfast in your purpose. I only hope to emulate that as I walk through life. To my support system: Ebon, Kenitra, Miranda, you've been there from the start: DIVAS: Christina, Keyona, Nicci, Maya; The Brunch Crew: Roosevelt, Rachel, Leniqua, El, Eric, Coltrane, Stokely; Work Fam: Grace, Danielle, Aaron, Karrie, Angélica, Regina, Tracy, Katrina, Monique, Tia - thank you all for your support, grace, understanding, and accountability. To my mentor, Lasana, thank you for seeing my potential from day one and being a constant champion. And for taking me to the movies to make sure I get out the house. To all the Aunties, I so appreciate you cheering me on. To Alina for all of the love, support, and wine over the past 10 years. To The Fam: EDDL Class of 2020: Thank you for trusting me and Norma with your voices. I'll see you on the next Monday zoom. Thank you to my committee members for the feedback, questions, and support. To Hercules, Apple Music, and Dr. T., thank you for your comfort. To the Wakandans- Denicia, Haneefah, Porscha, Silindra, Ashley, Ish, Chris: I love you, family. THIS is Black Excellence. To my students: I hope I've made you proud. A.C.W. I could not have done this without you. Thank you to my ancestors. Thank you all. Your turn, Mom. 


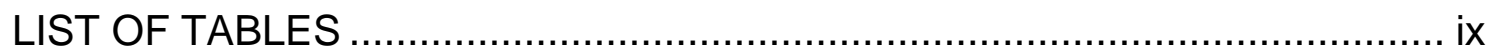

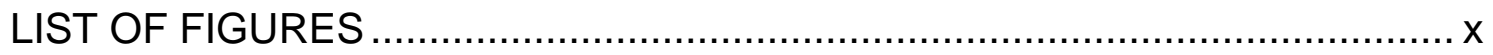

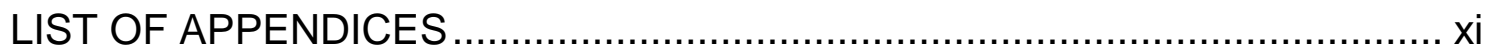

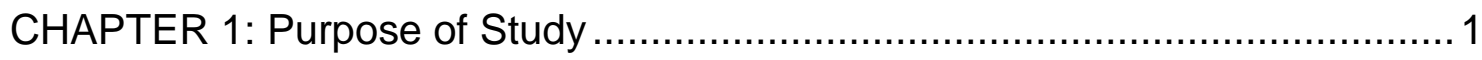

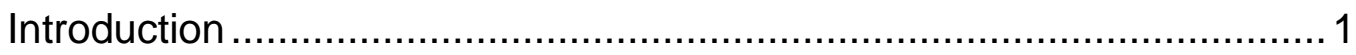

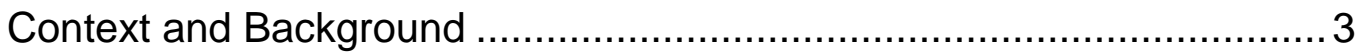

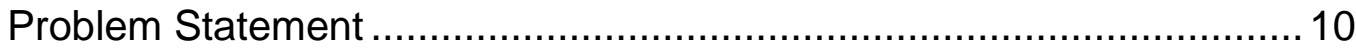

Research Questions ................................................................. 11

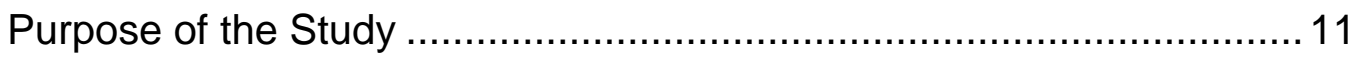

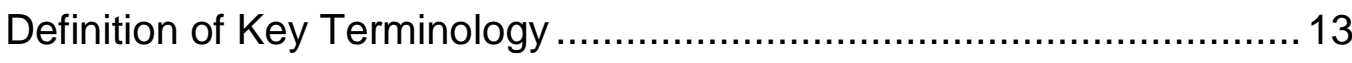

Background of Researcher .............................................................. 15

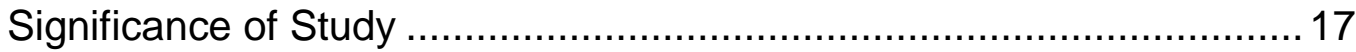

Conceptual Framework ................................................................. 19

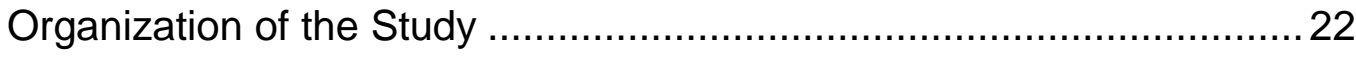

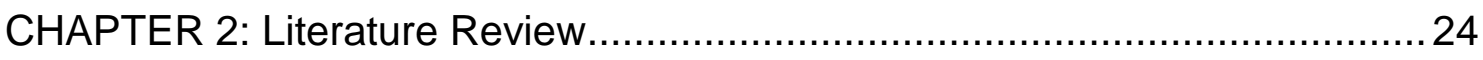

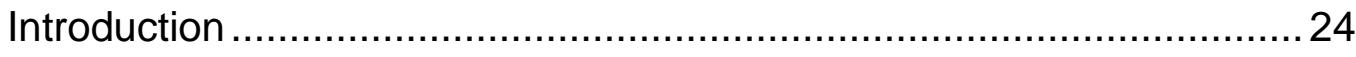

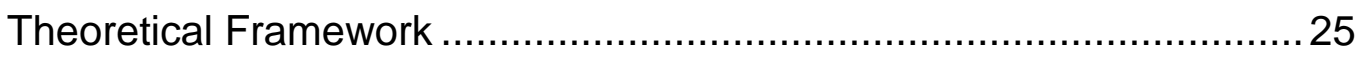

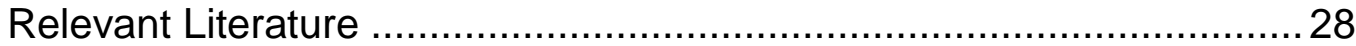

California Community College Reform ..................................... 28

Policy Reform Implementation.................................................... 34

Former Foster Youth In Community College ............................... 42

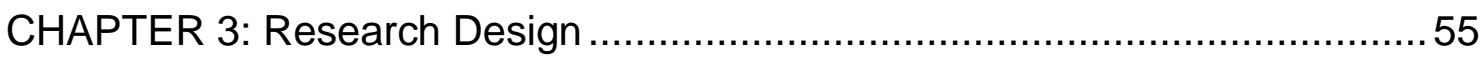

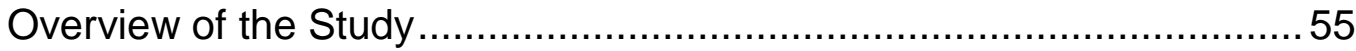

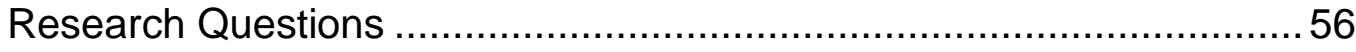

Research Design: Qualitative Cross-Case Study ...............................56

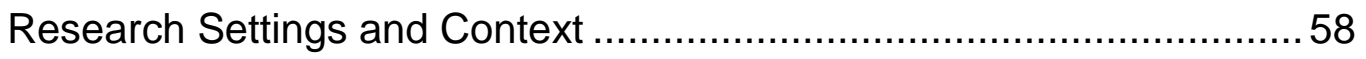




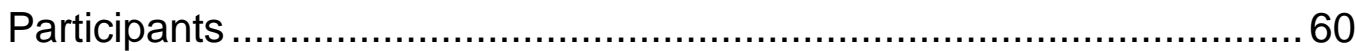

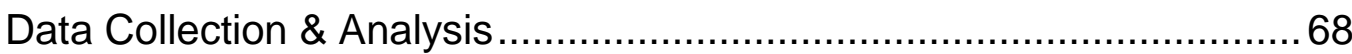

Phase I - Community College Practitioners Data Collection .......69

Phase I: Community College Practitioners Data Analysis ........... 73

Practitioner Themes and Codes............................................. 75

Phase II - Foster Youth Scholars Data Collection ....................... 80

Phase II: Foster Youth Scholars Data Analysis.......................... 87

Foster Youth Scholars Themes and Codes ............................... 88

Phase III: Cross-Case Study Analysis...................................... 92

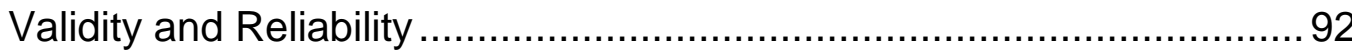

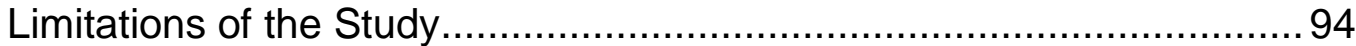

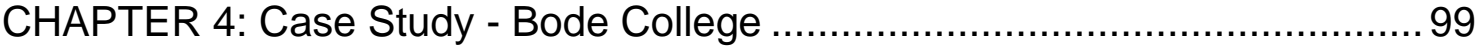

BC Guided Pathways Involvement ...................................................... 99

BC Guided Pathways Practitioner Participants ...................................... 100

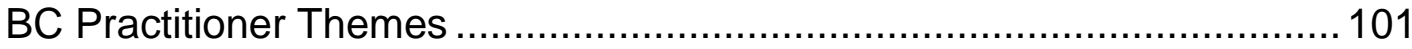

Bode College Practitioner Summary ................................................. 114

Bode College Foster Youth Scholars …….......................................... 115

The Bode College Case Summary ....................................................... 115

CHAPTER 5: Case Study - Little Streams College .................................... 117

LSC Guided Pathways Involvement ................................................ 118

LSC Guided Pathways Practitioner Participants …............................... 118

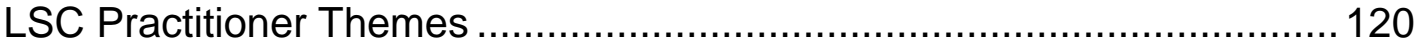

Little Streams College Practitioner Summary ...................................... 133

Little Streams College Foster Youth Scholars....................................... 134

Little Streams College Foster Youth Scholar Participants ....................... 135

Little Streams College Foster Youth Scholar Themes.............................. 136

Little Streams Foster Youth Scholars Summary................................... 144

The Little Streams College Case Summary ........................................ 145

CHAPTER 6: Case Study - Foggyville College .......................................... 147

Foggyville College Guided Pathways Involvement................................. 147 


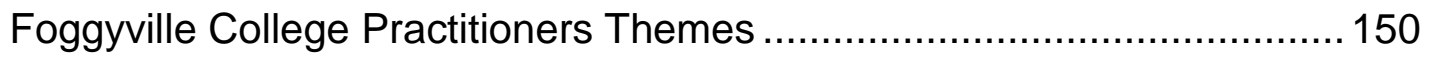

Foggyville College Practitioners Summary ............................................ 159

Foggyville College Foster Youth Scholars ……..................................... 160

Foggyville College Scholar Participants ................................................ 160

Foggyville College Foster Youth Scholar Themes ................................ 162

Foggyville College Foster Youth Scholars Summary .............................. 183

The Foggyville College Case Summary ............................................... 184

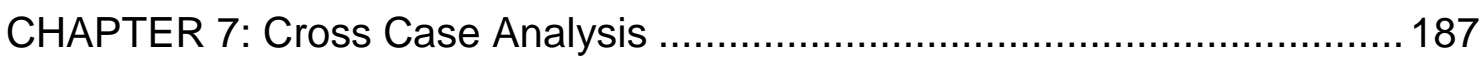

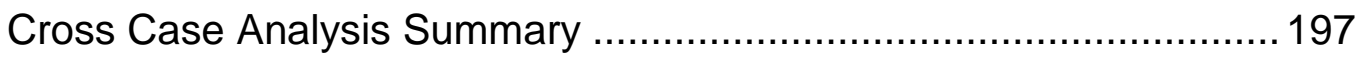

CHAPTER 8: Summary, Discussion, \& Recommendations.......................... 201

Discussion of Related Findings...................................................... 202

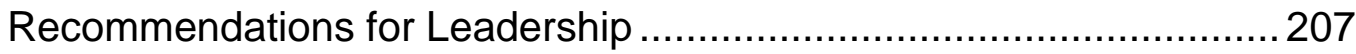

Recommendations for Policymakers …......................................... 217

Recommendations for Future Research ........................................ 219

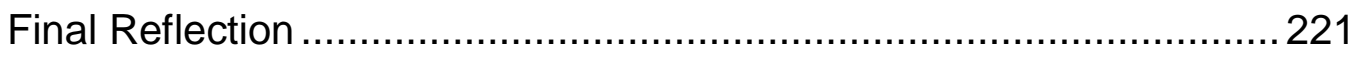

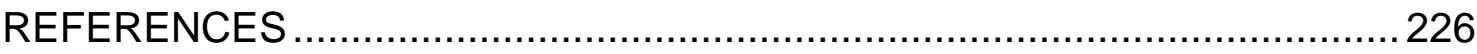

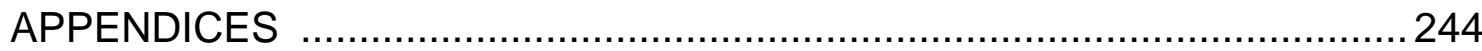




\section{LIST OF TABLES}

Table

Page

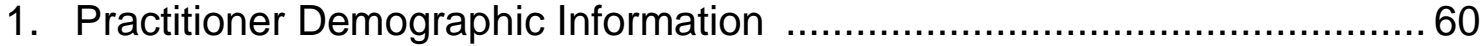

2. Paired Interview Participant Demographic Information .........................65

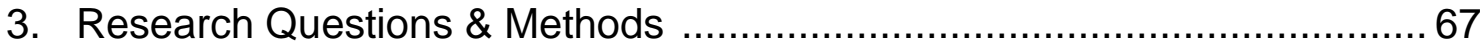

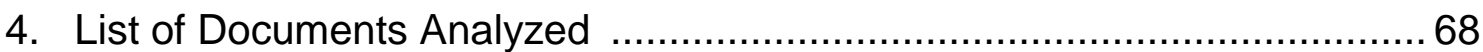

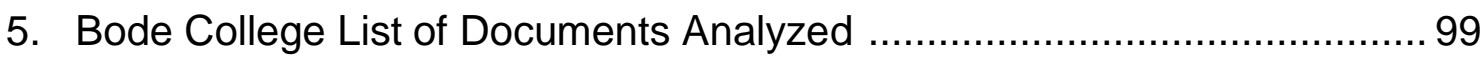

6. Little Streams College List of Documents Analyzed ........................... 117

7. Foggyville College List of Documents Analyzed ............................... 148 


\section{LIST OF FIGURES}

Figure Page

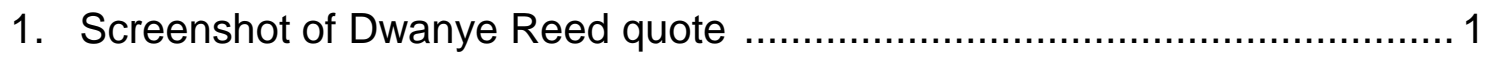

2. Neal \& Neal Neworked Model of Ecological Systems .............................. 19

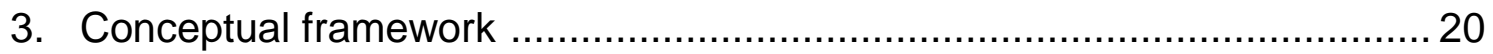

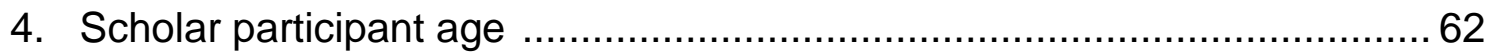

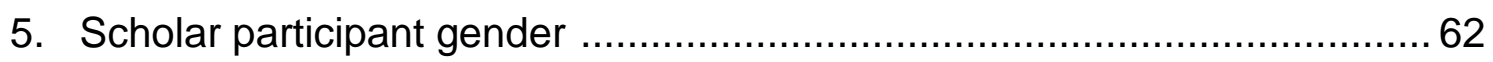

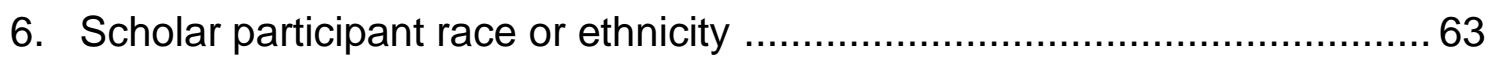

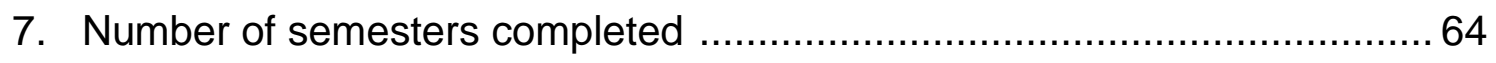

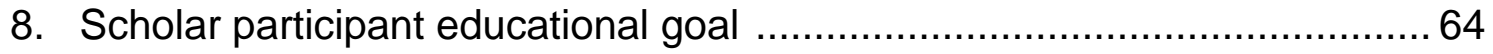

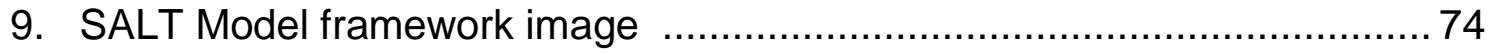

10. Bode College Guided Pathways org structure ….................................. 104

11. Little Streams College Guided Pathways change paradigm .................... 119

12. Little Streams College Guided Pathways org structure .......................... 126

13. Foggyville College Redesign framework ............................................ 146

14. Foggyville College Design Team structure ........................................... 151

15. @_cuban_link Instagram post re: COVID-19 ....................................... 220 


\section{LIST OF APPENDICES}

Appendix $\quad$ Page

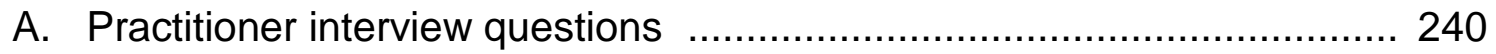

B. Practitioner interview invitation E-Mail .............................................. 242

C. Foster youth scholar E-Mail invitation to participate ..............................243

D. Scholar electronic interview questions .............................................. 245

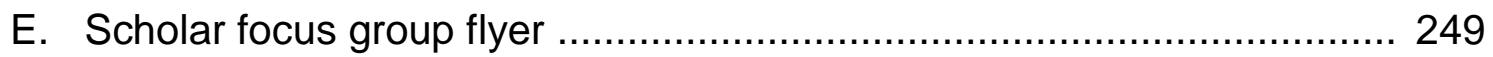

F. Scholar focus group informed consent form ..................................... 250

G. Scholar paired interview questions ……........................................ 253 
Community College Reform: Placing Foster Youth at the Center of a More Equitable Vision for Success

\section{Chapter 1: Purpose of Study}

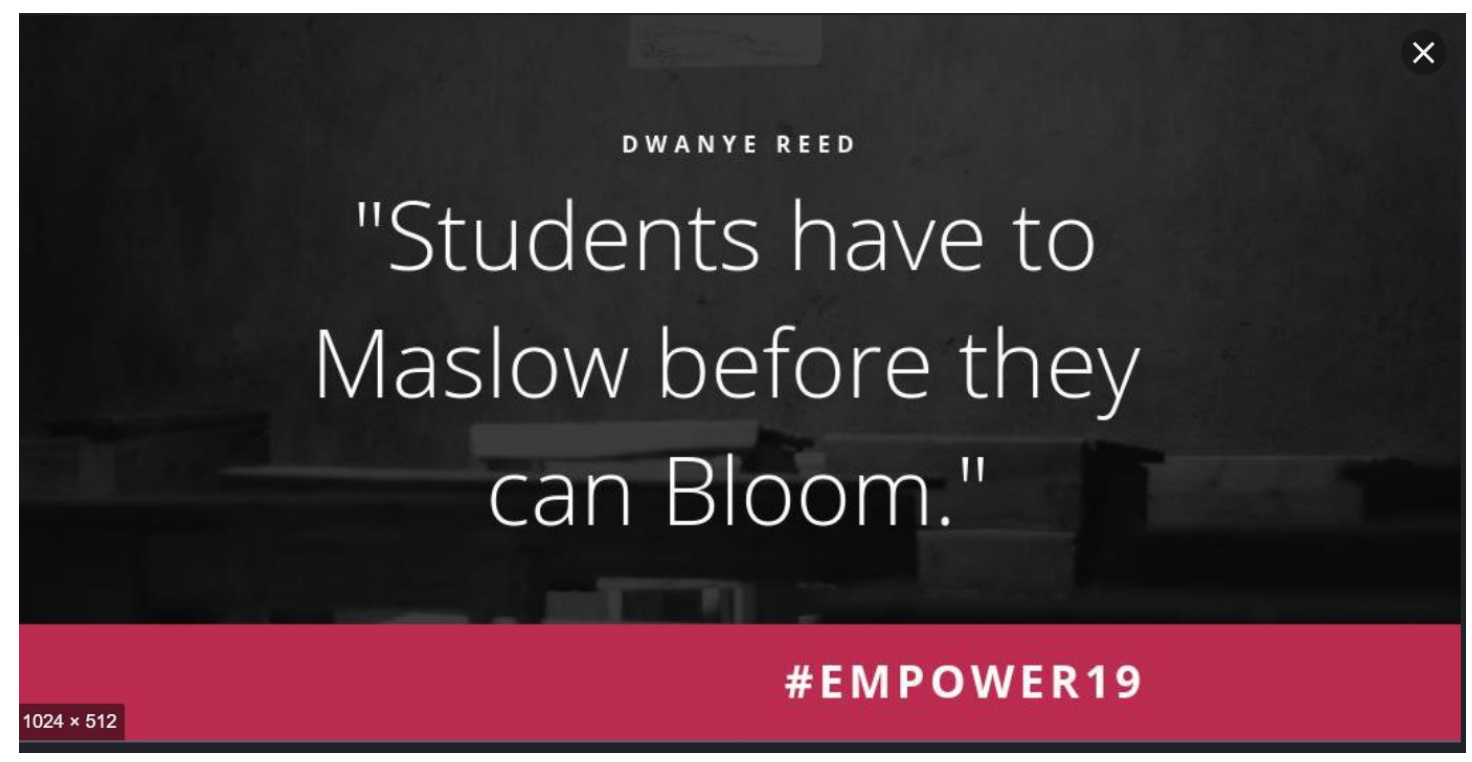

Figure 1. Screenshot of Dwanye Reed Quote "Students have to Maslow before they can Bloom."

\section{Introduction}

The quote above - Students have to Maslow before they can Bloom was delivered by Dwayne Reed during the Association for Supervision and Curriculum Development's (ASCD) 2019 Empower Conference. Dwyane Reed is a young (28 year old), Black, 4th grade teacher from Chicago. He is best known for his viral videos that highlight the creative ways in which he creates a warm, welcoming, and student centered classroom and educational experience 
for his students. I first saw the quote above on Facebook posted by a friend and K-12 Black, male educator, and I had a visceral reaction. I had never seen something so profound and yet simple in my life as it comes to the state of education today and the call for change. The idea that students need to have their basic needs met before they can truly engage in the core tenants of education - understanding, analyzing, evaluating, creating - is such a simple idea. And yet, in many educational settings, including higher education, the expectation is that students will enter our hallways and automatically begin to Bloom regardless of whether or not their Maslow has been taken care of. As an aspiring $^{1}$ community college leader, I am more and more concerned with students' feelings of safety, love and belonging, esteem, and self-actualization, and the ways in which college educators can develop an environment that fulfills these fundamental needs. As the older sister of a previously homeless, now first year community college student; and daughter of a former college drop out who returned to school after a 30 year hiatus to finish her degree, I can personally attest to the ways in which creating a welcoming, affirming, empowering, and structured college experience can take those with the most doubt and provide the space and opportunity to transform them into proud,

\footnotetext{
${ }^{1}$ Both Imposter Syndrome and my humble midwest upbringing lead me to believe that I am still an *aspiring* educational leader. However, my classmates and colleagues constantly attempt to reassure me that I am CURRENTLY an educational leader. My imposter syndrome is not the focus of this dissertation so let's move on...
} 
successful, college students. For our most minoritized students, including those that have been system impacted such as former foster youth, such opportunities for transformation can be life changing. Identifying ways in which community colleges can make intentional changes in order to help students Maslow and Bloom and as a result graduate is, to me, the premise behind the reform efforts currently taking place in California's community colleges.

The following chapter provides context and background information on the current initiatives taking place in California community colleges, outlines the problem statement, my rationale for this study, research questions, definition of key terms, and provides a roadmap of the chapters to follow.

\section{Context and Background}

The California Community College (CCC) system currently enrolls the largest portion of community college students in the United States. There are over 2.1 million students enrolled within California's 115 community colleges (Community College League of California [CCLC], 2018). For a majority of minoritized students, community colleges are the first and only entry into higher education (Ma \& Baum, 2016). Seventy-eight percent of CCC students are lowincome, 43 percent are first generation (CCLC, 2018), and 59 percent of foster youth that enter higher education start at a CCC (Frerer et al. 2013). Forty-five percent of all CCCs students are Latinx (CCLC, 2018) and Fifty-nine percent of 
all Black students enrolled in higher education are enrolled in a community college in the U.S. (American Association of Community Colleges, 2017). CCCs are the primary postsecondary option for minoritized students and as such have a tremendous responsibility to ensure that these students are successful. Unfortunately, CCC have not historically been successful in graduating students.

The overall six-year completion rate for CCCs is 48 percent (California Community College Chancellor's Office [CCCCO], 2018), even though most community college programs only require 2-3 years of coursework for a full-time student. When disaggregated to examine the completion rates of special populations, students that are former foster youth have the lowest college completion rates for ever earning an associates degree at four percent (Rassen, Cooper, \& Mery, 2010). The current structure of the community college is one in which a majority of students are unable to successfully navigate in order to achieve their intended goals. This failure disproportionately impacts low-income students, students of color, and first-generation students. Because so many minoritized communities utilize community colleges as a primary access into higher education, it is vital that community colleges are structured in a way to support student success in earning career certificates, degrees, or transfer requirements within a timely manner. The inability to earn 
a degree, certificate, or transfer within a timely manner also carries larger equity implications. For example, adults without at least an associates degree are often excluded from accessing sustainable wages, have an increased reliability on public assistance, and have more difficulty breaking generational cycles of poverty (Adair 2001; Grubb, 2002). To address these issues of inequity and to increase overall graduation rates for community college students, nationwide reform efforts are underway.

In 2015, the Obama administration issued national decree to increase the number of degree or certificate holders, nationwide, by the year 2020 (The White House, 2015). In order to achieve this goal, the national Promise initiative was developed to promote free community college to support access and decrease financial barriers to postsecondary education. The goal of the initiative was to increase the number of degree and workforce certificate holders by $50 \%$ by the year 2020 . Also in 2015 , a group of researchers from the Community College Research Center published a book entitled Redesigning America's Community Colleges, in which they explicitly posited that in order to increase completion rates for students, the community college system needs to undergo a systemic redesign (Baily, Smith Jaggers, Jenkins, 2015). Two years later in 2017, CCC Chancellor Eloy Ortiz Oakley announced a new strategic plan through a report titled "Vision for Success: Strengthening the California 
Community Colleges to Meet California's Needs." The Vision for Success report was a collaborative report written with the input of various representatives comprised of community college administrators, students, shared governance bodies, and Chancellor's Office. The report addresses concern regarding the community college system's consistently low average completion rates. It also provides recommended solutions to eliminate the equity gap, improve access, and increase completion rates. The recommendations included: more accurately assessing students upon entry into college, providing structured pathways for students, providing professional development for faculty and staff to support students, greater coordination with local school districts to support college and career pathways, and revising financial accountability systems and organizational structure to better support students. Many of these solutions have since turned into legislation to be implemented in all community colleges in California.

In an effort to close the equity gap, the Chancellor's Office specifically mentions the need to improve completion rates for underserved student populations. These student populations included student veterans, formerly incarcerated students, former foster youth, low-income students, and students with disabilities. While each of these student populations certainly face unique challenges in both navigation and completion of community college, I am most 
interested in understanding the barriers that former foster youth face. Annually, there are over 60,000 young people up to age 21 in the California foster youth system at any given time (Webster, et al., 2019). There are currently over 32,000 former foster youth enrolled in California community colleges (California Community Colleges Chancellor's Office [CCCCO] Management Information Systems Data Mart, 2019). One third of foster youth are in kinship care where they reside with a member of their family that is not their biological parent (Frerer, Davis Sosenko, \& Henke, 2013). Additionally, several studies have noted that youth in foster care often have multiple school placements while in care. The Midwest Study, a seminal, longitudinal study on the lived experiences of foster youth, reported that over 33 percent of foster youth have five or more school placements between PK-12th grade (Courtney, Terao, \& Bost, 2004). Whereas, the Northwest Study, a similar longitudinal study of foster care alumni, found that 65 percent of former foster youth have seven or more school changes (Pecora et al., 2005). The Midwest Study, also found that half of participants reported that they experienced homelessness at least once before they were 26 years old (Courtney et al., 2011). Due to the challenges that foster youth experience both inside and outside of educational settings, the postsecondary completion rates for former foster youth have consistently been low. 
The ability for foster youth to access higher education is of particular concern because there is a significant difference between the percentages of foster care youth that indicate an interest in attending college versus those that actually do. Rassen, Cooper, and Mery estimate that 4,000 foster youth emancipate from the California foster care system, annually (2010). Seventy percent of youth in foster care indicate that they would like to attend college, but only about 33 percent actually do (Rassen, Cooper, \& Mery, 2010). When looking deeper into this issue it is found that only about 50 percent of foster youth graduate from high school, 33 percent enroll in college prior to age 25, four percent earn a certificate or associate degree from a community college, and two percent earn a bachelor's degree (Morris, 2017; Rassen, Cooper, \& Mery, 2010). In comparison, over 50 percent of the general population attend college prior to age 25, and 25 percent have bachelors degrees (Salazar, 2012). The positive economic benefits of having a college degree have been widely documented. Research has found that attending college has also had positive economic outcomes on foster youth. Former foster youth that have some college, earn an associates degree, or earn a four-year degree have higher incomes and are less likely to be unemployed or rely on public assistance than foster youth with only a high school diploma or GED (Okpych \& Courtney, 2014; Salazar, 2013) 
In 2013, the Center on Education and the Workforce (CEW) at Georgetown University predicted that by 2020 , the percentage of jobs requiring an associate's degree will increase by $30 \%$ and a $35 \%$ increase for bachelor's degree (Carnevale, Smith, Strohl, 2013). With such a large portion of new jobs requiring highly skilled and highly educated workers, the postsecondary education system - especially community colleges - will be tasked with providing the education needed to secure such positions. With California's 115 community colleges the success of California community college students is vital to achieve this goal and fulfill this workforce need. In order to increase the number of degree and certificate holders, colleges will need to evaluate the challenges that students face that prevent them from completing their educational goals. The reform taking place in the California Community College system will, hopefully, increase the number of all students, including former foster youth, in accessing and completing essential programs needed to fulfill the future workforce needs and therefore change the economic trajectory of families and communities. This reform will also impact the experiences of former foster youth that attend community colleges and their potential workforce options. However, in order for students to receive the requisite training or credential to access such employment, they have to be able to successfully access, navigate, and complete their college educational goal. Seeing as how 
there are still so many students that never finish, community colleges will have to take drastic measures to move this needle.

\section{Problem Statement}

California Community Colleges are being tasked with improving overall student completion rates. One fundamental component of increasing completion rates is in the ability for an institution to identify equity gaps and implement systematic changes to address and abolish these gaps. The legislation, policies, and practices stemmed from the Vision for Success are currently being reviewed and implemented at community colleges throughout California. While the Vision for Success is not the first set of directives from policy makers to encourage, or enforce, systemwide change, it is the most recent and the most overarching reform effort in the history of CCC.

Unfortunately, little is known about the policy implementation process in community colleges.

Additionally, very few studies have captured the experiences of foster youth at community colleges - a population noted to have historically low college completion rates. Better understanding the experiences of the most vulnerable students and aligning them with the current community college reform efforts could provide a framework for college administrators to address 
the gap between the student experience vs. institution expectations, in an effort to increase overall student completion.

\section{Research Questions}

To highlight the ways in which community college practitioners operationalize equity as well as identifying what practitioners can learn from the lived experiences of former foster youth the following research questions are guiding this study:

RQ1: What are the intentional ways in which community college leaders are addressing equity in the implementation of the Vision for Success through the Guided Pathways framework?

RQ2: How can the educational experiences of former foster youth inform the equitable implementation of $\mathrm{CC}$ reforms?

\section{Purpose of the Study}

The purpose of this qualitative, cross-case study is to understand the ways in which community college practitioners implement equitable reform efforts. Launched in 2017, the Vision for Success has served as a strategic plan to guide policy makers and college administrators in systemic and campus reform efforts. As a result, new laws, updates to California Education Code, and new policies and procedures have been established in order to enact large scale reform. While the Vision for Success has provided a framework in which 
reform efforts can be made, each of the 115 community colleges is responsible for interpreting and implementing the reform efforts on their individual campuses. The main components of the Vision for Success include Guided Pathways (which focuses on increasing student completion rates); Promise Programs (which focuses on increasing student access); Assemblybill (AB) 705 Irwin. Seymour-Campbell Student Success Act of 2012: matriculation: assessment. (which focuses on reforming assessment strategies to ensure students are entering credit-bearing coursework upon entry to the college); and combining funding from Student Equity, Basic Skills Initiative, and Student Success and Support Programs (which is intended to streamline funding in order to assist students with the most need). College practitioners are responsible for the implementation of the Vision for Success within their institutions. I specifically use the terms "college practitioners" or "practitioners" within this study because the individuals on each campus that are working on campus reform range from faculty, classified staff, and administrators. Utilizing the term "administrator" would be too limiting and my intention is to showcase the importance of having a diverse working team within a large scale reform In order to address questions of equity within implementation efforts, it is important to cross-check the intended implementation against the actual experiences and needs of students with historically inequitable outcomes. As a 
result, legislation and funding has been created to support foster youth in accessing, persisting, and completing post-secondary education. However, completion rates for former foster youth have remained drastically low. Therefore, there is a need to examine the experiences of foster youth in community colleges, especially in relation to the implementation of equitable reform efforts. As colleges are redesigning the way in which they approach student access, course completion, teaching and learning, and building navigational capital through the Vision for Success efforts, it would be of benefit for foster youth - as well as all students through the concept of universal design - for practitioners to really ensure that the changes being made at the campus level, are being done with the student in mind. And this begs the question, what are the ways in which community colleges are helping all students Maslow and Bloom as they enter, persist, and succeed within our institutions?

\section{Definition of Key Terminology}

There are several operational definitions that I provide below in order to provide clarity and context to key terms or phrases that will be mentioned throughout this study. In order to align this work with the larger Vision for Success, many of the definitions found below are directly from the California Community College Chancellor's Office (California Community Colleges Student Success Task Force, 2011). 
Student Success is defined as when a student successfully completes a certificate, degree, and/or transfers while earning less than 79 units before completion.

Equity Gap is the gap that exists between the success of disproportionately impacted students on campus compared to students that are not disproportionately impacted. These students might be identified through characteristics such as race/ethnicity, socioeconomic status, court impacted (former foster youth or formerly incarcerated), etc.

Foster Youth are students that are currently or have ever previously been in court-ordered, out-of-home placement. While there are many students that may live with a non-parent based on a mutual understanding or agreement with their parents and guardians, for the purpose of this study I will only be focusing on students with court-ordered placements that have been identified as foster youth on their college campus. This definition is in alignment with the state management information systems (MIS) data definition of former foster youth which will provide a clear way to identify students that may fit into this category. Throughout this study, I will refer to both current and former foster youth as "foster youth" as the institutions do not differentiate whether or not a student is still in the foster care system or if they have emancipated. In my findings and 
recommendation chapters, I will refer to the foster youth participants as

\section{"scholars."}

Equity is defined as a "helping students achieve equal outcomes on success indicators as compared to either their own percentage in the community or college student body, or to other student groups" (Noldon, 2015, p.1).

Practitioners are community college faculty, staff, and administrators who are actively working on their campus' Guided Pathways project.

Vision for Success is the statewide strategic plan launched by the California Community Colleges Chancellor's Office. The Vision for Success initiated the several changes to the legislature and education code including revisions to assessment and placement, funding for Promise programs to remove financial barriers, and Guided Pathways to streamline the student experience.

Guided Pathways is a major component of the Vision for Success. Guided Pathways is a framework for colleges to utilize in an effort to streamline the student experience from onboarding, major selection, and education goal completion.

\section{Background of Researcher}

Although I was not a foster youth myself, I empathize greatly with this population. My mother was raised by various family members throughout her childhood which is similar to the one-third of foster youth students are in kinship 
care (Stuart Foundation, 2013). Between preschool and 12th grade, I attended six different schools, which is similar to the forty percent of foster youth that have three or more school placements between PK-12th grade and the 65 percent with seven or more school changes (Merdinger, Hines, Lemon Osterling, \& Wyatt, 2005; Pecora, 2012). While in graduate school, I experienced a bout of homelessness which, unfortunately, is also a challenge that half of the former foster youth in the Midwest Study had experienced at least once before they were 26 (Courtney et al., 2011). Although I was able to successfully navigate educational systems, my success could be considered an outlier for students with similar experiences. In my work at community colleges, and serving as a mentor for my campus foster youth program, I have attempted to take my lived experiences and turn them into learned experiences for students entering and navigating higher education. Having had familiar experiences of many of our foster youth, I am able to connect with the students and better understand their needs without approaching the students through a deficit lens.

Additionally, I do aspire to serve in community college leadership. I have developed and grown programs within and across community college districts. I am familiar with the challenges and process of undergoing institution-wide inquiry and implementing large-scale policies in real time. Having served on my 
own college's Guided Pathways design team, I am acutely familiar with the expectations of the Chancellor's Office, challenges navigating and changing institutional culture, and excitement that can be found when transformative work is applauded and normalized. As a systems thinker, I often find myself exploring the ways in which educational systems have failed students - not how students have failed to succeed in the educational system that was never created with them in mind. Therefore, the Vision for Success reform efforts which take the blame of student failure or success away from the student and place it as a responsibility of the institution, is of both personal and professional interest of mine.

\section{Significance of Study}

My study was inspired in large part by the influential literature that has informed and prompted much of the Guided Pathways work in California. Starting with Bailey, Jaggars, \& Jenkin's (2015) Redesigning America's Community Colleges: A Clearer Path to Student Success and Brown McNair et al. (2016) Becoming a Student-Ready College: A New Culture of Leadership for Student Success both provide tangible examples of how educational leaders can address gaps in student completion through intentional reform efforts. However, both books are seen as a starting point for colleges to begin engaging in inquiry and dialogue around the reforming the student experience. My study 
will provide very specific insights as to how community colleges in California approach equitable reform creation and implementation in order to guide student success.

My study also builds on Rassen, Cooper, \& Mery's (2010) study about former foster youth in California Community Colleges. This is one of very few published articles on foster youth in community colleges, so to specifically focus on California community colleges is quite unique. This study highlighted both the ways in which students utilized services on their campus and the barriers that students faced in accessing services. Additionally, Salazar et. al (2015) study on former foster youth in higher education explored the perceived interventions that education practitioners thought would benefit foster youth in higher education and gathered recommendations from the foster youth themselves. Gaining insight not only from the practitioners but also the students that would experience the intervention is of particular interest to me and is the crux of this study.

My study aims to reveal any potential gaps in practitioner intentions and student needs in order to emphasize the importance of including students in the reform process. Students, as a key stakeholder in this change process, should absolutely be included in the work taking place across the CCC. Furthermore, there is a need for there to be a diverse subset of students included in the 
inquiry and recommendation process. The Career Ladders Project (2017) published insights on the ways in which CCCs were utilizing student voice in the Guided Pathways work. Results of my study will inform CCC practitioners of the ways in which they can utilize the voices of historically underserved, vulnerable populations to better understand the current experiences of students in order to institute more equitable reform efforts.

\section{Conceptual Framework}

The conceptual framework for this study stems from Neal \& Neal (2013) nested ecological systems theory (NEST). The NEST is derived from Bronfenbrenner's (1977, 1979), ecological systems theory (EST), that introduced the concept that humans develop within and as a result of interactions with various systems. Neal \& Neal reframe Bronfrenbrenner's original EST from a nested set of systems to an interworking of networks that humans interact with and ultimately shape the way in which they develop (Figure 2). 


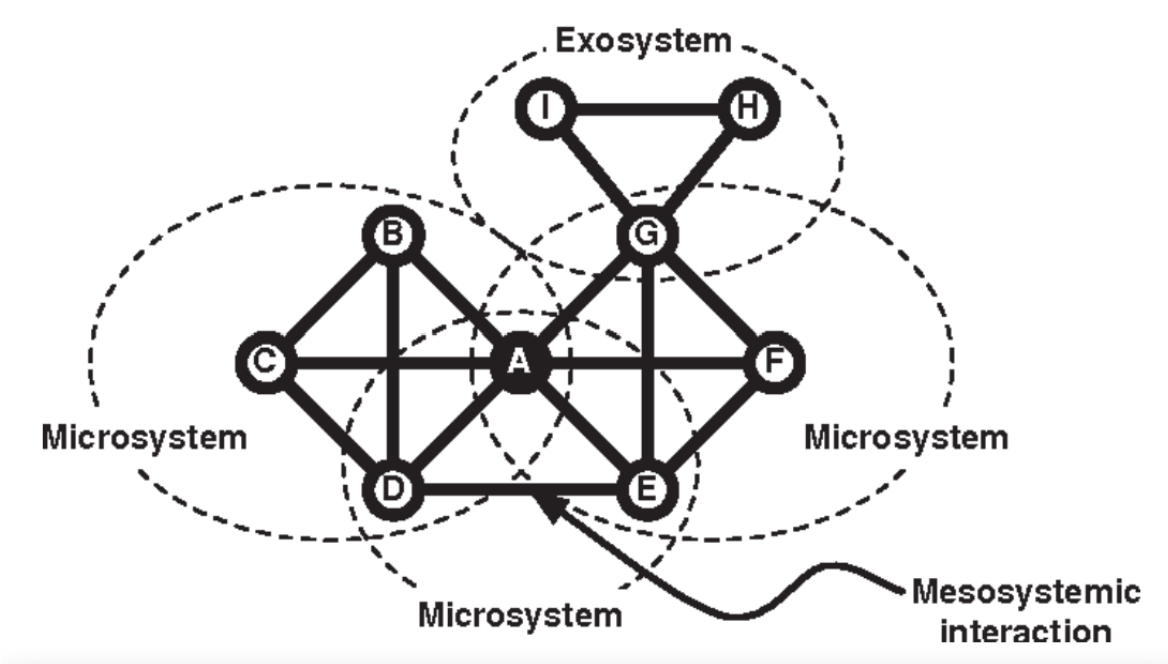

Figure 2. Neal \& Neal (2013) Networked Model of Ecological Systems, Focused on Person A (p. 728)

Although Bronfenbrenner's original theory was in relation to how young people develop, I argue that the same concept of a networked systems approach to development can also be applied to adults seeking educational development. Therefore, I have adopted Neal \& Neal's NEST framework to a higher education setting as seen in Figure 2. 


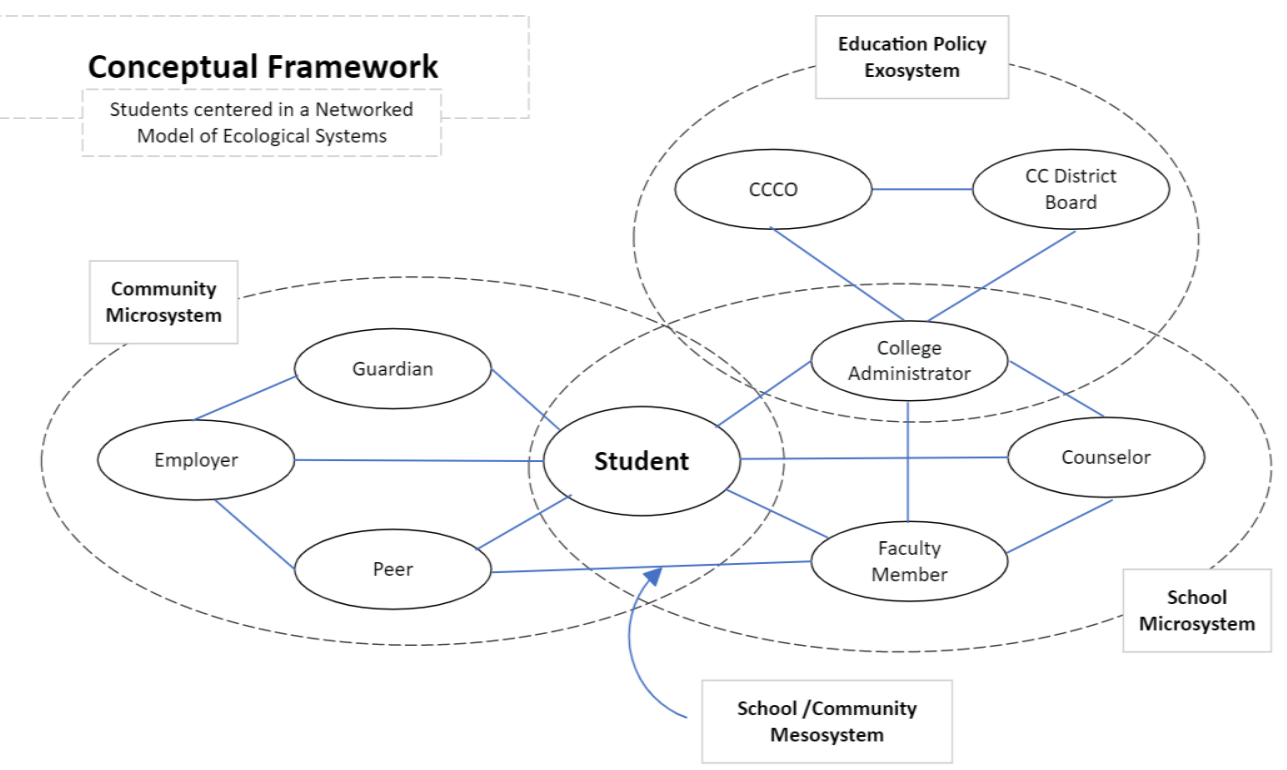

Figure 2. Conceptual Framework: Students Centered in a Networked Model of Ecological Systems.

This conceptual framework places the student in the middle of the interconnected systems of various networks. Each network develops a microsystem that houses "people engaged in social interaction" (Neal \& Neal, 2013, p. 728). In Figure 2, the student's microsystems include "School" and "Community". The way in which the student's microsystems interact with one another creates a mesosystem. In Figure 2, one example of a mesosystem is the way in which a peer from the student's community microsystem might also engage with the student's faculty member from the school microsystem. This type of interaction occurs when a friend that the student knew prior to college 
takes the same class as the student or recommends a particular faculty member. The exosystem, or the set of people who engage with one another but not the student - and an outcome of such engagement has direct impact on the student and how they might be able to interact with one of their microsystems. In Figure 2, the example of an exosystem is Educational Policy. Educational Policy is typically set by outside actors that do not include the actual individual who would experience the impact of the policy. Take, for example, the impact of Guided Pathways on a student's experience. Similar to Bronfenbrenner and Neal and Neal's view on ecological systems and the impact on human development, I posit that the way in which student ecological systems - including community, school, and policy based structures - interact has great impact on student development and overall success in college.

\section{Organization of the Study}

In the remaining pages of the dissertation, I seek to gain a better understanding of how practitioners address equity within reform. I also hope to shed light on the community college experiences of former foster youth, understanding that they have traditionally been underserved. It is my intention to utilize these findings to provide recommendations on how practitioners can be more mindful of the reform recommendations they make as it comes to foster youth. Each chapter within this dissertation will have a slightly different 
focus connected to the community college reform. Chapter 2 includes an exhaustive review of the literature. Chapter 3 will highlight the qualitative procedures through a methodology section. Chapters 4-6 will present findings from each individual participating community college case study. Within these chapters I will highlight findings of both community college practitioners and foster youth scholars in order to answer both research questions. Chapter 7 will present the cross case study findings to understand how multiple colleges are addressing equity in the implementation of the Vision for Success AND what can be learned from the experiences of foster youth to support equitable reform efforts. Chapter 8 will identify recommendations of how to utilize this information within leadership, advocacy, and practice as a way to address equity within community college reform. 


\section{Chapter Two: Literature Review}

\section{Introduction}

The purpose of the Vision for Success is to provide guiding principles for community colleges to follow in order to increase student success. However it is important to note that the Vision for Success, and all of the policies and laws that have stemmed from it, are not the first efforts to reform community colleges in California. Understanding modern community college reform efforts requires a review of previous policies, recommendations, and research conducted on and within California Community Colleges. Additionally, as this research is intending to identify the ways in which effective reform efforts are implemented, it is important to discuss various implementation strategies within public policy and higher education. Understanding the way in which decisions are made, identifying the members of the decision making process, and acknowledging the importance of student voice within the decision making process are three main tenants discussed below.

Finally, it is also important to understand the experiences of students that the reforms were made to support. Unfortunately there is not a large amount of empirical research that investigates the experiences of former foster youth as community college students. Also, much of the research conducted to understand the postsecondary experiences of former foster youth are 
somewhat deficit based and focus on all the ways in which institutions are failing former foster youth. While this research is absolutely important, there is something rather refreshing about reviewing strengths based literature that focuses on the success of former foster youth in higher education. Therefore the portion of this literature review that is focused on former foster youth will be highlighting the successes and positive educational experiences of former foster youth in higher education.

The following review of literature aims to provide both context and a historical overview of modern reform efforts in California Community Colleges, highlight the positive experiences of former foster youth in higher education, and provide insight into campus implementation strategies that highlight student experiences. This literature review is built upon a theoretical framework which is comprised of Social Justice Leadership and Community Cultural Wealth, which is a related aspect of Critical Race Theory. The combination of these two strands of theory connects both the leadership needs of the practitioners and the need for practitioners to acknowledge the capital that students bring to the institution.

\section{Theoretical Framework}

I grounded this study primarily in Social Justice Leadership theory. Social Justice Leadership acknowledges the need to "make issues of race, 
class, gender, disability, sexual orientation, and other historically and currently marginalizing conditions in the United States central to...advocacy, leadership practice, and vision...[and] centers on addressing and eliminating marginalization in schools" (Theoharis, 2007). Based on the low college degree attainment rates for foster youth, combined with the lack of research on the community college experiences of foster youth, this research takes a specific and clear stance on addressing the experiences of this marginalized student group. Similar to Theoharis, Shield's Transformative Leadership Theory addresses the "academic and social justice needs of complex, diverse, and beleaguered education systems" (2010, pp. 562). The Vision for Success has a strong emphasis on closing the equity gap for underrepresented and minoritized youth. Acknowledging the minoritized groups and the intention to eliminate barriers for such groups provides an opportunity to examine the Vision for Success through a social justice framework.

One such framework that is focused on practical application and takes Social Justice Leadership Theory and explicitly calls out issues of systemic oppression is the Social Action, Leadership, and Transformation (SALT) model (Museus et al., 2017). The seven components of the SALT model are: 1) capacity for empathy; 2) critical consciousness; 3) commitment to justice; 4) equity in purpose; 5) value of collective action; 6) controversy with courage; and 
7) coalescence. In practice, the SALT model provides an opportunity for social justice leaders to critically examine larger "systemic social problems and effectively lead in ways that do not exacerbate existing systems of oppression, but move the needle towards equity" (Museus et al., 2017, p. 6).

Through the Vision for Success, the Chancellor's Office acknowledged that the college system needed to no longer penalize students for not being familiar with the community college system (CCCCO, 2017). Yosso's Community Cultural Wealth (2006), a tenant of Critical Race Theory, addresses the need to understand that students entering the community college may not have the knowledge or resources needed to navigate higher education. While this study is not specifically focused on explicit issues of race, it is important to note that children of color, especially African American children, are overrepresented in the foster care system (Harris, Jackson, O'Brien, Pecora, 2009). Therefore, it is appropriate to utilize a tenant of Critical Race Theory due to the racialized reality and perceptions of political and social movements that impact communities of need.

In alignment with Community Cultural Wealth, Karp \& Bork (2014) provided examples of how navigational and cultural capital are not inherent for community college students. Guided pathways, assessment and basic skills reform, and affordability measures are all ways in which the college is taking 
into account the Community Cultural Wealth of students. Hearing directly from students' experiences, especially former foster youth, will allow practitioners the opportunity to identify areas in which the cultural capital of students can be best illuminated throughout the Guided Pathways implementation.

\section{Relevant Literature}

\section{California Community College Reform}

While much of the current California Community College reform is being attributed to Chancellor Eloy Oakley Ortiz's Vision for Success, there were reform efforts that were in place prior to the 2016 report. In 2011, the former Community College Chancellor, Jack Scott, formed a task force to identify best practices needed to boost student completion rates (CCCCO, 2011). This task force, commonly referred to as the Student Success Task Force, proposed several recommendations to help students access, matriculate through, and complete their community college studies in a timely manner. The recommendations included: more accurately assessing students upon entry into college, providing structured pathways for students, providing professional development for faculty and staff to support students, greater coordination with local school districts to support college and career pathways, and revising financial accountability systems and organizational structure to better support students. For the purposes of this literature review, I am going to focus on 
three particular areas: access, assessment, and guided pathways as these are the main components of the Vision for Success.

Access. The findings and recommendations from the Student Success Task Force resulted in the passing of Senate Bill 1456 - Student Success Act of 2012. The focus of SB 1456 was to ensure that students had a streamlined matriculation process at the beginning of their postsecondary career to ensure that students are on the right track to completion from the beginning (CCCCO, 2012).

SB 1456 provides priority registration to students that are certificate, degree, or transfer seeking and have completed orientation, assessment, and developed an education plan with a counselor prior to registration. While the goal of SB 1456 was to start all students off on a strong pathway to completion it is not without its critics. Grigorieff (2016) posits that AB 1456 prioritizes traditional degree or transfer seeking students and perpetuates the oppression of the traditionally underserved. For example, students that may not be on a specific completion track, such as English Language Learners that may be interested in taking English Language Courses wouldn't have access to priority registration or could be deterred from the requirement to complete so many steps before being able to access a previously open-access system. Now with the requirement that students complete several steps of matriculation prior to 
enrollment, critics such as Grigorieff asserts that community colleges are less accessible than before which contributes to another layer of hegemony within society (2016).

The cost of attending higher education is also seen as a barrier to enrollment. Although community colleges are intended to be the most accessible higher education institutions in California due to their mission of providing open access education to any community member, the inequitable cost barriers have not escaped these institutions and have negatively impacted low-income and minoritized students in their ability to access these institutions. In 2010 the U.S. Department of Education launched a call to action to increase the college degree and skills certificate attainment by $50 \%$ through what is commonly referred to as the America's College Promise Initiative (Harbour \& Smith, 2016). The goal of the America's College Promise Initiative (Promise) is to increase postsecondary degree and certificate completion in order to increase the economic growth within the country (Harbour \& Smith, 2016). The primary method for which the Promise aspires to reach this goal is to eliminate financial barriers to community colleges by promoting free college for all students. As of November 2016, 23 states had already enacted legislation to support free community colleges (Pingel, Parker, \& Sisneros, 2016). Promise Programs are being implemented in various stages through a variety of different 
models across the United States. In 2017, California passed Assembly Bill 19 to establish Promise programs at community colleges through the state (CCCCO, 2017b) . Components of Promise Programs range from covering the cost of tuition or enrollment fees, to covering the entire cost of attendance which includes tuition, books, transportation, and other costs that contribute to attending college. AB 19 provides college administrators the opportunity to implement the program according to the needs of the local populations the college serves. For colleges seeking to increase access only, offering free tuition or fees may be the solution to address that issue. Alternatively, for colleges seeking to increase both access and completion rates, programs that add student supports like counseling and career exploration and development, in addition to tuition and fees, may be the solution.

Assessment. Prior to the Student Success Task Force, in 2006 the Chancellor's Office established the Basic Skills Initiative - a grant funded program to support student access and success, specifically for students considered underprepared for college (LAO, 2016). Historically 70 to 80 percent of students are considered underprepared for college however only fewer than half of students enrolled in remedial courses complete their intended educational goal (BSI, 2007; LAO, 2016). The completion rates for minoritized students in remedial courses was even lower (CCCCO, 2017a). The Basic 
Skills Initiative was one of the first steps in addressing the need to reform assessment and placement practices within the community colleges. A decade of work within the Basic Skills Initiative was conducted to identify best practices in determining successful placement of students to support both course success and goal completion. A result of this work can be seen in the Assembly Bill 705 - Seymour-Campbell Student Success Act of 2012: Assessment. AB 705, an extension of the original Student Success Act - SB 1456 - requires community colleges to utilize multiple measures in initial placement and support students in successfully complete transfer-level Math and English sequences within one-year (CCCCO, 2017c). Although it is important to note that community colleges were technically required multiple measures for placement purposes prior to the passing of $A B 705$ by the amendment to the California Education Code, Title 5 §55502(i), many colleges simply did not utilize the technique and relied solely on standard assessment tests (ASCCC, 2014). The passing of $A B 705$ has elevated the requirement of multiple measures to state law, rather than just Education Code, and added the need to ensure student success and completion of transfer level courses within one-year.

Guided Pathways. When it comes to supporting persistence and completion of students in community colleges, Guided Pathways are an 
increasingly popular intervention to help students determine the path to completion. Though not necessarily a new idea, Guided Pathways gained popularity with the Bailey, Jaggars, and Jenkins' 2015 book entitled Redesigning America's Community Colleges: A clearer path to student success. Guided Pathways are sequential course pathways to program completion that take into account pre- and co-requisites. The idea is that if students have a sequential pathway to completion on day 1 , they are more likely to persist, take the appropriate class at the right time, and have a realistic idea of when their completion date is. One specific way in which colleges are providing a clear pathway for students is in the development of meta majors. EAB, formerly the Education Advisory Board and a higher education consulting firm, refers to meta majors as a group of individual majors under a larger academic umbrella (eab.com). For students that are unsure of their specific major, a meta major can allow them to explore courses that are relevant to a group of similar majors. For example, students interested in health care, could join a pre-health meta major and take general education courses that would be applicable to any program of study in health sciences.

As of Spring 2018, over 250 community colleges have already begun the process of implementing Guided Pathways (Jenkins, Lahr, Fink, \& Ganga, 2018). Students also have a bit more agency on their degree plan rather than 
having to depend solely on a counselor/advisor to create it for them each semester. Historically, students in community colleges attempt and earn more units/credits than they actually need to complete their degree (Haskins, 2016). By providing students with a clear guided pathway, college administrators hope that students will be able to more efficiently complete their coursework in a timely manner without acquiring excessive units.

\section{Policy Reform Implementation}

Policy expert Rhiana Gunn-Wright was recently on a podcast where she spoke about her vast experience within policy and challenges that impact the implementation of policy to enact positive change. She stated that policy focuses on answering two fundamental questions "what problem are you solving? And who are you solving it for?" (Gunn-Wright, 2019). Gunn-Wright noted that these two questions were essential in approaching both the creation of policy as well as the implementation of policy. She also made note of the disconnect often experienced between the policy makers attempting to solve the problem, and the people on the ground that are experiencing the problem that the policy makers are attempting to solve. Gunn-Wright asserts that:

"often a lot of policy goes off the rails because the folks making the policy define the problems different than the folks experiencing the problem and there's like quite a divide, especially when you add in like differences in 
identity. So race, class, etcetera, the distance between policy makers often and constituents actually can grow" (2019).

Recognizing that the Vision for Success is a strategic plan delivered from the California Community Colleges Chancellor's Office that served as a platform from which policy was created for practitioners to implement locally, it is important to review the literature around policy implementation and organizational change. Additionally, the literature review focuses on the importance of including constituents, specifically students through student voice initiatives, in decision making processes.

Higher education policy implementation. Higher education policy implementation research is relatively undocumented. Kohoutek (2015) recently reviewed 30 years of higher education policy implementation research only to find large gaps between publications of seminal studies from the 1980s and applied theories in use today. The 1980s provided hierarchical top-down frameworks, where policies are created through legislation, are built on compliance (Sabatier \& Mazmanian, 1980). Fullan (1994) argues that "centralized reform mandates have a poor track record as instruments for educational improvement" (p. 8). This sentiment is mirrored in the aforementioned quote provided by Gunn-Wright and is based on the disconnect that often appears between policy makers and practitioners. Due to this 
disconnect, there was more emphasis in the the 1990s to focus on bottom-up frameworks built on the personal behaviors and discretionary influence of local actors (Fullan, 1994; Kohoutek, 2015). Bottom-up frameworks utilized the experiences of practitioners and public workers who work directly with their constituencies in order to enact change. Lipsky (1980) would refer to such practitioners as street-level bureaucrats. However, Fullan (1994) also notes that decentralized initiatives, those that operate solely from a bottom-up framework, do not necessarily fare much better than top-down initiatives. Instead, he asserts that educational change is made when both top-down and bottom-up strategies are coordinated. He states that the role of the policy makers is to simulate local action, provide general direction, provide resources, and gather data and feedback. The role of institutions is to take action, monitor work on reform efforts and problem solve when necessary, create cultures of collaboration, and engage with external agencies in both proactive and responsive ways. As he states "researchers have found that change occurs when top-down mandates, and bottom-up initiatives "connect" (Fullan, 1994, p. 18). It could be stated that the way in which the Vision for Success initiative was rolled out served as a way in which the chancellor and policy makers stimulated action and provided guidance for local colleges to then take action in order to change the needle on student success. 
While Fullan provides helpful insights regarding organizational change within education, much of his focus is within primary and secondary school systems. The lack of higher education, specific, policy implementation research between the 1990s and the 2010s led Kohoutek to draw conclusions about the way in which the field of education is often connected to general public policy implementation theories and strategies. The author posits that researchers in higher education policy are either not abreast of theoretical developments within general public policy or they have long since determined that the concepts developed for general public policy are not applicable to the complexities of higher education policy implementation (Kohoutek, 2015).

In referring back to Gunn-Wright's position on the disconnect between policy makers and the individuals who both the policy was created for and who will experience the effects of the policy change, I believe that it is important to include students in this conversation. Specifically including student voice within the higher education change making process is an important tenet of the bottom-up framework that was not discussed in the overall higher education policy implementation literature. Therefore the next section will discuss the relevance of students voices within higher education change overall.

Student voice. Diana Mitra, a well established researcher on student voice efforts, defines "student voice" as "youth sharing their opinions of problems and 
potential solutions" (2004, p. 651). The importance of engaging students in conversations about teaching, learning, and schooling in the K-12 system dates back to the early 1990s as both large scale educational reform efforts and emphasis on student rights were both underway. However, there is not much research on how schools and school systems actually involved students in their reform discussions (Mitra, 2004). The premises at the onset of the student voice movement were children's right to be heard, respect for children, and the importance of listening to children as it comes to matters that pertain closely to them (Cook-Sather, 2006). Such premises were built upon the idea that the traditional school culture prevents practitioners from listening to students effectively silencing them from providing any feedback on one of the largest aspects of their lives (Cook-Sather, 2006). Mitra posits that "student outcomes will improve and school reform will be more successful if students actively participate in shaping it” (2004, p. 652).

While the positive benefits of involving student voice in reform efforts may be inherently obvious, it is important to note that there are critiques in both including student voice as well as how one might approach the inclusion of student voice within reform (as well as research). Lodge (2005) asserts that the approach to student voice can be analyzed from two lenses: the role of the student and the purposes of which the student is being sought. Lodge's four 
typologies for approaching student involvement include: 1) quality control; 2) students as a source of information; 3) compliance and control; and 4) dialogue. When the purpose of engaging students is for quality control, the student is considered a passive participant, merely providing feedback to the institution on the quality of their educational experience. When the purpose is to have students serve as a source of information, the experience is still passive but are being engaged for the purpose of improvement providing information for institutions to act upon. Compliance and control acknowledges the active potential of students but utilizes the student voice to serve the needs of the institution. An example is if an outside organization were to conduct student focus groups to gain insights on a student experience but the institutions selectively identified which students could speak and predetermined what information the students could share. Finally, dialogue provides both values students and acknowledges them as active participants in idea creation, critical analysis, and decision making. Because of the nature of this research and acknowledging that I will be asking students about their experiences within the community colleges they currently attend - none of which I, as the researcher are connected to - the approach that this study follows is including students as a source of information. This information I hope to provide insights on how the 
California Community College system might be able to better serve former foster youth and start ongoing dialogue on college campuses across the state. Although much of the empirical research on student voice within education reform is focused on the $\mathrm{K}-12$ level, recent reports have been pushed from the Chancellor's Office highlighting the importance of student voice within the Vision for Success reforms. In 2017, the Chancellor's Office funded a report focusing on the findings of focus groups held at two community colleges. The focus groups specifically inquired about students' onboarding into college, course selection, and barriers for course completion (Dagar et.al, 2017). Each of these topics are directly connected to the Vision for Success which provides practitioners with useful information to create new policies and procedures to enact change based on student experiences. Additionally, the Chancellor's Office also created and distributed a Student Voices Inquiry Guide on how to collect student voice in regards to the work on Guided Pathways. Within this guide are recommendations on how to engage students - including student selection and recruitment suggestions - methodology, and examples of five colleges that have engaged students within their campus reform efforts (IEPI, 2018). Of the five colleges included in the Student Voices Inquiry Guide, only one college explicitly mentions including historically underserved student populations - including former foster youth - based on the institution's equity 
plan. This research study will provide valuable information to close the gap on not only the importance of utilizing student voice in higher education reform efforts - but also highlight the importance of lifting up the voices of historically underserved students as well.

Student voice can raise issues of equity and injustices that students face that practitioners may not be aware of (Mitra, 2004). Therefore, it is important to engage the voices of students from a diverse set of perspectives (CookSlather, 2006). Mansfield notes that historically marginalized students are often the subject of much reform but rarely actors in shaping the reform efforts (2013). A goal of the current study is to listen to and learn from former foster youth, who due to lack of sufficient research on their experiences in community college have effectively been silenced from academia, and bring their voices front and center within the Vision for Success.

Over the years there has been much work done to move the needle on student success. However, many of the initiatives created were implemented as one-off solutions without addressing the needs of an entire college system. The Vision for Success is an opportunity to take all of the best practices gained from practitioners in the field, task force recommendations, and a deep dive into systemic barriers in order to envision a new, more successful postsecondary experience for students. The students that have the navigational capital, 
familial resources, and community support will be, and have been, successful regardless of the current reforms taking place. However, these new reform efforts are focused on supporting students that have been historically underserved in order to help them complete their goals. One such group of historically underserved students are former foster youth. In the introduction I mentioned the hardships that former foster youth have with the educational system. However, I decided to focus my review of the literature for foster youth in community college on the positive educational experiences that foster youth have in higher education in order to create a framework to support foster youth success.

\section{Former Foster Youth In Community College}

Postsecondary access for foster youth. Foster care alumni have unique educational experiences that differ greatly from the traditional student. Young people in foster care are, on average, placed in out-of-home care around the age of 10 . Forty four percent of foster youth lived in more than three placement settings, and $65 \%$ of foster youth experience seven or more school changes in K-12 (Merdinger, Hines, Lemon Osterling, \& Wyatt, 2005; Pecora, 2012). Due to, sometimes abrupt, school changes students in foster care experience disruptions in their education. Missing information can increase delays to educational enrollment by 6.5 times (Pecora, 2012). Without proper 
advocates to ensure that students in foster care are being placed in comparable courses as they switch schools, foster care students can end up repeating grades, being placed in special education courses, or underplaced in courses that do not allow the student to be challenged academically (Pecora, 2012). However, when students in foster care have caring adults concerned about their education, both in school as well as at their foster care placement, they often perform better within the $\mathrm{K}-12$ system and are able to better access postsecondary education. While caring adults certainly help foster youth access higher education, their journey to doing so does not always follow the traditional pathway into college.

Horn and Carroll developed the Pipeline to College model to showcase the five stages of college access (1997). According to Horn \& Carroll the Pipeline to College is linear and includes: 1) the aspiration to attend college, 2) becoming qualified, 3) taking the appropriate admissions tests, 4) applying to college, and 5) enrolling in college. However, Rios and Rocco challenge Horn and Carroll's Pipeline to College stating that such a linear experience does not align with the experience of foster youth (2014). While they may aspire to attend college, their multiple school placements may not provide them with the coursework required to apply to college. In the state of California, Assembly Bill 167 allows for youth in foster care to graduate from high school with the state 
minimum amount of high school credits (Alliance for Children's Rights, 2013). The state minimum credits are less than those required to apply to any of the state's public four-year institutions. Therefore, many foster youth utilize community colleges, which are open access, as their access point into higher education (Rios \& Rocco, 2014).

Rios and Rocco found that former foster youth that successfully accessed higher education attributed this success to four main factors: 1) school stability and structured transitions; 2) positive relationships with adults; 3) positive peer influences, and 4) challenging academic coursework. The positive relationships with adults was the most prominent finding in relation to the alignment of discourses and development of college literacy. Students indicated that the support they received from guidance counselors on the application process, access to fee waivers, and overall encouragement to attend college was a primary factor in their ability to apply (Merdinger, Hines, Lemon Osterling, \& Wyatt, 2005; Rios \& Rocco, 2014; Strolin-Goltzman, Woodhouse, Suter, \& Werrbach, 2016). Researchers also found that when teachers and social workers worked together to support students, intervene as advocates, and set high expectations, students eventually rose to those expectations (Merdinger, Hines, Lemon Osterling, \& Wyatt, 2005; Rios \& Rocco, 2014; Strolin-Goltzman, Woodhouse, Suter, \& Werrbach, 2016). 
Additionally, when foster parents provided structure, acted as advocates, and set high expectations, students also felt supported and motivated to pursue higher education. Finally, foster youth also attributed positive relationships with high achieving peers to their ability to apply to college (Rios \& Rocco, 2014; Strolin-Goltzman, Woodhouse, Suter, \& Werrbach, 2016).

Postsecondary support for foster youth. Many foster youth have the desire and intention to attend college. While it is true that very few actually attend and even fewer complete their higher education studies, there are foster youth that are successful in higher education. According to the literature, many of successes of foster youth in higher education can be attributed towards having supportive adults in their lives, being involved in campus support programs, and access to resources like academic advising, financial aid, and food and housing support.

Similar to foster youth's successful experiences in secondary school, foster youth attribute their collegial success to having a network of supportive adults/professionals around. Dworksy and Pérez (2009) found that connections that foster youth can make with teachers and supportive adults both on and off campus are vital to student success. Having supportive individuals on campus to turn to, provided, what St. John (2012) refers to as college knowledge, which is the ability to utilize resources, both human and information, to navigate the 
educational system. Additionally, Piel and Lacasse assert that while foster youth may depend on campus advocates to help them navigate the institution, they should also have the opportunity to feel empowered and have a voice within the decision-making process as it comes to their experience (2017). Beyond having individual staff or faculty members on campus to provide support for foster youth, support programs, such as Guardian Scholars, have also been attributed to postsecondary success of foster youth. Guardian Scholars Programs are able to provide foster youth students with safe spaces to develop relationships with supportive faculty and staff, as well as a physical space to turn to for assistance (Kinarsky, 2017). Dworsky and Pérez (2009) found that students involved in their campus foster youth program were often pleased with their experience. Foster youth were attracted to the programs often because of the financial aid and academic support provided. Seventy-one percent of student participants in their study reported that their campus support program helped them navigate the campus and diminish the feeling of solitude and isolation. While the intangible supports provided in these campus support programs have certainly been of benefit to foster youth students, tangible support such as financial aid, food access, and housing and transportation support can also be tremendous contributors to student success. 
Foster youth students in California are eligible for several different types of financial aid grants and waivers to help reduce the cost of attendance. Most foster youth qualify for the California College Promise Grant, which covers the $\$ 42$ per unit enrollment fees, and the California Chafee Grant, which are federal funds the state uses to support postsecondary enrollment for foster youth until the age of 22 (Hallett, Westland, Mo, 2018; Rassen, Cooper, Mery, 2010). The student participants in Rassen, Cooper, and Mery's report of foster youth experiences in community college found the Chafee Grant, and additional financial aid, to be the most beneficial resource as it provided some the opportunity to cut down on hours at work while still being able to support themselves (2010). Foster youth in their study expressed a sense of relief in students that received financial aid from their campus as it relieved economic insecurities and allowed the students to focus on their academics (2010). Dworsky and Perez's study found that $75 \%$ of foster youth receive financial aid support from their campus support program that includes tuition, book vouchers, and school supplies (2009). Students also used the financial aid received from campus on housing, technology needs like laptops or computers, and to cover emergencies.

While the financial aid that students receive from their institutions can help cover some food costs, the reality is that students often receive a 
disbursement of that financial aid refund at the beginning of each term. Without the ability to save and allocate the disbursement to last an entire semester, students may rely on their campus support programs to assist with accessing food. The Wisconsin Hope Lab reported that $55 \%$ of foster youth have the greatest level of food insecurity on community college campuses (Goldrick-Rab, Richardson, \& Hernandez, 2017). Kinarsky (2017) found that foster youth students often relied on their Guardian Scholars Program staff to support them in accessing food resources on campus. Additionally, a fifth of foster youth in Kinarsky's study expressed challenges with managing finances needed to maintain food and housing security.

Relevant policies for foster youth in higher education. According to the California College Pathways, a statewide foster youth advocacy and resource for higher education practitioners, there are around 20 enacted laws in California to support postsecondary access and success for foster youth. I will briefly highlight a few of the most relevant and prominent laws and policies developed to support foster youth in higher education.

In 1996, Assembly Bill 2463 Postsecondary education: outreach and assistance for emancipated foster youth: California State University: California Community Colleges. This bill was created to provide campuses with outreach assistance to recruit foster youth and provide support in completing college and 
financial aid applications. A.B. 2463 also required the campuses to track their outreach efforts to foster youth in order to report back to the Board of Governors and the CCC Chancellor's Office. Additionally, A.B. 2463 recommended that, when appropriate, that a current or former foster youth student serve on advisory committees within the higher education institution. A.B. 2463 was the first initiative in California to support the intentional engagement of foster youth in higher education. A.B. 2463 also permitted foster youth to receive support through Extended Opportunity Programs and Services, a student success program for low-income, academically underprepared, and historically underrepresented students attending CCC (Raucher, Tran, Lemley, 2005). In 2017, A.B. 1567 added to A.B. 2463, by allowing social services offices to verify foster youth eligibility in order to access campus services.

In 2003, the California Legislature passed Assembly Bill 490 Education: foster children. A.B. 490 recognized the educational disparities and disruptions that foster youth face and provided provisions to existing education code to address and remove barriers for foster youth (Troia, Woodward, Bussiere \& Ramiu, 2006). Though, A.B. 490 is primarily focused on K-12 education, some of the provisions that it established impact foster youth's ability to access higher education. For example, under A.B. 490, provided foster youth that have been 
placed in care outside of their former school district the ability to immediately enroll in the new, local district without waiting on prior school and immunization records. Immediate enrollment shortens the time foster youth spend out of school in an attempt to minimize academic disruption. AB 490 also provides guidance for granting partial credit, grade promotions, and grade protections due to updates in foster care placement. Having clear guidance across the state regarding the academic continuity for youth in foster care can better support their ability to progress through grade school, receive their diploma, and be eligible for college enrollment.

In 2007, the CCC Chancellor's Office established the Foster Youth Success Initiative (FYSI) (CCCCO, 2006). The goal of the FYI was to identify and develop structured supports across the state's community colleges for the 8,000 foster youth students enrolled. A major outcome of the FSYI was the requirement for all CCCs to designate a foster youth liaison for each campus located (Cooper, Rassen, \& Mery, 2010). While all campuses may have a foster youth liaison, not all liaisons are dedicated to managing support programs for foster youth. Hallett, Westland, and Mo conducted a qualitative study of foster youth experiences at a community college in Northern California (2018). One of their findings claim that though the students engaged with their campus foster youth liaison, many times the engagement was transactional - 
simply to pick up their financial aid check. The authors suggest that the lack of and intentional relationship with the foster youth liaison simply creates another point of contact for students without any clear guidance or direction to truly support their success.

Assembly Bill 12, California Fostering Connections to Success Act was passed in 2010. The most impactful aspect of A.B. 12 was the extension of foster care benefits up until the age of 21 for youth living with a non-related legal guardian. Over the next three years, A.B. 12 was amended four times (A.B. 121, A.B. 1013, A.B. 1712, A.B. 787). A.B. 12 (and subsequent amendments) establish Independent Living Programs (ILPs) that provide housing, employment, and postsecondary assistance to emancipated youth over the age of 18 - to assist with the transition to self-sufficiency. Additionally, A.B. 12 extended CalWORKs aid to support foster youth that are still considered dependents though are over 18 years old. This allows for foster youth, over 18 years old though still in the foster care system, to access the public cash assistance benefit as they work or attend school. The update to CalWORKs access is of particular interest to community colleges as the California Education Code grants community colleges the ability to provide CalWORKs services on campus (California Community Colleges, 2019). 
In 2016, A.B. 801, Bloom. Postsecondary education: Success for Homeless Youth in Higher Education Act, all 115 California Community Colleges are required to have a foster youth liaison on campus. A.B. 801 requires all higher education institutions to designate an employee to serve as a Homeless and Foster Youth Liaison. This liaison is to provide college recruitment and financial aid information for prospective and current homeless and foster youth students. Additionally, A.B. 801 extended provisions for the Board of Governors fee waiver, now referred to the California College Promise Grant, to include homeless youth in addition to foster youth, who were already provided the waiver.

Assembly Bill 194, Public postsecondary education: priority enrollment: foster youth, was passed in 2011. The purpose of A.B. 194 was to ensure that any student that was identified as a foster youth on their campus, and under the age of 24 , was granted access to priority enrollment. Priority enrollment allows for students to access courses early in the registration period. Due to the fact that some courses often reach maximum capacity early in the enrollment period, students that register later in the registration window may not be able to access a course that is needed to satisfy their academic plan. Having priority registration allows for students, in this case foster youth, to gain access to the courses they need in order to continue and complete their education. 
Also in 2016, the Education Commission of States (ECS) published a report with recommendations on how states could strengthen policies that support foster youth postsecondary access and completion. While conducting the research for the report, the authors discovered the myriad of overlapping federal, state, local, and institutional policies that develop into a tangled web through which foster youth and college leaders are expected to navigate (Sarubbi, Parker, \& Sponsler, 2016).

There is an absence of studies that specifically addresses the needs of former foster youth in community college. Geiger and Beltran (2017) recently conducted a literature review focused on foster youth in higher education. In their search of literature they only found 51 articles in peer-reviewed journals with the first being published in 1997 and the most recent in 2016. Of the 51 articles only one was focused on the experiences of foster youth attending a community college; two articles included foster youth enrolled at both community colleges and four-year institutions. There were several more articles, within that group, that focused on foster youth scholars however their settings included four-year institutions only. There is also an absence of studies that specifically address how community colleges both implement policies as well as approach equity through change. This study seeks to explore both the needs of foster youth and understand the ways in which 
community college practitioners address equity through large-scale reform. By asking questions of community college practitioners involved with implementing reform on their campuses, and including the experiences of foster youth, I hope to create a framework for practitioners to use during future reforms or institutional changes that can more explicitly provide opportunities to ensure that equity is at the center of change and not an afterthought. Therefore, again, the following research questions are guiding this study:

RQ1: What are the intentional ways in which community college leaders are addressing equity in the implementation of the Vision for Success through the Guided Pathways framework?

RQ2: How can the educational experiences of former foster youth inform the equitable implementation of $\mathrm{CC}$ reforms? 


\section{Chapter 3: Research Design}

This chapter describes the research procedures employed in this study. The chapter is organized as follows: (a) overview of the study, (b) research questions, (c) research design, (d) research settings and context, (e) participants, (f) data collection and analysis, (g) validity and reliability, (h) limitations, (i) summary.

\section{Overview of the Study}

This study explored how community college practitioners are implementing the major components of the Vision for Success utilizing the Guided Pathways framework. This study also explored how the experiences of foster youth in community college can help practitioners implement change with equity in mind. Community colleges in California have been long known for being accessible, though not focused on completion as evidenced by the low and stagnant overall graduation rates for the past 50 years (CCCCO, 2014). Additionally, although foster youth have many policies and programs geared toward their success in higher education their graduation rates are still tremendously low. This qualitative, cross-case study seeks to examine how colleges are implementing large scale reform to improve graduation rates while also understanding the experiences of students with the lowest completion rates in order to make equitable recommendations. 


\section{Research Questions}

This study was guided by the following research questions, which asked:

RQ1: What are the intentional ways in which community college practitioners are addressing equity in the implementation of the Vision for Success through the Guided Pathways framework?

RQ2: How can the educational experiences of former foster youth inform the equitable implementation of community college reforms?

\section{Research Design: Qualitative Cross-Case Study}

According to Yin and Campbell (2018), a case study is an appropriate research method when attempting to "explain some contemporary circumstance" (pg. 42). The contemporary circumstance in this instance is the urgency and intentionality in which the state of California is approaching equitable outcomes. Additionally, Yin and Campbell suggest that within case study research, the real-world phenomena that is taking place ought to be studied within its real-world context. In this study I sought to understand the ways in which practitioners are taking a contemporary directive and implementing it within their college setting, right now. Because this case study took place during the implementation phase of this statewide initiative, I acknowledge that I was not able to review outcomes of implementation in order to claim causation. And that is ok because that was not the purpose of this 
study. The case study methodology allows for in-depth understanding of a particular phenomena at a given time (Gerring, 2007). As Gerring states, "the product of a good case study is insight" (2007, pg. 7 ), and the goal of this research study is to provide insights to practitioners in how to best implement impactful, equity-based change.

Therefore, to address the research questions above, this study utilized a qualitative cross-case study design, which consisted of three distinct phases (Creswell \& Creswell, 2018). The first phase examined practitioner's understanding of equity, the use of student voice in their inquiry process, and their campus approach to implement the Vision for Success through the Guided Pathways framework. This phase, focused on practitioners, consisted of document analysis and an interview with the Guided Pathways lead at the college site. The second phase examined the higher education experiences of foster youth in community college. This phase, focused on students, consisted of an open-ended online interview followed by in-person, paired interviews in order to dive deeper into their experiences as they relate to the research questions. The final phase takes the information gleaned from the first two phases in order to compare the intentions of the practitioners and the needs of students. This final stage serves as the crux of the cross-case study. Providing a separate analysis of each participant type and then presenting a cross- 
analysis of both participants during the final phase is what qualifies this study as a cross-case study (Yin \& Campbell, 2018).

\section{Research Settings and Context}

The primary settings for this study are the California Community Colleges. The California Community Colleges mission and vision is "put students first" (https://www.cccco.edu/About-Us). There are currently 115 colleges that make up the California Community College system. Three of these 115 colleges were selected for this study. Each college was provided with a pseudonym to ensure the confidentiality of both the students and the practitioner participants. For the purposes of this study, the colleges will be referred to as Little Streams College (LSC), Foggyville College (FC), and Bode College (BC). These institutions were selected because of their early adoption to implement the Guided Pathways framework as well as the presence of foster youth support programs on their campus. Whereas LSC, FC, and BC were selected to participate in this study based on their progress in implementing Guided Pathways, there is one significant difference in the ways in which the campuses are approaching this implementation. Little Streams College and Bode College are members of the Guided Pathways Project and Foggyville College is not. The Guided Pathways Project was established by the Foundation for California Community Colleges in 2017, as an effort to assist 20 
colleges in the initial Guided Pathways implementation work on their campus to prepare for students entering college in fall 2019

(https://www.caguidedpathways.org/). To be selected to participate in this project, institutions were required to complete an application and pay a membership fee to cover the cost of the professional development and consultation on Guided Pathways. While LSC and BC participated in the Guided Pathways Project and received direct support in the implementation of Guided Pathways on their campuses, FC had no such dedicated, external support. Yet, all three campuses have implemented major components of the Guided Pathways framework within their respective institutions and therefore, I believe that a fair case study of the implementation can occur.

LSC, FC, and BC are suburban colleges that offer certificates, two-year degrees, and transfer opportunities to four-year institutions. According to the CA Management Information Systems Data Mart, LSC enrolls on average 15,000 students annually, about 100 of which are classified as foster youth (2019). FC enrolls, on average, 10,000 students annually, about 100 of which are foster youth (CCCCO Data Mart, 2019). Bode College enrolls, on average, 11,000 students annually, about 50 of which are foster youth (CCCCO Data Mart, 2019). While the foster youth population may be small, all of the participating 
colleges acknowledge foster you has a disproportionately impacted student population in their campus equity plans.

\section{Participants}

A major challenge in qualitative research is gaining access to participants and establishing sufficient rapport necessary to glean valuable information (Seidman, 2013). Connecting with potential participants without having had an established relationship can be very difficult, especially when working with vulnerable populations - former foster youth - or the research topic can be perceived as sensitive/political - policy implementation. Therefore, I utilized purposeful sampling in order to access the appropriate participants for this study.

Purposeful sampling is a sampling technique in which participants are chosen based on their knowledge or experience with the phenomena being studied (Creswell, 2004). The expert knowledge or experiences that participants have could encompass life experiences, employment experience, or demographic characteristics. For this study, purposeful sampling was utilized to connect to practitioners leading Guided Pathways implementation and students in campus foster youth support programs.

\section{Phase I: Practitioners}


Three community college practitioners, one from Little Streams College, one from Foggyville College, and one from Bode College directly participated in this study through interviews. Additional practitioners from all three colleges indirectly participated in this study through their submission of campus documents available in an online database, regarding their guided pathways implementation. It is important to make this notation of both direct and indirect participation because without it an assumption could be made that all of the data to be analyzed from the college practitioners was derived from just one interview with one individual on each campus. That is not the case. Instead, the entire collection of practitioner data included documents and resources developed by a variety of individuals at varying levels of responsibility, authority, and classification. I will expand upon the practitioner data collected in the following section "Data Collection and Analysis."

With regards to the interview that was conducted, or the direct participation, the practitioners were selected to participate because of their position within their campus as the lead practitioner overseeing Guided Pathways implementation. Little Streams College and Bode College's lead serves in a Dean capacity whereas Foggyville College's lead serves in a Director level role. Little Stream's dean oversees an instructional division in addition to his responsibility to lead the Guided Pathways work on the LSC 
campus. The dean overseeing the guided pathways work at BC is also responsible for a student services division. While, the FC practitioner is relatively new to this administrative role, she had been involved as a faculty colead with the Guided Pathways implementation since the initiative was first brought to campus. Pseudonyms were assigned to each practitioner to ensure confidentiality (see Table 1. Practitioner Demographic Information).

Table 1. Practitioner Demographic Information - self-reported

\begin{tabular}{|l|l|l|l|l|l|l|}
\hline Campus & $\begin{array}{l}\text { Pseud } \\
\text { onym }\end{array}$ & Gender & $\begin{array}{l}\text { Race/ } \\
\text { Ethnicity }\end{array}$ & $\begin{array}{l}\text { Current } \\
\text { Position }\end{array}$ & $\begin{array}{l}\text { Years in } \\
\text { Position }\end{array}$ & $\begin{array}{l}\text { Previous } \\
\text { Role }\end{array}$ \\
\hline $\begin{array}{l}\text { Little } \\
\text { Stream } \\
\text { College }\end{array}$ & David & Male & $\begin{array}{l}\text { Multi-racial } \\
\text { (Native } \\
\text { American/Filipin } \\
\text { o/Portuguese) }\end{array}$ & Dean & 6 years & $\begin{array}{l}\text { Instructional } \\
\text { Faculty }\end{array}$ \\
\hline $\begin{array}{l}\text { Foggyville } \\
\text { College }\end{array}$ & $\begin{array}{l}\text { Christi } \\
\text { ne }\end{array}$ & Female & White & Director & $\begin{array}{l}6 \text { months } \\
\text { (as } \\
\text { Director); } \\
2 \text { years as } \\
\text { co-lead }\end{array}$ & $\begin{array}{l}\text { Instructional } \\
\text { Faculty }\end{array}$ \\
\hline $\begin{array}{l}\text { Bode } \\
\text { College }\end{array}$ & Joy & Female & White & Dean & 1.5 years & $\begin{array}{l}\text { Administrator } \\
\text { - Director } \\
\text { level and } \\
\text { above }\end{array}$ \\
\hline
\end{tabular}

\section{Phase II: Foster Youth Scholars}

A total of 32 foster youth students participated in this study. Twenty five foster youth contributed to an online electronic written interview and seven participated in in-person paired interviews. All student participants were over 
the age of 18. All students registered with their campus Guardian Scholars Program were invited to participate in this study. While I expect that most foster youth are registered with their campus Guardian Scholars Programs, it is possible that there are students that identify as foster youth that did not receive the invitation because they were not involved or registered in the Guardian Scholars Program. Additionally, due to the fact that the invitations to participate in this study were sent out by the campus foster youth liaison is impossible to calculate how many students were initially invited.

Electronic written interview. A total of 25 scholars completed the initial electronic written interview (electronic interview). Six scholars were from Little Streams College and 19 scholars were from Foggyville College. In an effort to maintain scholar privacy, demographic information was placed at the end of the online interview and optional for students to complete. Though some scholars did provide demographic information, many students elected "decline to state" as an option when asked about race and gender, or did not provide an answer when asked about age or semesters completed. Therefore, the demographic overview of participants may not be completely reflective of all participants. That being said, of the scholars that did share demographic information at the end of the interview, 13 were "traditional aged" students 18-24 years old (27\%) and four were over the age of $27(14 \%)$. 


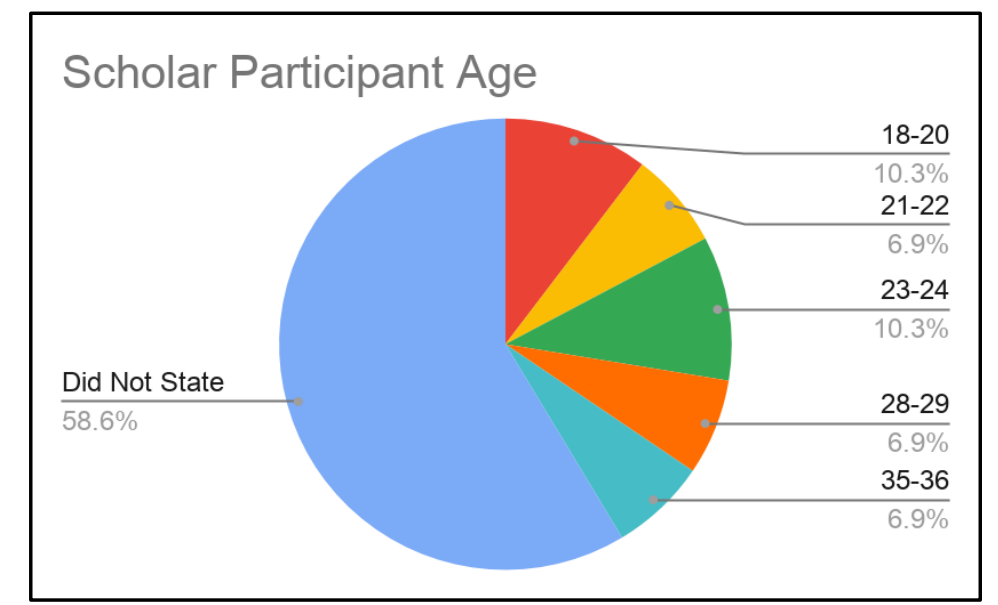

Figure 4. Scholar participant age by percentage.

Six scholars identified as female (29\%), five identified as male (24\%), one identified as other (5\%).

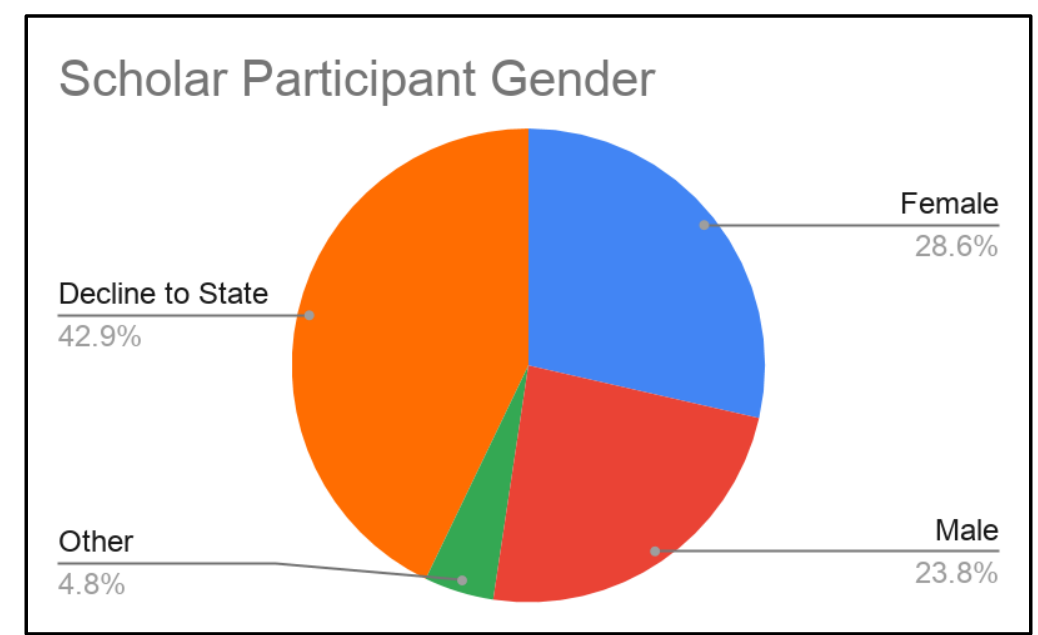

Figure 5. Scholar participant gender by percentage.

I utilized the race and ethnicity identification list that is included on the California Community Colleges application (which is used statewide for admission into any California community college). While race and ethnicity showcased a 
broad diverse background of students, the largest subset of scholars identified as Black or African-American (14.8\%) followed by Mexican, Mexican-American, Chicano (11.1\%).

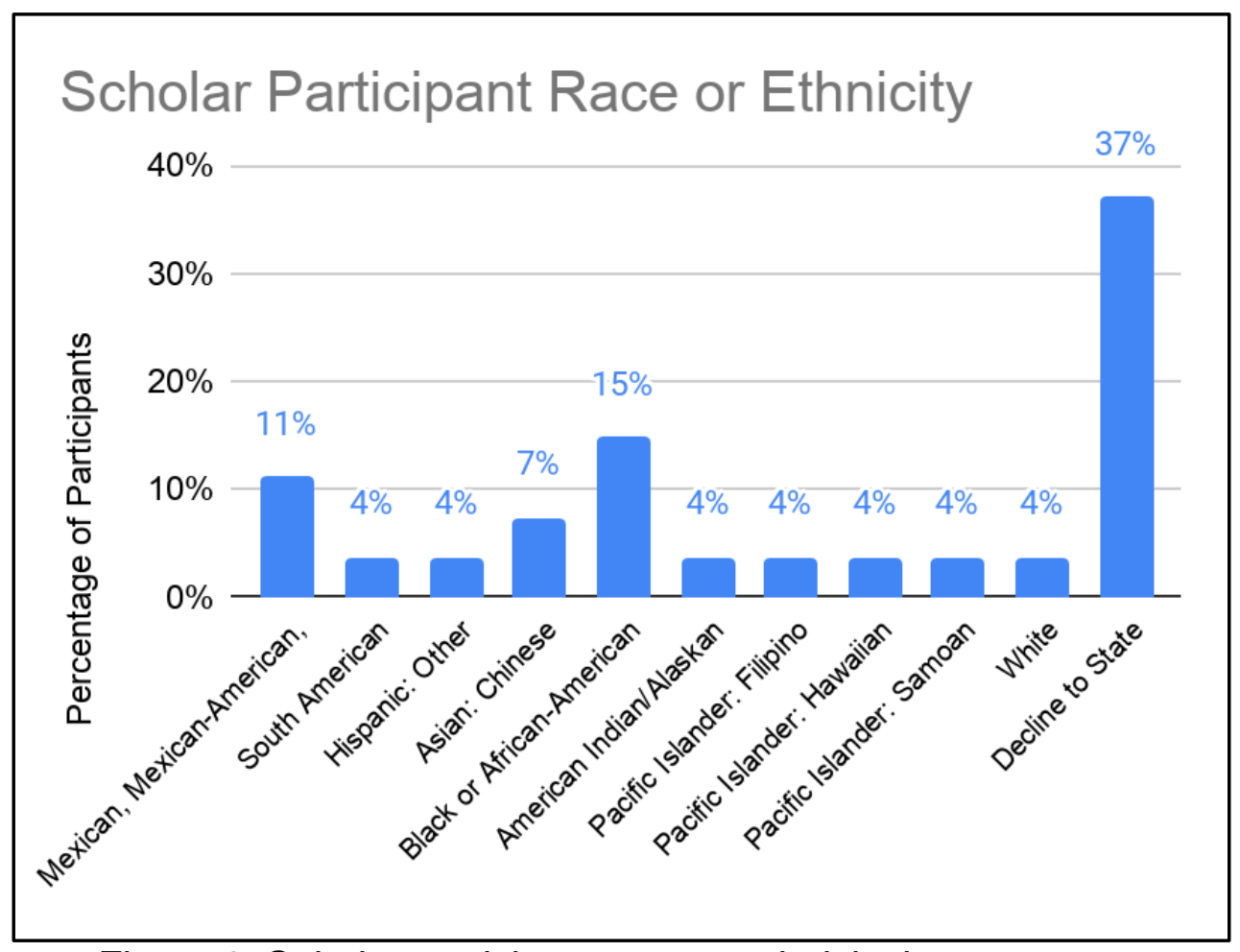

Figure 6. Scholar participant race or ethnicity by percentage

Finally, a majority of scholars were in their first two semesters (21\%), and have an educational goal of obtaining and associates degree and transferring to a 4year institution (45\%). 


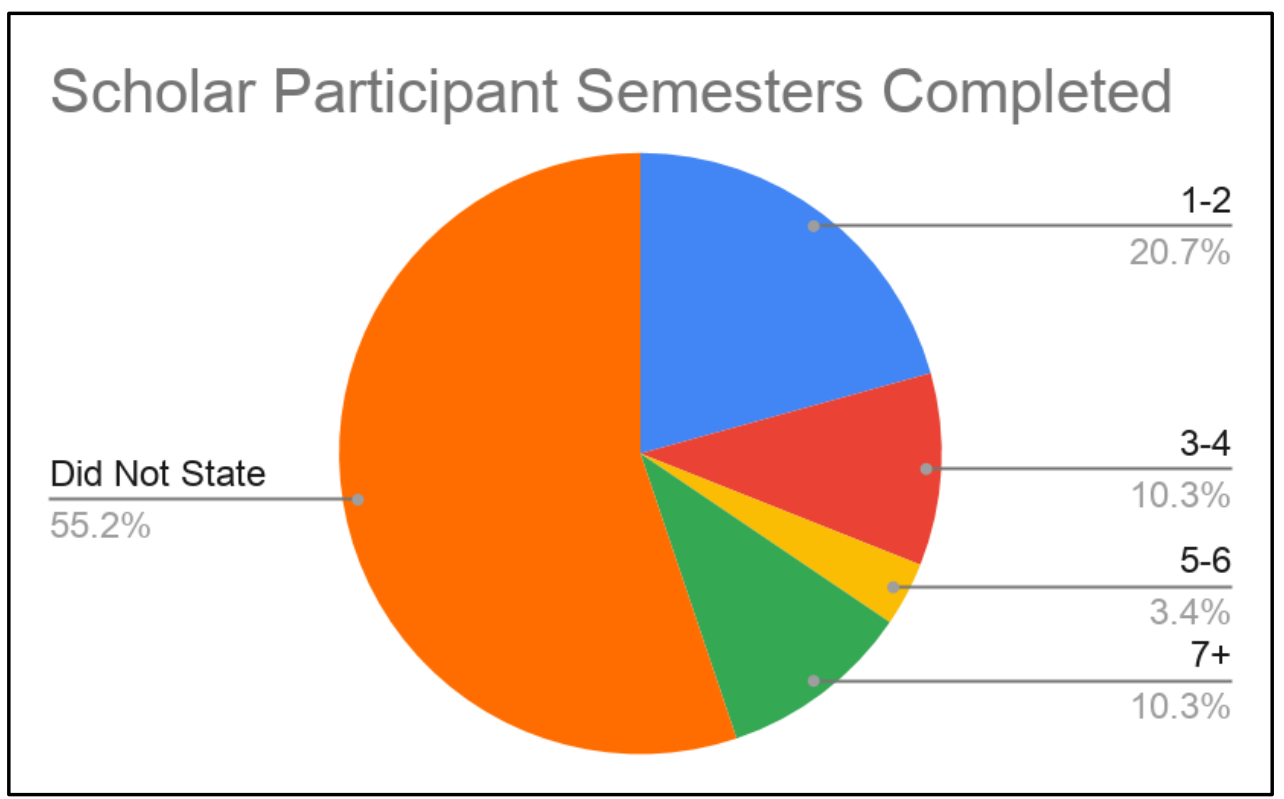

Figure 7. Number of semesters completed by percentage

\section{Scholar Participant Educational Goal}

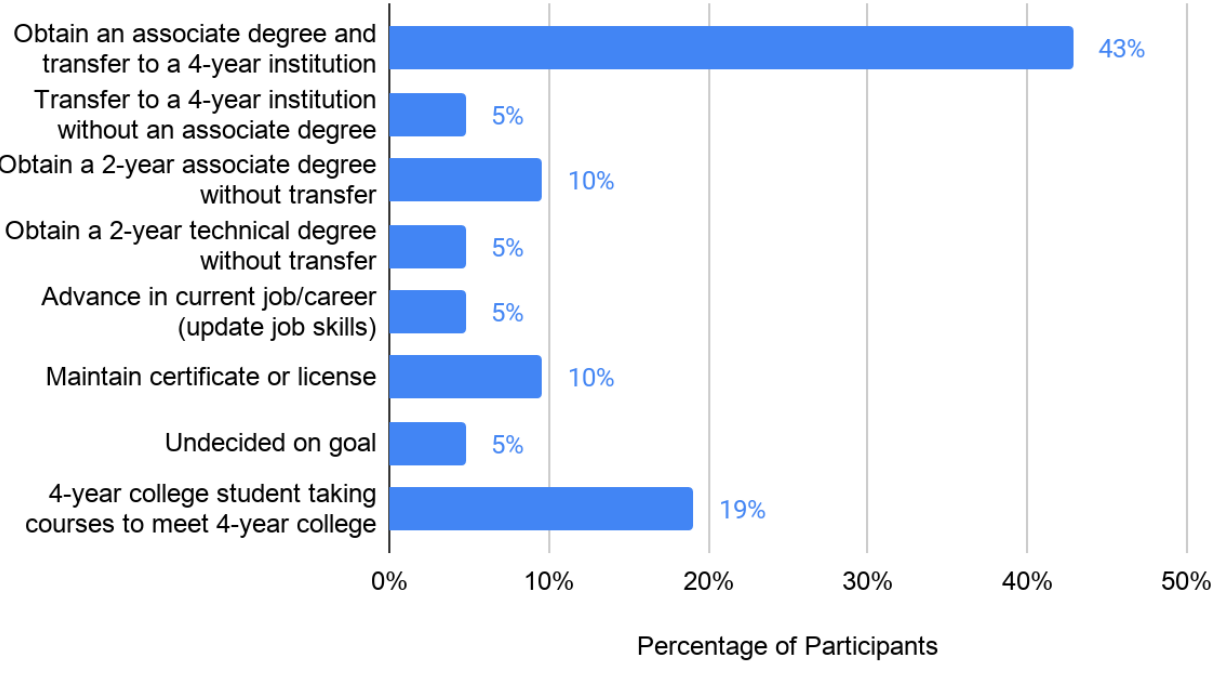

Figure 8. Scholar participant educational goal by percentage

Paired interview. Paired interview participants were also current community college students that were, or are, active in the Guardian Scholars 
Program at Foggyville College. There were a total of seven scholars that participated in the paired interviews, however one of the scholars was unable to complete the entire interview. There were five women and two men that participated in the interviews. Additionally, three of the scholars identified as White, two as Mexican, one as Black, and one as White/Hispanic (based on their personal identification). Pseudonyms were assigned to each paired interview participant in order to ensure confidentiality (see Table 2. Paired Interview Participant Demographic Information).

Table 2. Paired Interview Participant Demographic Information

\begin{tabular}{|l|l|l|l|l|}
\hline $\begin{array}{l}\text { Interview } \\
\text { Session }\end{array}$ & $\begin{array}{l}\text { Student } \\
\text { Pseudonyms }\end{array}$ & Gender & Race/Ethnicity & $\begin{array}{l}\text { Semesters } \\
\text { Completed }\end{array}$ \\
\hline \multirow{3}{*}{ Interview 1 } & Alina & Female & $\begin{array}{l}\text { White Non- } \\
\text { Hispanic }\end{array}$ & 3 \\
\cline { 2 - 6 } & Jeff & Male & Black & 1 \\
\hline \multirow{3}{*}{ Interview 2 } & Adam & Male & White/Hispanic & 6 \\
\cline { 2 - 6 } & Tia & Female & $\begin{array}{l}\text { White Non- } \\
\text { Hispanic }\end{array}$ & 2 \\
\hline \multirow{3}{*}{ Interview 3 } & Norma & Female & Mexican & 10 \\
\cline { 2 - 5 } & Laura & Female & Mexican & 3 \\
\cline { 2 - 5 } & *Karrie & Female & $\begin{array}{l}\text { White Non- } \\
\text { Hispanic }\end{array}$ & 3 \\
\hline
\end{tabular}




\section{Data Collection \& Analysis}

In order to answer my research questions, I collected a variety of data

from various sources. A key aspect of case study research is the ability to investigate multiple sources of evidence (Yin \& Campbell, 2018). Therefore, it was important to capture information from college practitioners regarding their campus' approach to equitable Guided Pathways implementation as well as hear from foster youth students about their experiences in community college. Table 3 below provides an overview as to what data sources were utilized to answer the research questions. The information that follows Table 3 in this section provides more details regarding data collection and analysis for Phase I, Phase II, and Phase III. 
Table 3. Research Questions \& Methods

\begin{tabular}{|c|c|c|c|c|}
\hline Research Question & Participants & Method & Data Purpose & $\begin{array}{c}\text { Research } \\
\text { Phase }\end{array}$ \\
\hline \multirow{2}{*}{$\begin{array}{l}\text { 1. What are the } \\
\text { intentional ways in } \\
\text { which community } \\
\text { college leaders are } \\
\text { addressing equity in } \\
\text { the implementation of } \\
\text { the Vision for } \\
\text { Success? }\end{array}$} & \multirow[b]{2}{*}{$\begin{array}{c}\text { College } \\
\text { Practitioners }\end{array}$} & $\begin{array}{l}\text { Document } \\
\text { Analysis }\end{array}$ & $\begin{array}{l}\text { Overall insights on the } \\
\text { inquiry process and Guided } \\
\text { Pathways implementation } \\
\text { thus far. }\end{array}$ & \multirow[b]{2}{*}{ Phase I } \\
\hline & & $\begin{array}{l}\text { Semi- } \\
\text { Structured } \\
\text { Interview }\end{array}$ & $\begin{array}{l}\text { Provided deeper insights } \\
\text { on the Guided Pathways } \\
\text { implementation, decision } \\
\text { making processes, student } \\
\text { involvement, and } \\
\text { intentional focus on equity. }\end{array}$ & \\
\hline \multirow{3}{*}{$\begin{array}{l}\text { 2. How can the } \\
\text { educational } \\
\text { experiences of former } \\
\text { foster youth scholars } \\
\text { inform the equitable } \\
\text { implementation of CC } \\
\text { reforms? }\end{array}$} & \multirow[b]{2}{*}{$\begin{array}{l}\text { Foster Youth } \\
\text { Scholars }\end{array}$} & $\begin{array}{l}\text { Online } \\
\text { Interview }\end{array}$ & $\begin{array}{l}\text { Provided preliminary } \\
\text { insights to foster youth } \\
\text { experiences in community } \\
\text { colleges. }\end{array}$ & \multirow[b]{2}{*}{ Phase II } \\
\hline & & $\begin{array}{l}\text { Scholar } \\
\text { Paired } \\
\text { Interviews }\end{array}$ & $\begin{array}{l}\text { Provided deeper insights } \\
\text { into foster youth } \\
\text { experiences in community } \\
\text { college and } \\
\text { recommendations for } \\
\text { institutional change from } \\
\text { the scholar point of view. }\end{array}$ & \\
\hline & $\begin{array}{l}\text { College } \\
\text { Practitioners \& } \\
\text { Foster Youth } \\
\text { Scholars }\end{array}$ & $\begin{array}{l}\text { Cross Case } \\
\text { Study } \\
\text { Analysis }\end{array}$ & $\begin{array}{l}\text { Provided an opportunity to } \\
\text { review information gleaned } \\
\text { from students and } \\
\text { practitioners cohesively, } \\
\text { within and across sites. }\end{array}$ & Phase III \\
\hline
\end{tabular}

\section{Phase I - Community College Practitioners Data Collection}

Document Analysis. The data collection for the practitioner phase of this study actually began online. In an effort to better track funding allocations and expenditure reporting for California Community Colleges, the Chancellor's 
Office worked with an external technology company to create NOVA. NOVA is an online software platform "designed and developed by productOps to increase student success rates through more efficient and relevant program creation, better fund management, and enhanced data management across the entire California Community College System" (Isenberg, 2018). In addition to fund management, the Chancellor's Office is also tracking progress of Guided Pathways implementation by requesting that colleges upload a Guided Pathways Scale of Adoption report to the site. The NOVA platform is not a publicly accessible platform and I had to request access to the site. Once I was granted access to the site, I was able to download and review the documents listed in Table 4 for Little Stream College, Foggyville College, and Bode Code as it related to my first research question: What are the intentional ways in which community college leaders are addressing equity in the implementation of the Vision for Success?

Table 4. List of Documents Analyzed

\begin{tabular}{|l|l|l|}
\hline Document Title & Contributing Authors & Purpose within this study \\
\hline Guided Pathways & Little Streams College (LSC) & This document was \\
Scale of Adoption & $-\quad$ College President & $\begin{array}{l}\text { utilized to gain an } \\
\text { understanding of what } \\
\text { inquiry has already taken } \\
\text { place as well as what } \\
\text { recommendations have } \\
\end{array}$ \\
& $\begin{array}{l}\text { Foggyville College (FC) } \\
\text { been proposed. }\end{array}$ \\
& $-\quad$ Dice President & \\
& $-\quad$ President, Academic Senate & \\
& & \\
\hline
\end{tabular}




\begin{tabular}{|c|c|c|}
\hline & $\begin{aligned} & \text { Bode College (BC) } \\
& \text { - } \text { College President } \\
& \text { - } \text { President, Academic Senate } \\
& \text { - } \text { Faculty Lead } \\
& \text { - } \text { Dean, Guided Pathways }\end{aligned}$ & \\
\hline $\begin{array}{l}\text { Local Vision Goals } \\
\text { Summary }\end{array}$ & $\begin{array}{l}\text { Contributing authors share the same } \\
\text { positions across all three campuses } \\
\text { - } \quad \text { Dean, Institutional Research } \\
\text { - } \quad \text { President, Academic Senate } \\
\text { - } \text { College President } \\
\text { - } \\
\text { Board of Trustees President }\end{array}$ & $\begin{array}{l}\text { This document was } \\
\text { utilized to better } \\
\text { understand the mission } \\
\text { and vision of each } \\
\text { institution. Additionally, } \\
\text { it includes information } \\
\text { about disproportionately } \\
\text { impacted students and } \\
\text { the institution goals to } \\
\text { improve outcomes for } \\
\text { these groups. }\end{array}$ \\
\hline $\begin{array}{l}\text { Student Equity \& } \\
\text { Achievement } \\
\text { Program Plan }\end{array}$ & \begin{tabular}{|ll} 
LSC & \\
- & Associate VP Equity, Institutional \\
& Effectiveness \\
- & Vice President, Student Services \\
- & Dean, Institutional Effectiveness \\
- & Vice President, Instruction \\
- & College President \\
& \\
FC & \\
- & Dean, Student Equity \\
- & Vice President, Student Services \\
- & Chief Financial Officer \\
- & Dean, Counseling \\
- & Division Assistant, Student \\
& Equity \\
- & Vice President, Instruction \\
- & College President \\
& \\
BC & \\
- & Vice President, Student Services \\
- & Director, Student Equity \\
- & Vice President, Instruction \\
- & College President
\end{tabular} & $\begin{array}{l}\text { This document was } \\
\text { utilized to gain clarity on } \\
\text { which student groups } \\
\text { were identified as } \\
\text { disproportionately } \\
\text { impacted. This } \\
\text { document also provided } \\
\text { insights to proposed } \\
\text { interventions to support } \\
\text { the success of } \\
\text { disproportionately } \\
\text { impacted students. }\end{array}$ \\
\hline
\end{tabular}

This initial document collection and analysis allowed me to gain a general sense of the work that LSC, FC, and BC have done thus far to implement 
Guided Pathways. Bowen (2009) would refer to this utilization of documentation as an opportunity to "bearing witness to past events" (pg. 29). My document analysis was an iterative process that included both content analysis and thematic analysis. In the first review of the documents I was searching for information related to the specific content that was provided. I looked for specific implementation strategies or program development that was mentioned as a part of the self assessment and plan. My thematic analysis pulled out specific themes related to: student voice, equity, disproportionate impact, and campus implementation. Both the data gathered from content analysis and thematic analysis provided valuable information upon which I was able to build a semistructured interview protocol that I utilized with the practitioners at LSC, FC, and BC (Bowen, 2009) (see Appendix A. Practitioner Interview Protocol).

Practitioner interview. Utilizing purposeful sampling (Creswell, 2004), I contacted practitioners leading the Guided Pathways implementation efforts at Little Stream College, Foggyville College, and Bode College. In a review of each campus' Guided Pathways websites and the Guided Pathways Scale of Adoption, I was able to identify the campus Guided Pathways lead practitioner. I sent an email to the campus Guided Pathways lead asking them to participate in an interview to be conducted either face-to-face or online. The email (see 
Appendix B for Practitioner Interview Invitation Email) offered the individual the opportunity to sign up for an interview time that was most convenient to them through a third party meeting scheduling system.

I personally conducted both of the practitioner interviews at each campus. The practitioner interview at LSC lasted approximately 38 minutes and was conducted via a cloud meeting software in which both the participant and myself could see and hear one another. The practitioner interview at FC lasted approximately 41 minutes and was conducted in person. The practitioner interview at BC was also conducted online and lasted approximately 36 minutes. All of the interviews were audio- and video-recorded after having received consent to do so by the participants, and I also took notes during the interview in order to quickly capture key concepts (Charmaz, 2014). I utilized an automatic transcription software that immediately transcribed the interview during the recording. I also reviewed the transcription software to ensure that the interviews were properly transcribed and made corrections as needed. Once the interviews were transcribed I uploaded the transcribed files into the Dedoose qualitative analysis software to assist with my coding process.

\section{Phase I: Community College Practitioners Data Analysis}

In order to analyze both the documents and the interviews with an equity lens, I utilized the Social Action, Leadership, and Transformation model. The 
Social Action, Leadership, and Transformation (SALT) model is a more recently published framework that takes Social Justice Leadership Theory and explicitly calls out issues of systemic oppression while also providing practical application recommendations for leaders in the field (Museus et al., 2017). The seven components of the SALT model are: 1) capacity for empathy; 2) critical consciousness; 3) commitment to justice; 4) equity in purpose; 5) value of collective action; 6) controversy with courage; and 7) coalescence. Deductive codes are those that are drawn from a pre-established framework, fact, or evidence (Charmaz, 2014; Saldaña, 2014). I utilized the seven components of the SALT model provided a framework upon which I was able to create deductive codes that align with my first research question: What are the intentional ways in which community college leaders are addressing equity in the implementation of the Vision for Success?

While the SALT model provided an intentional equity focused framework upon which I was able to develop deductive codes, I also created inductive codes to ensure that I was able to capture important themes that did not fit solely in the SALT model. Inductive codes are those developed based on principles of grounded theory in which "fresh categories" (pg. 187) are identified for analysis (Charmaz, 2006). With inductive codes I was able to identify additional themes that were more in alignment with the steps of implementation 
that would not have been included in the deductive codes built off of the SALT model only.

\section{Practitioner Themes and Codes}

The findings for the practitioner analysis are organized by three main themes: 1) Understanding Equity, 2) Equitable Implementation of Guided Pathways, and 3) Inclusion of Student Voice in Inquiry. These three themes were constructed by categorizing the deductive codes developed from the SALT model and the inductive codes created through the data analysis described in Chapter 3. In this section I will first provide definitions of the codes that I utilized, followed by definitions of the broader themes, followed by individual case analysis for each campus.

\section{Definition of Codes: Practitioners}

The entire Vision for Success has a direct intention to address issues of inequity within community colleges in order to close equity gaps. I utilized the Social Action, Leadership, and Transformation (SALT) model due to its explicit focus on socially conscious leadership whose purpose is to achieve justice. 


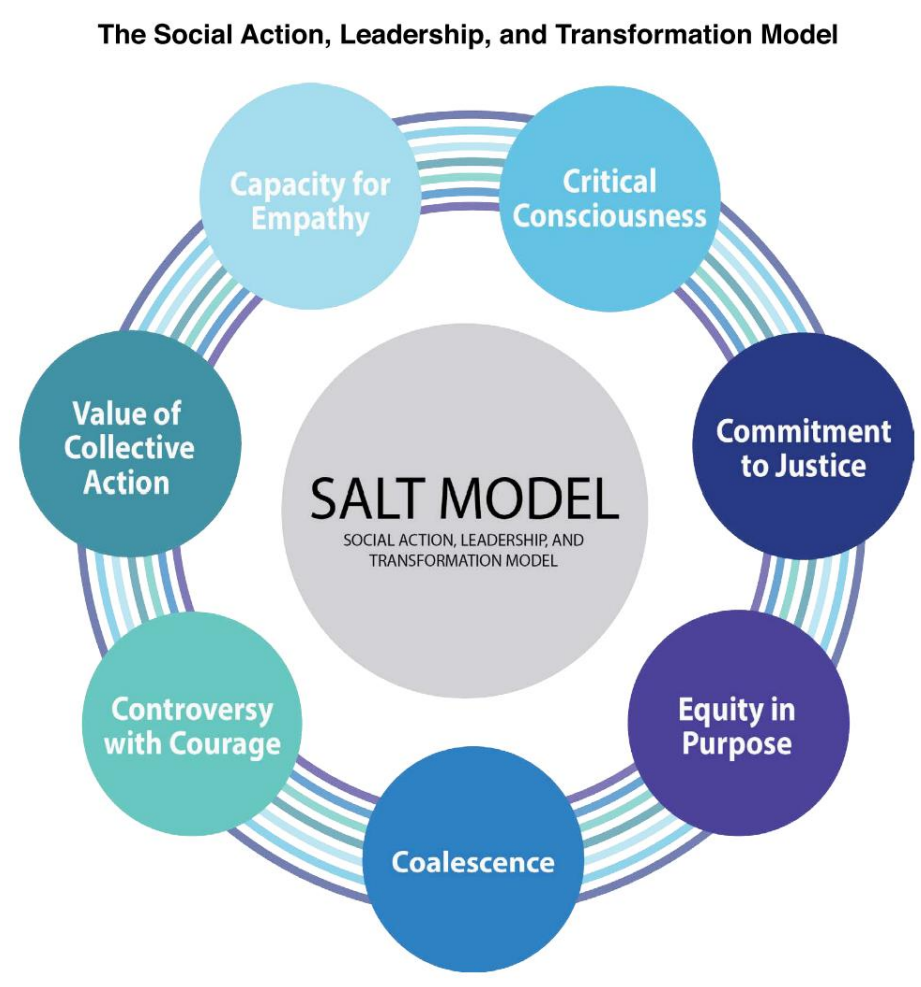

Figure 9. SALT Model Framework Image (Museus et al, 2017, pg. 5)

Because the SALT model is an existing framework, I utilized the author's definitions in order to better understand how to deduct the proper excerpts or images during my coding process. The definitions for each component of the SALT model are below:

1. Capacity for Empathy: includes instances where leaders understand the need to empathize with the experiences, perspectives, and life situations of others - especially historically oppressed communities. The intentional approach to implementing reform efforts that dismantle structural inequities and develop anti-deficit practices to empower historically marginalized populations. 
2. Critical Consciousness: includes having an express understanding of historical and contemporary forms of oppression in relation to the positionality of those in positions of power within larger structures.

3. Commitment to Justice: entails the motivation to prioritize the advancement and well-being of historically oppressed communities. This requires a cultivation of agency and sense of empowerment to develop the capacity to resist oppression.

4. Equity in Purpose: recognizes the multitude of relevant voices and ensures that diverse groups are equally centered in group efforts and purpose.

5. Value of Collective Action: this is enacted when leaders work with diverse groups to collectively resist forms of oppression and advance justice for historically underserved and marginalized communities.

6. Controversy with Courage: requires leaders to engage in controversy courageously by embracing discomfort, engaging in difficult conversations where privilege and oppression are acknowledged, and contribute to conversations about significant social problems.

7. Coalescence: refers to the process by which a shared understanding that systemic equity and justice is beneficial for all groups and goals should coalesce back to this main idea.

In addition to the seven tenets of the SALT model, the inductive codes were

8. Student First: refers to the acknowledgement that students are at the center of these reform efforts. The

9. Student Voice: includes the specific and intentional opportunities in which students were directly connected to the reform efforts within the campus.

10. Participatory Governance: focuses on the approval process that any recommended change would need to pass through in order to be implemented on campus. Participatory governance can include Academic Senate (which supports faculty), Classified Senate (which supports classified professional staff), and Student Senate (which supports students on campus). For example, much of the Guided Pathways reform efforts are focused on addressing issues of equity within the college classrooms. As such, according to Title V. Education 
Code of Regulations, any changes or recommendations that directly impact instruction, have to be approved by Academic Senate before it can be implemented.

With these 10 tenets in mind, I reviewed the documents and transcripts of the semi-structured interviews to determine the ways in which Little Streams College, Foggyville College, and Bode College are approaching an equitable implementation of Guided Pathways efforts. I grouped the seven tenets into themes which are defined in the following section.

\section{Practitioner Definition of Themes}

Understanding of Equity. The Vision for Success was initially developed to address issues of equity within the California Community Colleges. In order for the community colleges to address issues of equity, there must be a clear understanding of what equity is in the first place. In this work, I believe, there are two ways in which practitioners can view equity. One way is based on a technical definition of equity that was provided in Chapter 1: helping students achieve equal outcomes on success indicators as compared to either their own percentage in the community or college student body, or to other student groups" (Noldon, 2015, p.1). The other is less technical but crucial to approaching the work in a meaningful way. Equity, to me, means acknowledging the systemic barriers of oppression that have prevented all students from gaining equal access and success within education, and being intentional about removing such barriers. It is my belief that the technical 
application of equity cannot fully take place unless there is a systemic understanding of equity. Within the SALT model's explicit approach to addressing equity and social justice, there are four specific tenets that align with the idea of "Understanding Equity." These tenets are:

- Equity in Purpose

- Capacity for Empathy

- Critical Consciousness

- Commitment to Justice

Equitable Implementation of Guided Pathways. Beyond having a clear understanding of equity, I also wanted to inquire about the ways in which practitioners were being intentional about connecting their understanding of equity to practice. Connecting back to Rhiana Gunn-Wright's statements in Chapter 2 that there are often disconnects between the the policy makers attempting to solve a problem and the people on the ground experiencing the problem for which the policy was intended to serve (2019). I was curious about how the college practitioners, who received a statewide directive to close equity gaps, were actually intending to do so with their specific campus community in mind. The SALT model tenets and inductive codes that best align with the "Equitable Implementation of Guided Pathways" include:

- Controversy with Courage

- Coalescence

- Value of Collective Action

- Participatory Governance 
Inclusion of Student Voice in Inquiry. Student voice is an integral part of education reform efforts. As Mitra posits, "student outcomes will improve and school reform will be more successful if students actively participate in shaping it" (2004, p. 652). The Vision for Success, as a document, encourages the inclusion of students and student voice in campus reform efforts. On the Vision for Success website there are even toolkits to guide practitioners in meaningful practices around capturing student voice. The tenets of the SALT model and the inductive codes that best align with "Student Voice" include:

- Students First

- Value in Collective Action

- Student Voice

The subsequent chapters will separately include a case based analysis of each campus, utilizing the three themes of understanding equity, equitable implementation of Guided Pathways, and utilization of student voice in inquiry, in order to address research question one: What are the intentional ways in which community college practitioners are addressing equity in the implementation of the Vision for Success?

Phase II - Foster Youth Scholars Data Collection

Network sampling, a variation of purposive sampling, was utilized to connect with former foster youth on campus (Merriam, 1998). Similar to Rassen, Cooper, and Mery's (2010) study on former foster youth in community 
colleges, I relied on campus foster youth liaisons to share the initial electronic interview request to gather preliminary data as well as promote the focus groups, or paired interviews, for students to join. These programs would be able to verify the students that would qualify as a current or former foster youth. Foster youth have to be coded within the data reporting systems in order to receive both state and federal postsecondary education benefits. However, each benefit may require unique paperwork that has to be verified by the requesting office. For example, students that may be receiving the Chaffee Grant have to be verified by the financial aid office as having been in the foster care system at any point between the ages of 16-18 years old (California Student Aid Commission, n.d.). However, students that participate in campus Guardian Scholars Programs, which are state funded programs to support current and former foster youth, may only need to showcase documentation indicating that they were in the foster care system at some point for at least a year. Thus, I relied specifically on the Guardian Scholars Programs to validate and confirm the eligible foster youth on their campus to participate in this study.

Electronic interview. I reviewed a directory of campus contacts listed on the California Community College Chancellor's Office Foster Youth Success Initiative website to determine the appropriate person to contact. These foster youth liaisons were emailed a request to share the electronic interview with 
students in their Guardian Scholars program (see Appendix C. for Foster Youth Scholar email invitation to participate). The liaison at Little Streams College forwarded the email to students within their listserv, whereas the liaison at Foggyville College posted the email to the online student education portal which sent a notification to all students registered in the program. Unfortunately the liaison at Bode College did not respond to my request to share the interview and I therefore do not have any student responses from this institution. A total of 25 scholars completed the initial electronic interview (see Appendix D. Scholar Electronic Interview Questions). Six scholars were from Little Sreams College and 19 scholars were from Foggyville College. While the interview link was sent to the campus foster youth liaison with explicit language stating that the interview was meant to elicit insights from students that were foster youth, a screening question was included to allow only students that were "either currently or ever in court-ordered foster care" to complete the survey. Therefore, the responses that I was able to analyze were those of participants that stated that they were currently, or had previously been, in court-ordered foster care.

Groves, Singer, and Corning's Leverage-Saliency Theory of Survey Participation (2000) posits that an individual's participation in a survey is based on three factors: altruism (wherein there is an internal desire to provide 
insights), survey-related (wherein the participant is interested in the survey topic), or egoistic reasons (wherein the participant enjoys answering surveys or are motivated by money). While accessing student participants through their campus foster youth program was a primary approach to encouraging student participation, an additional motivator to participation was through the use of a $\$ 10$ electronic gift card (e-gift card) incentive for the completion of the electronic interview. One of the most prevalent considerations of this practice are the ethical implications of incentive use in qualitative research. In reviewing her own research study examining the lives of single mothers, Head (2009) asserts that the use of incentives in qualitative research needs to be thoughtfully considered as an intentional aspect of the research project. The inclusion of an incentive should not be included in research haphazardly - but instead be included with intention, or reason, where not including an incentive may have not produced the same access to participants. For this study, I elected to include a $\$ 10$ e-gift card incentive to scholar participants as a token of appreciation for the time they took to respond to the electronic interview. This is referred to as a promised incentive as the participant was required to complete the online interview prior to receiving the incentive (Singer \& Bossarte, 2006). Kelly et al (2017), found that potential participants in a qualitative interview study were more willing to participate in studies that offered a monetary 
incentive versus studies that did not. I specifically chose to provide a $\$ 10$ e-gift card as an opportunity to thank scholar participants for their time, but not to unduly influence participation by providing an inappropriate "overture in order to obtain compliance" (Singer \& Bossarte, 2006, pg. 414). A $\$ 10$ e-gift card for a college student is not going to significantly change their lives or financial situations, but I did want to provide a small financial token of appreciation for students that are providing their responses, voluntarily and on their own time. Due to the fact that the electronic interview link was provided to students via their foster youth liaison, participants were asked to provide their email address as a way to receive their $\$ 10$ electronic gift card. I worked with the third party vendor, Tango Card Services, to provide the e-gift card automatically sent to the email address that the student provided in the interview. This removed any potential bias or error on my part in ensuring that all students were able to receive their \$10 electronic gift card. Additionally, the third party vendor has access to a number of retailers to which the student is able to identify what type of $\$ 10$ gift card they wanted to receive.

Paired Interviews. While I initially intended to conduct focus groups of foster youth, it proved to be challenging to gather the participation of more than two students at a time. Creswell and Creswell (2018) recommend focus group sizes to be between six to eight participants, however there were only between 
two and three student participants per focus group. Therefore, the discussions with the foster youth participants naturally shifted to paired interviews rather than focus groups. Paired interviews provide an opportunity for the researcher to interview two participants at the same time so that the participants can interact with one another and build on their conversation through a more natural discussion (Wilson, Onwuegbuzie, \& Manning, 2016). Additionally, I am mindful that I was working with a vulnerable population and while the questions focused mainly on their academic experiences, there could have been opportunities where participants shared personal stories that may have been difficult to share in a larger group. As a result the paired interviews proved to be an effective method to engage in discussion with the foster youth and gain more insights around their experiences in community college.

Three paired interviews were conducted at Foggyville College. Similar to the invitation to participate in the online interview, I worked with the foster youth liaison to invite students to participate in a student focus group that evolved into a paired interview (see Appendix E. Scholar focus group flyer). The flyer was sent out to students via their school portal email and posted in the Guardian Scholars office. Students were sent a reminder notification two days prior to the paired interview in order to reduce attrition. The paired interviews took place mid-day and therefore, I provided lunch for the attendees on both days. 
Additionally, students that attended the paired interview were also eligible to receive a $\$ 10$ electronic gift card as an appreciation for their time.

In reviewing the informed consent forms, it was communicated that participation in the paired interview was voluntary and would have no effect on their academic standing at their current institution or at San Francisco State University if they so choose to one day enroll (see Appendix F. Scholar Focus Group Informed Consent Form). With verbal consent of all participants, the paired interviews were audio recorded utilizing an automatic transcription software. I also took notes during the paired interview to quickly capture any key themes or ideas that scholars shared (Charmaz, 2014).

I, personally, facilitated the three paired interviews. Each paired interview lasted less than an hour each, 50 minutes, 52 minutes, and 52 minutes. Prior to starting the interview questions, I facilitated the community builder "Would You Rather" as an opportunity for the participants to chat with one another, learn about some similarities and differences they may have, and create a space of warmth where sharing and listening are welcomed (Gibson, 2007). The community builder was not recorded, as this time was focused on rapport building and not data collection.

Career Ladders Project (CLP) recently published a report entitled Bringing Student Voices to Guided Pathways Inquiry and Design Findings From 
Student Focus Groups at Two California Community Colleges (2017). The Career Ladders Project (2017) student voice guide focused specifically on student experiences in access, major selection, choosing classes, and identifying college barriers and supports. I utilized the focus group protocol from the Career Ladders Project (see Appendix G. Scholar Paired Interview Protocol) to guide the paired interviews at Foggyville College. After the initial paired interview questions were asked, scholars also brainstormed recommendations to help support student success within community colleges based on their own experiences. After each interview session I reviewed the transcription created through the automated transcription software for accuracy and cleaned/edited the transcripts as needed. I then uploaded the transcriptions to Dedoose for analysis. The data collected were stored safely and securely, and the identities of all participants were changed to ensure confidentiality.

Phase II: Foster Youth Scholars Data Analysis

Similar to the practitioner analysis, I utilized both deductive and inductive codes to identify themes and trends in the student data. I developed deductive codes based on the findings in the CLP Bringing Student Voices report, in order to build on the learnings from this study. The main themes from the Career Ladders Project 2017, study Bringing Student Voices to Guided Pathways 
Inquiry and Design: Findings from Student Focus Groups at Two California Community Colleges report focused on: challenges in major selection, selecting and accessing the right courses, awareness and connection to support services, counselor involvement, and seeking a sense of community. Because the CLP report focused on a broader, more generalized student population, there were codes and themes that emerged based on the specific experiences of foster youth. These specific experiences contributed to the development of inductive codes as I analyzed the student transcripts.

\section{Foster Youth Scholars Themes and Codes}

The findings for the foster youth scholars analysis are organized by four main themes: 1) Understanding scholars' motivation in pursuing higher education; 2) Understanding what's working for foster youth scholars; 3) Exploring the areas of opportunity; and 4) Hearing scholar recommendations. These four themes were constructed by categorizing the deductive codes built from the CLP Bringing Student Voices report. In this section I will first identify the codes that I utilized, followed by definitions of the broader themes. As a note, I will just be identifying the codes developed for the foster youth scholars but will not be defining them. I elected to define the codes for the practitioners as they were built from a framework that had a specific definition for each code and I wanted to adhere to the framework authors' definitions. That is not the 
case with the deductive codes for the foster youth scholars analysis. The deductive codes for foster youth were developed based on findings of the report - not existing definitions.

\section{Foster Youth Scholars Identification of Codes}

Having built my interview protocol off of the Bringing Student Voices report, I developed my codes to be in alignment with the report's findings. The five main findings from the report included: 1) choosing a major, 2) choosing courses, 3) awareness and use of support services, 4) importance of counselor involvement, and 5) desire for a sense of community and culturally relevant education. These five findings provided the basis for my deductive codes. In addition to the five deductive codes I also utilized inductive coding to develop my themes. The inductive codes included: external expectations, convenience, sense of purpose, faculty support, Guardian Scholars support, peer support, empathy, goals and aspirations, confidence in decisions made, balancing life and school, financial barriers/insecurity, housing barriers/insecurity, access to information, guidance, and connections to campus.

With both the deductive and inductive code list, I was able to identify four main themes to support the foster youth scholars analysis and learn more about the educational experiences of foster youth enrolled at Foggyville College and Little Streams College. 


\section{Foster Youth Scholars Definition of Themes Understanding Scholar's Motivation in Pursuing Higher Education.}

In order to understand the experiences of foster youth scholars in community college, it is important to understand why they decided to attend college in the first place. Much of the research suggests that foster youth scholars are most influenced by an external person, such as a teacher, social worker, or foster parent, that encourages the foster youth scholar to attend college. In addition to learning about the external factors that encourage students to enroll in college, I was also curious about foster youth's internal motivators.

Understanding What's Working for Foster Youth Scholars. A part of understanding the experience of foster youth scholars includes knowing what is working well. The passing of $A B$ 801, Bloom. Postsecondary education: Success for Homeless Youth in Higher Education Act, all 115 California Community Colleges are required to have a foster youth liaison on campus. According to the California College Pathways website, a resource for foster youth to find information regarding higher education, there are 93 community colleges with a specific program for foster youth - such as Next Up/Guardian Scholars. While the intent of these programs were developed to provide additional support for students there is not a lot of empirical research on the impact of such programs to foster youth success. Though the main focus of 
this study is not on specific program impact, each of the colleges included in this study do have a foster youth program to which the scholar participants are connected. Beyond the structured foster youth support program additional supports that students recognize community supports, faculty engagement, and more.

Exploring the Areas of Opportunity. As previously mentioned, each of the colleges included in this study have established foster youth support programs: Next Up/Guardian Scholars. However, completion rates for foster youth are still low. In fact, foster you are listed as a disproportionately impacted group regarding completion for each of the colleges included in this study. Therefore, it is important to gain a sense of what might be missing, or what more could colleges be doing, to help support the success of foster youth.

Scholar Recommendations. Building on Clemens et. al (2017) study in which they asked foster youth for recommendations on how schools can increase high school graduation rates, I asked the scholars for recommendations on how colleges can better support foster youth. Some of the recommendations were identified by highlighting the challenges that students mentioned throughout the interview. While other recommendations were identified based on the responses given when I asked the foster youth what their recommendations would be. 


\section{Phase III: Cross-Case Study Analysis}

After conducting individual case studies for each campus, I conducted a cross case analysis in order to answer my second research question: How can the educational experiences of former foster youth inform the equitable implementation of community college reforms? I analyzed the entire set of practitioner findings and foster youth scholar findings amongst all of the campuses in order to develop the cross-case analysis. In reviewing both data sets, practitioner data and scholar data, collectively I was able to identify the following:

- Needs of students - provided by the scholar paired interviews

- Attempts to address student needs - provided by the practitioners

- Opportunities for practitioner considerations - provided by the scholar paired interviews

I utilized the Dedoose qualitative analysis software to assist with the cross-case study analysis by identifying and coding themes that emerged from this process which will be presented in chapter 6 .

\section{Validity and Reliability}

According to Creswell and Creswell (2018), validity in qualitative research requires the researcher to "determine whether the findings are accurate from the standpoint of the researcher, the participant, or the readers of an account" (pg. 199). The utilization of both the document analysis and interviews is one way in which I was able to triangulate - or validate - the 
practitioner data (Best \& Khan, 2006; Bowen, 2009; Creswell \& Creswell, 2018). Similarly, utilizing the student electronic interviews to guide the topics discussed in the in-person, paired interviews was an additional way in which I was able to validate the student data. Having a preliminary source of data provided by the participants, which in this instance were the documents (practitioners) or electronic interview answers (students), and then connecting with the constituency groups to further confirm and clarify initial findings through the interview (practitioners) and in-person, paired interviews (students) is an example of triangulation within this study to validate the findings.

Reliability in qualitative research is based on having a consistent approach across different researchers and research projects (Creswell \& Creswell, 2018). The concept of collecting insights from both practitioners and foster youth builds off of Dworksy and Pérez's (2010) exploratory study of campus support programs for foster youth. Additionally, the initial interview and paired interview questions for foster youth student participants was built off of the Career Ladders Project (2017) focus group protocol on student voice and engagement within Guided Pathways. While I was able to triangulate data to validate my findings and I was able to build upon previous research to ensure reliability, there were still limitations to this study. 


\section{Limitations of the Study}

In conducting this research, some limitations emerged. While all 115 of California's community colleges are engaged in the Vision for Success reform efforts, this study only included experiences from colleges in northern California. Though there was an attempt to garner insights from various college types - rural, suburban, urban, large, small - all of the participating campuses were from suburban locations with between 10,000 - 15,000 students enrolled annually. The way in which suburban campuses might approach equitable reforms could differ from those of urban or rural campuses based on demographic makeup of students, funding opportunities and challenges, and even the lens in which different campus cultures might view equity and identify disproportionately impacted students. Moreover, the culture of northern California when addressing issues of equity, may be quite different than the culture and approach of colleges in the far north, central valley, or southern California. Additionally, each campus has specific contacts regarding campus redesign efforts. Any information gathered from this one individual in the interview could be biased, could lack specific details, or not reflect an entire campus approach depending on how the redesign team is structured. While I did gather multiple sources of data that were co-constructed by several practitioners within each college setting, my in-depth discussions were only with 
one practitioner. This provides a limitation as the opportunity to gain insights is dependent on that one individual's knowledge and connection with the additional documents that were submitted to the NOVA system. If the practitioner was new to the work, the campus, or that particular position, they were unable to provide direct feedback on the intent of the college's actions. Additionally, each of the practitioners that I spoke with served as administrators. Campus administrators may have different perspectives regarding the implementation of initiatives than would a faculty or classified professional as they may have greater access to resources to determine what, in fact, is being implemented. There is also a different level of accountability for administrators than for staff and faculty members, or street level bureaucrats, who are actually "doing the work" of implementation. Finally, the Guided Pathways initiative is still in the early phases of implementation. Without any discernible outcomes to measure, this study can really only analyze the intent of the practitioners that are attempting to implement this large scale reform effort.

An additional limitation of this study is in regards to the foster youth access. In order to access and contact foster youth students at the participating campuses, all communications and requests for participation were managed by the campus foster youth liaison. While, many foster youth liaisons generally manage programs to support foster youth within their campuses, there are 
some foster youth liaisons who have other primary job responsibilities while also serving as a main point of contact for foster youth. The availability of the foster youth liaison to distribute the interview request was paramount to collecting valuable data. If any liaison was unable, or unwilling, to distribute the interview request, then I would have no way of accessing the students to include their voice within this study. Additionally, the foster youth that were contacted through this study are only the foster youth that were registered within their campus foster youth programs. There could have been foster youth that were not registered within their campus program for a variety of reasons lack of paperwork, no desire to self-disclose, unawareness of the existence of such program, etc. - and therefore their voices are not included in this study. Furthermore, while the focus is on examining the needs of foster youth in order to address and abolish issues of equity, foster youth experiences may differ greatly from Veteran students, formerly incarcerated students, students with disabilities, or any other student that is considered disproportionately impacted. Given the limitations of sampling, regional representation, and the focus on capturing the impact of change during implementation - a moment in time these findings should not be assumed to be generalizable to other student populations or institutional types.

\section{Summary}


This study utilized a qualitative cross-case study approach and social justice analysis to address the research questions. Validity was achieved through the use of triangulation where I collected multiple sources of data including document analysis, semi-structured interviews, and paired interviews. The individual interviews and paired interviews were recorded, transcribed, and uploaded to a qualitative analysis software to organize and highlight emerging themes. Findings from my data collection will be discussed in the following chapters, with each chapter addressing both research questions. Chapter 4 will discuss findings on Bode College; Chapter 5 will discuss findings on Little Streams College, and Chapter 6 will discuss findings on findings from Foggyville College. Within these chapters I will highlight findings of both community college practitioners and foster youth scholars in order to answer both research questions. Chapter 7 will present the cross case study findings to understand how multiple colleges are addressing equity in the implementation of the Vision for Success AND what can be learned from the experiences of foster youth to support equitable reform efforts. Chapter 8 will identify recommendations of how to utilize this information within leadership, advocacy, and practice as a way to address equity within community college reform.

\section{Case Study Roadmap}


Yin and Campbell suggest that within case study research, real-world phenomena ought to be studied within its real-world context (2018). For this study, I identify the case as being at the institutional level. Therefore, research questions one and two will be addressed separately for each institution, utilizing the data gleaned from each institution's participants. With this in mind findings from my data collection will be discussed in the following chapters:

Chapter 4: Case Study - Bode College

Practitioner Analysis

Case Analysis/Summary

Chapter 5: Case Study - Little Streams College

Practitioner Analysis

Foster Youth Scholars Analysis

Case Analysis/Summary

Chapter 6: Case Study - Foggyville College

Practitioner Analysis

Foster Youth Scholars Analysis

Case Analysis/Summary

Chapter 7: Cross-Case Analysis 


\section{Chapter 4: Case Study - Bode College}

Bode College $(\mathrm{BC})$ is located in a small town on the Northern California coastline. Founded in 1969, Bode College is a college in a single college district. BC has a main campus and an off-site center that offers both general education courses and non-credit courses. The off-site center provides financial aid resources, a bookstore, computer lab, learning support, and counseling. BC has a vision to "improve the world, one student at a time." Additionally, their value statements include: collaboration, equity, esteem, learning, and student focused.

According to DataMart, BC enrolls approximately 17,000 students annually. In the $2018-2019$ academic school year, $54 \%$ of students were under the age of 25 . Females comprised $51 \%$ of the student population. The ethnic distribution of students at BC were $44.4 \%$ White, $42.7 \%$ Hispanic, 5\% MultiEthnic, and 2.9\% Asian. In the fall 2019, the term for which we have the most recent data, 53 students were identified as foster youth at BC in DataMart.

\section{BC Guided Pathways Involvement}

Bode College was a member of the California Guided Pathways Project. The California Guided Pathways Project was a consortium of 20 community colleges that received professional development around the intentional implementation of Guided Pathways (GP) on their campus. This collection of 
institutions are often referred to as the Guided Pathways 20. Between the fall 2017 through fall 2019 the Guided Pathways Project hosted six institutes for participating colleges to send teams of professionals to receive guidance on how to approach GP implementation. Some of the training topics at the six institutes included: making the case for Guided Pathways, processes for program mapping, connecting to career and transfer pathways, student intake and onboarding, and affective domain. Colleges paid $\$ 15,000$ annually to participate in the California Guided Pathways Project.

\section{BC Guided Pathways Practitioner Participants}

For this study, both direct and indirect participants were included. The direct participant consisted of the Dean for Guided Pathways, Joy, with whom I conducted an interview. Joy identified as female and White. She has served in the dean position for two years; prior to this administrative appointment Joy served in a different administrative role within the institution.

The indirect participants contributed to the development and publication of the key documents analyzed in this study. The documents analyzed include the Guided Pathways Scale of Adoption, Local Vision Goals Summary, and Student Equity and Achievement Plan (Table 5. Bode College List of Documents Analyzed). These indirect participants consisted of the College President, President of Academic Senate, Dean of Institutional Research, Instructional 


\section{Faculty, Board of Trustees President, Vice President of Student Services,}

Director of Equity, and Vice President of Instruction. The documents analyzed

in this study provided preliminary information that guided the questions asked in the interview with Joy.

Table 5. Bode College List of Documents Analyzed

\begin{tabular}{|c|c|c|}
\hline $\begin{array}{l}\text { Document } \\
\text { Title }\end{array}$ & Contributing Authors & Purpose within this study \\
\hline $\begin{array}{l}\text { Guided } \\
\text { Pathways } \\
\text { Scale of } \\
\text { Adoption (18- } \\
\text { 19) }\end{array}$ & $\begin{aligned} & \text { Bode College (BC) } \\
& \text { - } \text { College President } \\
& \text { - } \text { President, Academic Senate } \\
& \text { - } \text { Faculty Lead } \\
& \text { - } \text { Dean, Guided Pathways }\end{aligned}$ & $\begin{array}{l}\text { This document was utilized to gain } \\
\text { an understanding of what inquiry } \\
\text { has already taken place as well as } \\
\text { what recommendations have been } \\
\text { proposed. }\end{array}$ \\
\hline $\begin{array}{l}\text { Local Vision } \\
\text { Goals } \\
\text { Summary }\end{array}$ & $\begin{array}{c}\text { Contributing authors share the same } \\
\text { positions across all three campuses } \\
\text { - } \quad \text { Dean, Institutional Research } \\
\text { - } \quad \text { President, Academic Senate } \\
\text { - } \quad \text { College President } \\
\text { - } \\
\text { Board of Trustees President }\end{array}$ & $\begin{array}{l}\text { This document was utilized to } \\
\text { better understand the mission and } \\
\text { vision of each institution. } \\
\text { Additionally, it includes information } \\
\text { about disproportionately impacted } \\
\text { students and the institution goals } \\
\text { to improve outcomes for these } \\
\text { groups. }\end{array}$ \\
\hline $\begin{array}{l}\text { Student Equity } \\
\& \\
\text { Achievement } \\
\text { Program Plan }\end{array}$ & $\begin{aligned} \text { BC } & \\
\text { - } & \text { Vice President, Student } \\
& \text { Services } \\
\text { - } & \text { Director, Student Equity } \\
\text { - } & \text { Vice President, Instruction } \\
\text { - } & \text { College President }\end{aligned}$ & $\begin{array}{l}\text { This document was utilized to gain } \\
\text { clarity on which student groups } \\
\text { were identified as } \\
\text { disproportionately impacted. This } \\
\text { document also provided insights } \\
\text { to proposed interventions to } \\
\text { support the success of } \\
\text { disproportionately impacted } \\
\text { students. }\end{array}$ \\
\hline
\end{tabular}

\section{BC Practitioner Themes}

The first research question explores the intentional ways in which community college practitioners are addressing equity in the implementation of the Vision for Success, through the Guided Pathways framework. The three 
main themes that fall under this research question are 1) understanding equity, 2) equitable implementation of guided pathways, and 3) the inclusion of student voice in inquiry.

Understanding Equity. The Guided Pathways work at Bode College has a deep rooted focus in equity. In fact, Guided Pathways is explicitly mentioned in the Student Equity Plan (SEP). The SEP executive summary reads,

[Bode College] agreed to focus on activities that can make the greatest change, for the greatest number of students, with the greatest equity needs.

We understand we have the institutional responsibility to identify and remove barriers to student success in order to improve outcomes for historically underserved students. Under the umbrella of Guided Pathways, we are working to improve outcomes on a substantial scale through fundamental rethinking of our organization, its culture and its impact on the student experience.

The direct mention of the need to serve students with the greatest equity needs through the Guided Pathways framework provides a clear purpose for which the members of the institution can refer back to. In addition to having a grounding framework that reflects equity in purpose, it is important to interrogate the current experiences of students within the institution. 
According to the Guided Pathways Scale of Adoption, Bode College worked with Community College Equity Assessment Lab (CCEAL), a research laboratory based at San Diego State University that works with community colleges in assessing the experiences of, and identifying interventions to support, students of color. CCEAL conducted several student focus groups at $\mathrm{BC}$ in order to have a better understanding of the student experience. When reflecting on the purpose of the focus groups at BC, Joy shared that We wanted a baseline because we didn't really have much on what was going on on campus. And we've been, we've been fairly intentional about infusing equity into our Guided Pathways discussions, but this was kind of a good overall report to get to the whole campus because it talked about specific groups of students and how they felt in different areas of the college Guided Pathways, or not.

Sixty-nine students participated in the CCEAL focus groups. According to Joy, there were 36 women, 20 men, 5 gender non-conforming participants; 31 were Latinx, 9 were Multi-Ethnic, and 8 were African-American. Joy also mentioned that there were student participants that were foster youth and some were students with disabilities. There was an intention to include students that are named on the BC Disproportionate Impact list in the SEP, and hear, specifically from them to learn about the gaps in student experiences. The focus groups provided the opportunity for a diverse group of students to serve as a source of 
information for which the institution can act upon - as mentioned in Lodge (2005). BC was able to glean really important insights from the focus groups.

Some of the overarching things that came out of it. Were people just feeling like it was a kind of a transactional environment around here and various like it especially in counseling. And in the Welcome Center. There was a little bit of stuff about faculty not making people feel seen or heard. And then about people, how people externally and their family life or home life and how that affected how they come to school.

Hearing about the ways in which students were not feeling seen or heard, that the institution did not care about them or value them but was more focused on being transactional, creates the capacity for empathy within the institution. This empathy can then evolve into a commitment to justice.

As mentioned before, the Bode College SEP begins with a clear statement identifying the need to reinvision the institutional structure and culture to support students with the greatest need. The SEP specifies what BC means when they state "students with the greatest need."

$[B C]$ recommends implementing activities that support student populations that demonstrate consistent disproportionate impact in the last five years, have the highest disproportionate impact according to local metrics, and have a significant sample size according to local enrollment counts. 
Identifying specific student populations within a specific time-frame provides clarity to both internal and external stakeholders on how and who BC has decided to focus efforts on improving outcomes for. The commitment to justice does not extend only to improving outcomes of diverse student populations. It also is reflected in BC's commitment to valuing the time commitment that faculty and staff are spending to implement GP at BC. However, the requirement that the activities must support disproportionately impacted groups that have a significant sample size could have adverse effects for smaller, yet still vulnerable groups, such as foster youth. Without being intentional about supporting disproportionately impacted students of all sizes, there could be the chance that even with the Guided Pathways implementation some students will still be left behind.

Equitable Implementation of Guided Pathways. The GP efforts at BC are led by Joy, the Dean for Guided Pathways who also serves in a dual administrative role overseeing a student services division. In addition to the Dean for Guided Pathways, GP efforts are also being advanced through the support of faculty, staff, and administrators who make up the Pathways Implementation Team, also referred to as the PIT Crew. The PIT Crew provides guidance to work groups who are investigating ways in which to 
implement efforts surrounding Student Onboarding, Guided Pathways Support Teams, and Website Redesign. BC has a website that hosts robust information, including meeting minutes, regarding the GP implementation process.

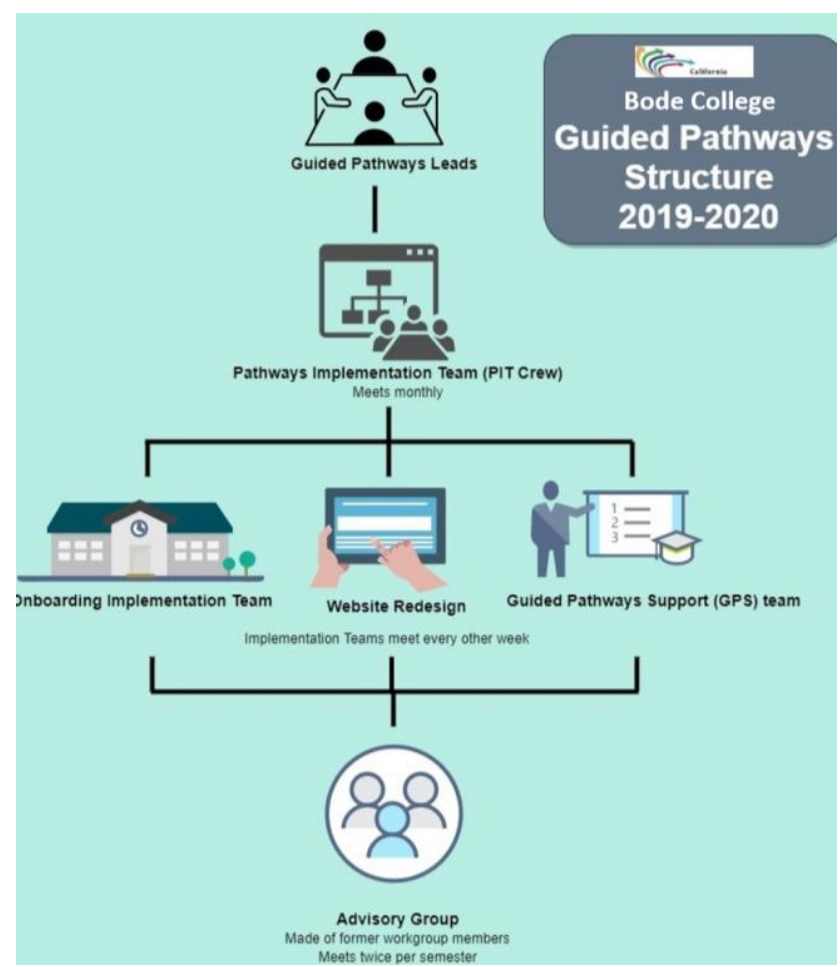

Figure 10. Bode College Guided Pathways Organizational Structure

The GP team at BC is primarily comprised of faculty and classified professionals. Community college faculty have the primary responsibility of teaching and supporting students, and their colleagues, in the classroom. Classified professionals have primarily responsibilities within a variety of student services capacities including financial aid, student leadership, or 
instructional support such as libraries and tutoring centers, administrative support, etc. It can be taxing and overwhelming to take on additional responsibilities within an institution, especially responsibilities that involve a complete overhaul of the way in which the institution has traditionally functioned. In order to both encourage the participation of different constituencies, $\mathrm{BC}$ compensates all campus community members who are on the GP implementation team.

The implementation team - our goal is to get stuff done...we've kind of framed it as we're past the point of talking about stuff and let's get going. So, we pay our faculty as a unit overload and we pay our classified professionals overtime. We do, yeah, two hours every two weeks, approximately, and then the oversight body meets once a month.

By compensating both faculty and classified professionals to take on the additional responsibility to approach the GP implementation contributes to a sense of agency and empowerment for the employees of the institution. This agency and empowerment can then be reflected in the way in which the employees can support students in their agency and empowerment, as well.

When asked about buy-in for Guided Pathways, Joy shared that the college hosted several all college days in an effort to getting people from 
all across camp together to kind of conceptualize guided pathways. We've had professional development sessions throughout this whole process, several times a year, or semester, we have all college days that are dedicated to Guided Pathways. We try to weave it into everything we do.

The all college days provided an opportunity to both develop a shared understanding of the purpose behind the GP reform efforts and create buy-in from the larger campus community. The result of these all college days the administration put out a call for proposals to the campus to gather ideas of what changes, or interventions, to proceed with. It was through the campus proposals that essentially led to the three workgroups that BC is currently operating: 1) Onboarding Implementation Team, 2) Website Redesign Team, and 3) Guided Pathways Support Teams. Additionally, the GP efforts have been greatly supported by the Academic Senate. Indeed, Joy stated that, "our Senate is very supportive of Guided Pathways so they're always bringing us to the forefront." Having support from campus entities such as the Academic Senate provides additional opportunities to share the importance of GP and the need to address issues of equity on campus. Additionally, the SEP stated that [Bode] College operates under the concept of shared governance. Thus, efforts to foster and institutionalize student equity must be supported by administrators, faculty, and staff in order to: (1) improve completion rates, (2) improve retention rates, (3) enhance professional development 
to develop a campus-wide equity lens, (4) implement annual data-based inquiry, (5) improve student engagement with a focus on student development.

The statement above displays dedication that $B C$ has in addressing equity from all areas of campus. Critical consciousness drives the intention to implement annual data-based inquiry provides the opportunity for the campus to engage in continuous reflection to ensure that the equitable practices of today are still effective in the future - or identify the need to update practices due to the shift in time.

The previously mentioned focus groups conducted by CCEAL provided qualitative data upon which the campus could connect the quantitative data that identified the disproportionately impacted groups at BC. So, how does a campus take this large subset of data and develop interventions to better support students? According to Joy, it is done through trial and error, with a realization that it may not be perfect, but something must be done because what we are currently doing is not working.

because we can't get to the exact level of things that they [faculty and staff] want so we're trying to think of this as an iterative process so we're like okay we're going to revamp orientation. And we're going to do it this way, and people are like oh this isn't going to work, we should really do more research. It's like okay we have to do something at some point. So, so there is a little bit of a culture of it's it's not totally perfect you shouldn't 
roll it out. But then there's the other camp, it's like okay just try it and we learn that way.

Not everyone at BC is completely comfortable with this idea and would rather wait until all aspects of a particular plan is fully thought out before implementation, but Joy believes in the sense of urgency and upholding the notion of controversy with courage. The reality is that if the campus were to wait until each plan were perfect, there is a possibility that nothing would happen - which is not the purpose of the reform efforts in the first place.

One way in which the Onboarding Implementation Team is addressing equity in by reviewing the way in which they communicate with students. Joy shared that BC has a large population of non-native English speakers in their community. However, all of the messages that a student receives after they have applied to the campus are in English. With this realization, BC has begun to translate these onboarding messages into different languages, starting with Spanish, to better serve the community and welcome non-native English speakers to the campus. Additionally, there was a recognition that students may need different information during the orientation based on different attributes connected to their identity or lived experiences. For example, students that are veterans may need to be aware of the veteran services and requirements to access their veterans educational benefits. This information 
may not be necessary for all students coming into the college, but it is necessary for students that identify as veterans for them to get the support they need. With this in mind, the orientation, which is available only online, was updated to incorporate different modules that appear based on a specific attribute that the student may have identified in their college application. The concept of providing students with relevant orientation materials is in alignment with the Guided Pathways framework in that it is intended to not overwhelm the student with too much information, such as the cafeteria style approach to selecting classes, but instead provide relevant information to students about the services on campus available to support them and meet them where they are.

Inclusion of Student Voice in Inquiry. Similar to the way in which BC has employed faculty and classified professionals to engage in GP implementation, Joy has also hired eight student assistants to support the GP work on campus. The student assistants serve on the work teams, they assist with administrative functions of the GP office, and they lead student inquiry on campus. Hiring student assistants was also listed in the Guided Pathways Sale of Adoption as a part of the implementation plan.

Joy shared that there are often times when the GP work teams have a question about a students' experience with an aspect of campus, or are curious as to a student's understanding of a proposed concept or idea. While the 
student assistants on the work team might be able to provide some insights, the team understands the importance of having a variety of diverse student feedback in order to have more depth in their understanding of the student experience. As such, the student assistants take the question from the work team and canvas the campus in order to get a breadth of responses. Joy explained the process of utilizing student assistants to garner student feedback.

So what we have created as a student feedback request for them, that the team is if they're in a meeting or for doing Guided Pathways work and you're like, students would probably not understand that, or I wonder what students think about this, you can just zap it into a Google form and then we kind of divvy it up to the students. So they'll come in and get a folder, okay and then survey 20 people about this today. I'm going to go in the library and talk to 8 people about this. I'm going to show 30 people this flyer and get a vibe. And then we compile the data, and we use it, we take it back to whomever requested it and we kind of use it you know with caution.

This approach allows students to lead the student inquiry and provide timely feedback to the work teams prior to implementation. Lodge (2005) would consider this approach as both gathering information from students as a data source, as well as incorporating students in the actual decision making process for GP implementation. Such inclusion also highlights BC's value of collective action by incorporating multiple voices in the decision making process. 
While including students in the inquiry process is important to developing equity based, student-ready reform efforts, it is also essential to ensure that the student assistants, like the faculty and classified professionals, had a baseline understanding of equity as well. To do this, Joy stated that when thinking about the role that student assistants would play in the inquiry and data collection and reporting process, it was important to provide the proper training.

We talked, we had our equity, a Director of Student Equity coming in to just do equity basics. We had a communications professor come in and talk about a variety of different communications issues and strategies when you're approaching people to ask them questions. How to look, look for unconscious bias and we talked about making sure that you get a good cross section of students without, you know, as best as you can, and how to stay safe, etc. And so that's kind of how we launched it and they all kind of dove in.

Not only did BC compensate student assistants for their involvement in GP, they also provided them with the tools needed to be effective and intentional in the work that they do. Through financial support, providing proper training for student assistants, and entrusting them to take the lead in outreaching to their peers, BC supported the agency and empowerment of students on their campus. While BC's efforts to include students in the inquiry and decision making process are admirable, it is important to note one way in which the value of students was overlooked. In reviewing the Guided Pathways 
organizational chart (Figure 10.), student assistants were not included. It would be helpful for BC to display both externally and internally the value of student voice within their Guided Pathways implementation process by including students on the graphic that depicts the organization of the GP structure on campus.

\section{Bode College Practitioner Summary}

The first research question for this study was to identify the intentional ways in which community college practitioners are addressing equity in the implementation of Guided Pathways. Bode College's Student Equity Plan (SEP) provides guidance regarding the way in which BC should approach its equity work: to make the greatest change, for the greatest number of students, with the greatest equity needs. This directive makes clear the intention for $\mathrm{BC}$ to focus on allocating resources, time, and energy towards innovations that help close the equity gap. Through updating and translating the website and written materials to better accommodate non-native English speakers, to revising orientation so that unique student groups will be provided information most relevant to them, are two concrete ways in which the college is attempting to address equity through their GP implementation. Additionally, including students in the inquiry process by hiring student ambassadors has been instrumental in BC's approach to including student voice in the GP 
implementation efforts - even if they aren't included on the GP organizational chart. The intention taken to provide training for the student ambassadors on topics such as unconscious bias, communication skills, and proper interviewing technique further highlight the way in which $\mathrm{BC}$ is addressing equity in the GP inquiry process.

\section{Bode College Foster Youth Scholars}

While I did attempt to collect foster youth scholars insights from Bode College, I, unfortunately was unable to collect any. I reached out to the foster youth liaison at Bode College several times throughout the course of my data collection period. Similar to my approach at Little Streams and Foggyville Colleges, I asked that they share the link to the electronic interview with students that identified as foster youth within the BC campus. However when monitoring the results from the electronic interview, there were unfortunately no responses from foster youth scholars at Bode College. Therefore, the case analysis for Bode College will be based solely on the information provided by the practitioners.

\section{The Bode College Case Summary}

The second research question for this study was to identify the ways in which the educational experiences of former foster youth can inform the equitable implementation of Guided Pathways. Unfortunately, because I was 
not able to glean insights from the foster youth population at BC I won't be able to address this question within the case summary. However, I would recommend that through their continued student inquiry process, BC conduct intentional outreach to foster youth, and other small yet vulnerable populations, to learn more about the barriers and challenges they face. Especially if the campus is prioritizing reform efforts to focus only on vulnerable populations that also have significant enrollment. When looking at the statewide Student Success Metric Dashboard, there is no visible data on the completion rates of foster youth as annually there are less than 10 students that earn a degree or transfer. Therefore, if the campus is prioritizing innovations to better support students that are both vulnerable and make up a significant population on campus, foster youth will always be overlooked. 


\section{Chapter 5: Case Study - Little Streams College}

Little Streams College (LSC) is located in the suburbs of a major city in Northern California. Founded in 1970, LSC is one of many colleges in a fourcollege district. LSC has both a main campus and a satellite center that offers general education classes and access to student services such as a library, financial aid office, and computer labs. LSC's vision is "To be an exemplary and innovative community college that empowers students and employees to strengthen the cultural, social, economic, and environmental well-being of their communities" (https://crc.losrios.edu/about-us/our-values).

According to DataMart, the statewide database that hosts the California Community Colleges' enrollment data, LSC enrolls approximately 15,000 students annually (datamart citation). In the 2018-2019 academic school year, the majority of students, 64 percent, were considered traditional aged students, or under the age of 25 , and 56.0 percent identified as female. The ethnic distribution of students at LSC were $26.9 \%$ Hispanic, $24.6 \%$ Asian, $23.1 \%$ White non-Hispanic, 7.0\% Multi-Ethnic, and 4.8\% Filipino. In the fall 2019, the term for which we have the most recent data, 81 students were identified as foster youth at LSC in DataMart (datamart citation). 


\section{LSC Guided Pathways Involvement}

Little Streams College was a member of the California Guided Pathways Project. The California Guided Pathways Project was a consortium of 20 community colleges that received professional development around the intentional implementation of Guided Pathways (GP) on their campus. This collection of institutions are often referred to as the Guided Pathways 20. Between the fall 2017 through fall 2019 the Guided Pathways Project hosted six institutes for participating colleges to send teams of professionals to receive guidance on how to approach GP implementation. Some of the training topics at the six institutes included: making the case for Guided Pathways, processes for program mapping, connecting to career and transfer pathways, student intake and onboarding, and affective domain. Colleges paid $\$ 15,000$ annually to participate in the California Guided Pathways Project.

\section{LSC Guided Pathways Practitioner Participants}

For this study, both direct and indirect participants were included. The direct participant consists of the Dean of Guided Pathways, David, with whom I conducted an interview. David identified as male and Multi-Racial. He has served in the dean position for six years; prior to this administrative appointment David served as instructional faculty. 
The indirect participants contributed to the development and publication of the key documents analyzed in this study. The documents analyzed include the Guided Pathways Scale of Adoption, Local Vision Goals Summary, and Student Equity and Achievement Plan (Table 6. Little Streams College List of Documents Analyzed). These indirect participants consist of the College President, President of Academic Senate, Dean of Institutional Research, Board of Trustees President, Associate Vice President of Equity, Vice President of Student Services, and Vice President of Instruction. The documents analyzed in this study provided preliminary information that guided the questions asked in the interview with David.

Table 6. Little Streams College List of Documents Analyzed

\begin{tabular}{|c|c|c|}
\hline $\begin{array}{l}\text { Document } \\
\text { Title }\end{array}$ & Contributing Authors & Purpose within this study \\
\hline $\begin{array}{l}\text { Guided } \\
\text { Pathways } \\
\text { Scale of } \\
\text { Adoption (18- } \\
\text { 19) }\end{array}$ & $\begin{array}{cl}\text { Little } & \text { Streams College (LSC) } \\
\text { - } & \text { College President } \\
\text { - } & \text { President, Academic Senate } \\
\text { - } & \text { Dean, Guided Pathways }\end{array}$ & $\begin{array}{l}\text { This document was utilized to } \\
\text { gain an understanding of what } \\
\text { inquiry has already taken place } \\
\text { as well as what } \\
\text { recommendations have been } \\
\text { proposed. }\end{array}$ \\
\hline $\begin{array}{l}\text { Local Vision } \\
\text { Goals } \\
\text { Summary }\end{array}$ & $\begin{array}{cl}\text { LSC } & \\
\text { - } & \text { Dean, Institutional Research } \\
\text { - } & \text { President, Academic Senate } \\
\text { - } & \text { College President } \\
\text { - } & \text { Board of Trustees President }\end{array}$ & $\begin{array}{l}\text { This document was utilized to } \\
\text { better understand the mission } \\
\text { and vision of each institution. } \\
\text { Additionally, it includes } \\
\text { information about } \\
\text { disproportionately impacted } \\
\text { students and the institution } \\
\text { goals to improve outcomes for } \\
\text { these groups. }\end{array}$ \\
\hline $\begin{array}{l}\text { Student } \\
\text { Equity \& }\end{array}$ & $\begin{array}{l}\text { LSC } \\
\text { - Associate VP Equity, Institutional }\end{array}$ & $\begin{array}{l}\text { This document was utilized to } \\
\text { gain clarity on which student }\end{array}$ \\
\hline
\end{tabular}




\begin{tabular}{|c|c|c|}
\hline $\begin{array}{l}\text { Achievement } \\
\text { Program Plan }\end{array}$ & $\begin{array}{ll} & \text { Effectiveness } \\
\text { - } & \text { Vice President, Student Services } \\
\text { - } & \text { Dean, Institutional Effectiveness } \\
\text { - } & \text { Vice President, Instruction } \\
\text { - } & \text { College President }\end{array}$ & $\begin{array}{l}\text { groups were identified as } \\
\text { disproportionately impacted. } \\
\text { This document also provided } \\
\text { insights to proposed } \\
\text { interventions to support the } \\
\text { success of disproportionately } \\
\text { impacted students. }\end{array}$ \\
\hline
\end{tabular}

\section{LSC Practitioner Themes}

The first research question explores the intentional ways in which community college practitioners are addressing equity in the implementation of the Vision for Success, through the Guided Pathways framework. The three main themes that fall under this research question are 1) understanding equity, 2) equitable implementation of guided pathways, and 3) the inclusion of student voice in inquiry.

Understanding Equity. In order to begin the process of instituting change, there must be an effort to develop a common understanding as to the purpose of change (Fullan, 2004). The Vision for Success was rooted in addressing the inequitable outcomes of students in the California Community Colleges. During my conversation with David, the Dean of Guided Pathways, he referred to the Organizational Change Paradigm as a tool for which the campus can reference to guide the work being done to implement Guided Pathways. The first point of their paradigm is "Inequity Informed Equity Work" (see Figure. ? LSC Organizational Change Paradigm). "Inequity informed 
equity work" is a recognition of the current inequities that persist at LSC and naming the GP efforts as equity work to address the inequities.

Figure 11. LSC Guided Pathways Organizational Change Paradigm

\section{The LSC Organizational Change Paradigm}

- Inequity informed Equity work

- Fix the College not the Student

- Kill the Pilot

- We have or can creatively create the bandwidth to handle radical change

- Iteration! It doesn't have to be perfect. It just has to be better. Failing Forward.

- Embrace Ambiguity \& Discomfort

- Interrogate ALL Practices \& Policies

- Willingness to be first

- Ongoing case making

- Sustained sense of urgency

- A strong belief that the needle can move

- Operate out of Courage and not the fear of.......

The Organizational Change Paradigm includes several guiding principles for the campus to refer back to when instituting change. Having a guiding set of principles with statements such as "kill the pilot," "failing forward," and "embrace ambiguity \& discomfort" actually challenges the notion that all ideas have to be perfect before they can be implemented. Instead, it encourages the opposite. It makes an attempt to be courageous by just "trying," and trying with equity and the students in mind. 
Additionally, during my interview with David he referred to the leadership of the college president in the development of the Organizational Change Paradigm. He stated that, Our president guides everything in the notion that we're looking at a system that was not designed for our $79 \%$ of students of color that come, right? So [the system is] just made for somebody else who don't look like us. And that's the reality of it.

Through the Organizational Change Paradigm, LSC recognizes the inequities that are, and have been, prevalent in the higher education system. David's statement also recognizes the historical and systemic practices that have prevented students from being successful in higher education, which connects with LSC's critical consciousness.

It's even more important for folks that have been locked out of education for a long time, historically, right? Or, I mean, community colleges have always been designed to be accessible. That was the whole point of community colleges and the master plan. But in reality, why then do we have disproportionate impact on, on just getting in. Right? Not to mention getting out because we haven't produced the structures that made 'accessible' mean 'successful'. So our focus on Guided Pathways has always been equity. With everything we do, questions that I, I, challenge, all the folks that Guided Pathways, that are part of what we call our Guided Pathways implementation team. 
During our interview, David also mentioned that during their inquiry process LSC colleagues asked themselves, "how do we as a college know who our students are, how do we...take care of them through the end?" He pointed specifically to the need to ask students "what can we do to help you." These questions have provided the LSC community the opportunity to reflect on both the expectations and assumptions that institutions have when working with students in order to implement change. He said,

When [the students] come to campus and they're looking and they're lost...We've been bringing them into the Access Center, so that they can meet with someone, there's a computer there they can, they can actually do it [apply to the college] with somebody there to actually guide them through.

Providing a resource to meet the students where they are, such as having accessible computers for students to complete the enrollment steps, is a way in which LSC is being intentional about implementing efforts to dismantle structural inequities to empower marginalized populations. This empathy was also present in establishing LSC's commitment to justice. Commitment to justice motivates leaders to prioritize the well-being and advancement of minoritized communities.

Mentioned as an activity in the Guided Pathways Scale of Adoption, LSC's Student Government held forums specifically for the student body to 
express their concerns, experiences, and recommendations for the campus, David noted that

a lot of the students that took part were those that, that anecdotally didn't really quite know what college was all about. A lot of them were first generation. A lot of them had already had experiences that weren't always as positive. Somewhere along the line, whether it was like, you know, so many forms or so many times, "why do I have to keep coming back to campus just to enroll?" I mean that was the crazy thing because, you know, why would they do that, right? You know, it's just very eye opening.

Having the Student Government lead Guided Pathways forums cultivated a sense of agency for the students, while also humanizing the student experiences for the practitioners that are responsible for developing new systems and structures to support student success. Therefore, being grounded in equity, critically conscious, empathetic to the student experience, and committed to justice all contribute to the campus' understanding of equity. Once there is a clear understanding of equity, the campus can then approach an intentionally, equitable implementation of Guided Pathways.

Equitable Implementation of Guided Pathways. Beyond having a clear understanding of equity, I also wanted to inquire about the ways in which practitioners were being intentional about connecting their understanding of equity to practice. Connecting back to Rhiana Gunn-Wright's statements in 
Chapter 2 that there are often disconnects between the policy makers attempting to solve a problem and the people on the ground experiencing the problem for which the policy was intended to serve (2019), I was curious about how the college practitioners, who received a statewide directive to close equity gaps, were actually intending to do so with their specific campus community in mind.

The SALT model identifies the need to address controversy with courage when desiring to enact equitable change. Within LSC's Organizational Change Paradigm, the directive to "Operate out of courage and not the fear of..." is listed as the final list point to serve as a reminder that intentional change requires courage. A specific example of this notion operationalized is in the way in which LSC approached revising their orientation. In accordance with the Student Success Act of 2012, colleges are required to include orientation as a part of the matriculation, onboarding process, for all new students. Title $\vee$ of the CA Education Code requires community college orientations to include specific information regarding policies, fee information, descriptions of programs and services, and important timelines, at minimum. Colleges have the ability to provide the orientations in various modalities, as decided by the campus or District. Through the GP inquiry process LSC reviewed their current orientation offering and, as David shared, identified potential gaps. 
The orientation for example. The question then is, how does that close that equity gap? Do we know how it is intended to do that? And then the evaluation in the end will be, did it closed the equity gap, right? And if it didn't, then Is there something there that needs to be, needs to be more thought out? Do we need to start again? Do we do we understand what it is that that needs to happen in order to close the equity gap? Because maybe it's not just an orientation, maybe it's in the information that we wanted to deliver. Maybe it's a variety of reasons that we, we will then suss out as we implement anything. So I continue to push as the Guided Pathways Dean on the notion that everything we do, must be equity focused and that that isn't just like that's my push because I'm the Dean. But that's a push that comes from our president. It comes from our Board of Trustees. It's part of our strategic plan that that equity matters. And, in, back when our strategic plan was written, Guided Pathways wasn't even a thing, right? Think about, right, fine, but we already called out the notion that students need to be on pathways to completion. So, guided pathways is apropos and it worked for us. We didn't take it lightly. We took it very seriously, we also knew that it's focus was equity.

Again, building off of the Organizational Change Paradigm, LSC made a commitment to "interrogate all practices and policies." The honesty in interrogating the purpose of orientation, and specifically questioning the way in which it can attribute to closing equity gaps, is an example of addressing controversy with courage. Being able to have the courage to interrogate internal practices also offers the possibility to identify ways in which to reconstruct the 
broken system that created inequities in order to benefit all students. This opportunity to create coalescence is still deeply rooted in understanding the systemic injustices that have plagued minoritized students while still connected to the overall goal of improving student success.

Another example of the way in which LSC displayed coalescence, was in how they defined their approach to GP implementation from the beginning. David shared that,

When we started as part of CA Guided Pathways Project, we defined the work from that point on, and I think we're known in, in, in these colleges as, and this is our equity work, Because the only reason we're doing it is because we need to change the reality. We need to make sure that we have equitable outcomes, equitable practices, and equitable access as, as well as the concept that that people who, people being all that matters. So the students matter.

Additionally, David's statement that "the students matter" expresses empathy for the students for whom the reforms were created in the first place. Multiple different constituencies were engaged in the GP implementation process at LSC. In addition to the Dean of Guided Pathways, the GP work is led through a tri-chair model that aligns with each of the GP pillars: Clarifying the Path, Entering the Path, Staying on the Path, and Ensuring Learning. The tri-chair model consists of a faculty member, classified professional, and 
campus administrator such as a Dean. The various workgroups meet throughout the semester to advance implementation efforts.

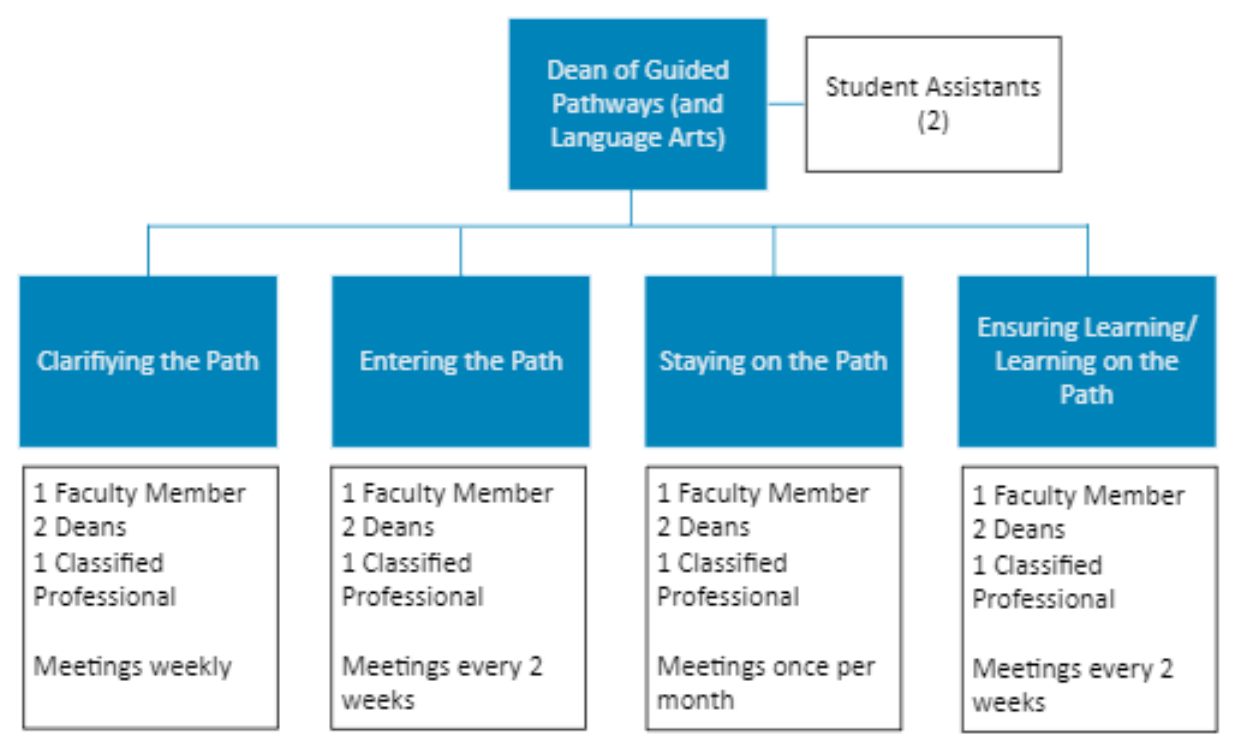

Figure 12. Little Streams Guided Pathways Organizational Structure

The tri-chairs work with their respective workgroup on identifying ways in which to implement interventions or update current practices within GP. They provide regular updates to the Dean of Guided Pathways who then works with LSC campus administration on providing the resources and support to move forward in the work. When asked about the administrative approval process, David shared that the process differs based on the constituency group most impacted by the proposed change. 
When things impact faculty, like the designing the program maps or what general education things are going to look like, or institutional institutional learning outcomes, all those impacts faculty impact curriculum. So community colleges Academic Senate have purview over what we call $10+1$, which get professional matters in curriculum. And so the final decisions that are made by academic senate through a vote of the Academic Senate. So, programs, a program mapping process was was taking before academic senate for your academic senate to discuss the long time. And then, and they decided to get voted on that this will be the process, and then the maps were made and those maps are finalized by the faculty teaching them.

David shared that for any decision that impacts curriculum, all changes must be proposed to the college Academic Senate. The Academic Senate is the campus governing body that represents faculty in the development of policy regarding all academic and professional matters. The " $10+1$ " rule that David mentioned is the actual list of 11 duties that faculty are responsible for overseeing within the California Community Colleges. There are 10 distinct responsibilities such as "establishing grading policies", "educational program development", and "processes for program review," while the 11 th responsibility is "other matters as agreed upon by the governing board and the academic senate" which is why it is commonly referred to as $10+1$.

While faculty are consulted about the aspects of Guided Pathways that most pertain to instruction, I was also curious as to how decisions are made for 
the aspects that pertain to student services, or the non-instructional portions of Guided Pathways. David's response to that question was much more simplistic. He stated that "in terms of processes that impact student services, the student services vice president was the final decision maker." David did not mention any efforts to take student services proposals to the Classified Senate for feedback, as is done with the Academic Senate, for approval prior to taking it directly to the campus administrator. While there may be a singular classified professional that serves as a tri-chair for each GP pillar, that one person may not be able to represent the variety of lenses through which the Classified Senate is comprised. This presents an unbalanced understanding of the value that different constituencies can bring to the GP discussions and implementation. In this instance, the value of collective action through participatory governance is not well represented. However, as it comes to the collective action of students in the GP implementation at LSC, David did share several instances in which student voice was front and center.

Inclusion of Student Voice in Inquiry. Student voice is an integral part of education reform efforts. As Mitra posits, "student outcomes will improve and school reform will be more successful if students actively participate in shaping it" (2004, p. 652). The Vision for Success, as a document, encourages the inclusion of students and student voice in campus reform efforts. On the Vision 
for Success website there are even toolkits to guide practitioners in meaningful practices around capturing student voice.

Little Streams College identified several instances in which student voice was utilized during the Guided Pathways implementation process. One aspect was the hiring of student assistants in the GP office. Starting in the Fall 2019, David hired two student assistants to provide support to both the workgroups and the general operations of the GP office. One student attends all of the GP workgroup meetings in order to provide some student insights to the various proposals from the lens of being a student and from having a general understanding of the connections between the various workgroups. The other student assistant helps to support a workgroup that is implementing Starfish, an early alert system that provides on-time, or just in time, support and interventions for students identified by campus employees as someone who could benefit from additional support. David made a point to ensure that the students were being compensated while serving in these roles as he recognized the economic needs of students.

Additionally, the student government initiated and led several student forums, as mentioned in the GP Scale of Adoption, to elicit feedback around the challenges and opportunities that students face at LSC. Working with the Dean of Guided Pathways, the student government forums included, 
Probably a couple hundred [students], it was like a two day event for about an hour and a half each day. And it was in a pretty, pretty nice place on the campus and you know where there was food offered to them as well they had they had always drew, and that was kind of nice because then there was another one where they had an open discussion and hundreds of students attended that one about an hour, hour 20 minutes, focused. And it. It turned out to be just a discussion of what students needed to have that we were trying to do. So when they weren't quite understanding, for example, like why am I taking general education in the first place? Because no one ever told me and it's all this time that that is required. So why is that important? That then led into more conversations about who to take, what to take, who to avoid all those kinds of things. It was crucial information for us that was all student led, and those are projects that were designed by the student ambassadors, but that they sort of took a life of their own. And it is when they, when they approached me. They were like so, would you support this? Of course! It is just, it was already well designed.

The GP team at LSC provided the students with an opportunity to lead the dialogue and conversation around GP for their fellow classmates. What began as an end of term project created by the student ambassadors evolved into much more. This level of involvement where students take the lead in the design, implementation, and reporting efforts is what Lodge (2005) would classify as dialogue within the realm of student voice. In this instance, LSC 
student's are seen as active contributors to the Guided Pathways work taking place on their campus.

\section{Little Streams College Practitioner Summary}

The first research question in this study was to identify the intentional ways in which community college practitioners are addressing equity in the implementation of the Vision for Success - through the Guided Pathways framework. The Organizational Change Paradigm at LSC provides a grounding framework to utilize in the approach to GP implementation. This framework guides LSC's recognition and understanding of historical practices that have contributed to inequity, investigate current college practices, and reflect on ways to best serve students by putting students first. Though the Organizational Change Paradigm is a beneficial framework, none of the interventions mentioned were particularly grounded in improving equity for any particular set of students. Instead, the recommendations within the LSC GP implementation focused on updating the orientation online and developing student support/success teams, which are aspects of the campus that all students will experience. Additionally, while LSC has included multiple constituency voices in the inquiry process to GP implementation, the same broad constituency approach has not been shared through the decision making process. With several governing bodies on campus, the only body that is 
included in the decision making is Academic Senate, leaving both the Classified Senate and Student Senate on the periphery of campuswide change efforts. One redeeming factor is the approach to hosting student lead forums to provide students space to share their experiences with campus leadership and serve as a reminder of why colleges are doing this work in the first place. This notion ties nicely into the second point of the Organizational Change Paradigm of "Fix the College, Not the Student." These changes that are being made are in an effort to do just that.

\section{Little Streams College Foster Youth Scholars}

As mentioned earlier in this chapter, Little Streams College (LSC) enrolls approximately 15,000 students annually. In the Fall 2019 term, there were 81 students that the college identified as foster youth students. While 81 students of 15,000 only represents $0.54 \%$ of the student population it is important that educators take a vested interest in the success of all students within their institutions, no matter how small their presence might be - all students' success matters. There may yet be additional students that are not formally recognized within the institution as foster youth that could qualify as foster youth, especially those in formal or informal kinship care (ie. living with relatives other than their parents), or were not able to take advantage of $A B 12$ wherein they remained in the foster youth system, or in their foster placement, after the age of 18. 
Additionally, the 81 students may only represent the students who were able to successfully navigate the financial aid process to be identified as foster youth within the campus coding process.

\section{Little Streams College Foster Youth Scholar Participants}

Six students from LSC, three female, one male, and four that declined to state, completed the electronic interview. The students that completed the interview completed between two and eight semesters in community college at the time in which they completed the interview. Two students identified as African-American, one student identified as Chinese, one student identified as Native American, one student identified as Filipino, and the rest of the student participants declined to state their racial or ethnic background. For this study, I utilized network sampling to send the link to an electronic interview to the foster youth liaison at LSC who coordinates the Guardian Scholars Program. The foster youth liaison then emailed out the link for students to complete.

The electronic interview asked participants open ended questions about their experiences in community college including accessing higher education, major and course selection, and identifying unique impacts for foster youth.

The interview ended with a short survey to collect demographic data. Upon the completion of the interview, participants received a $\$ 10$ electronic gift card to thank them for their time. The data from the electronic interview was analyzed 
to provide an understanding of the experiences of current and former foster youth in community college.

\section{Little Streams College Foster Youth Scholar Themes}

The second research question in this study explores the ways in which the educational experiences of former foster youth can inform the equitable implementation of community college reform efforts - specifically, the Guided Pathways initiative. I analyzed the data collected in the electronic survey to develop the scholar themes. The four main themes that fall under this research question are: 1) understanding scholar's motivation in pursuing higher education; 2) understanding what's working for foster youth scholars; 3) exploring the areas of opportunity; and 4) Hearing scholar recommendations. Please note as I analyze the four themes I will be using direct quotes from scholars that completed the electronic interview. In an effort to preserve the scholar's voices I will not be editing their quotes. The only changes that I may make to their quotes will be to preserve the anonymity of the scholar and the institution in which they are currently enrolled. I have also decided to place each scholar's quotes in a blocked quote, regardless of the word count, in an effort to up lift the voices of the scholars and limit the chance of losing their voice in my prose. 


\section{Understanding Scholars' Motivation in Pursuing Higher Education.}

The Casey Family Programs longitudinal study on youth in foster care reported that $70 \%$ of foster youth desire to attend college (2004). However, only between $10-20 \%$ of foster youth actually enroll in higher education (Berliner \& Lezin, 2010). Many of the scholars that eventually enroll in higher education, do so with the support of family members, social workers, teachers, or foster parents (Rios \& Rocco, 2014). In order to learn more about foster youth experiences in community college, I asked scholars at LSC why they decided to attend college and many of their answers reflected similar reasons. Foster youth enrolled at LSC due to the support and encouragement of family, social workers, teachers, or foster parents. One scholar stated:

I selected this college because my sister graduated from [LSC] and I never made a plan to go to a University so this seemed like the best choice.

Another scholar shared:

I was told by many friends and staff workers at my high school that this college had way more help than any other college in this area and $i$ found out that it was true.

LSC foster youth placed a significant amount of trust in the recommendations of their friends, families, and high school educators as four of the eight scholars 
included some mention of external influences towards enrolling into college. In addition to external influences, six scholars also highlighted the convenience of LSC as their local community college as being a major factor as to why they elected to attend that specific college. One scholar highlighted both the convenience of location and the programs offered as reasons why they selected LSC. When asked why they decided to attend LSC, they stated,

Because it was my local college and I love the programs they provided for me.

Beyond just convenience, the program offerings can also be attractive reasons to motivate foster youth to enroll in higher education.

Finally, four of the eight scholars that completed the electronic interview stated that their reason for attending college was to accomplish a goal. The goals desired to be accomplished were a mixture of personal goals, such as being the first person in their family to graduate from college, and professional goals, such as becoming a judge. One scholars mentioned the desire to pursue a professional goal that was connected to a lifelong passion attributed to an external motivator. 
To learn more about Key Framing and computers, things that could help me become a successful YouTuber just like the YouTubers i've been watching since i was in elementary school

Whether due to recommendations from family members or school officials, convenience, or to achieve personal or career goals, foster youth scholars at LSC were motivated to attend college by a variety of factors and influences.

Understanding What Is Working for Foster Youth Scholars. External factors such as peers, family, or school influences were motivating contributors to foster youth scholar's interest in pursuing higher education at LSC. External supports were also equally influential to scholar's continued enrollment and success at LSC. Much of the external support was attributed to the scholar's counselor. Five scholars specifically mentioned their counselor as being their resource for identifying which courses to take. However, one scholar also alluded to the challenge they faced when relying solely on the counselors to provide them with the exact information they needed. When asked how they decide which classes to take the scholar stated that

For me it was difficult because counselors are suppose to help but there were a lot of classes that I needed to take that they didn't tell me about.

When asked when they were expected to complete their educational program at LSC, that same scholar stated, 
We have a student education plan that maps out our classes for us but if you're anything like me I strayed from that plan a lot. Eventually you have less classes to take and you realize that you are nearing the end.

This could be one instance in which the guided pathways structure could have assisted both the scholar and the counselor to ensure that the scholar is aware of the required courses, in sequence, while still having the counselor to discuss electives and overall educational goals.

In addition to counseling support LSC has a Next Up/Guardian Scholars Program specifically developed to support foster youth scholars. However, upon asking scholars if they were aware of any specific programs on their campus to support foster youth, two specifically stated Next Up, one mentioned Extended Opportunities, Program, \& Services (EOPS) a different student support program, and one scholar explicitly stated that there were no such support programs for foster youth. One of the scholars that acknowledged the Next Up/Guardian Scholars as LSC's on campus support program for foster youth also highlighted the benefits of Next Up by sharing that

Besides Next Up Guardian Scholars, I don't know of any other programs, but we do get lots of support from them. We get meal tickets up to \$20 every week, school supplies, snacks and a $\$ 300$ book fund.

The benefit of Next Up/Guardian Scholars provides both the counseling support as well as financial support that scholars can utilize to meet their needs. EOPS also supports foster youth scholars as part of their mission within the CCC, so it 
is not a surprise that scholars attributed EOPS as a foster youth support program. When discussing their course and major selection process with their counselors, several scholars specifically mentioned meeting with their EOPS counselor. One scholar reflected on their college onboarding experience as being

scary and I didn't really have guidance. Once I found out about the programs i felt fully supported.

Through either Next Up/Guardian Scholars or EOPS, scholars have connected to a campus resource in which they feel safe, can belong, and strengthen their self-esteem around their ability to be successful in higher education.

Exploring the Areas of Opportunity. While the Next Up/Guardian Scholars Program is able to meet some of the scholars needs such as providing school supplies and meal vouchers, scholars expressed a greater need for campuses to meet their actual basic needs. When asked why foster youth may stop out of college, based either on their own personal experience or experiences of their peers, three scholars mentioned housing related reasons, two mentioned financial reasons, and two mentioned general life stresses often attributed to their foster youth status. One scholar shared

I think that life gets in the way. Maybe they don't have a good living situation and they need to find somewhere else but they have to work full 
time to make that happen. Or maybe they just feel that school isn't helping them.

Understanding that $44 \%$ of foster youth experience three or more home placements before they age out of foster care (Merdinger et. al, 2005) is incredibly important as housing instability can play a large factor in foster youth stop out in college. Another scholar attributed both housing and financial instability as a factor in why foster youth might stop out of college.

Living situations and finding a place to be stable, roommate problems, money problems mostly, and lack of motivation $\mathrm{n}$ the will to give up

Without the financial security needed to secure housing or pursue higher education it can be incredibly difficult for scholars to even access the institution. Even if they are able to access the institution through either self-motivation or support of a community member, their ability to persist in higher education is threatened by their need to ensure their basic needs - food, shelter, safety, etc - are being met. The Next Up/Guardian Scholars Program at LSC does provide meal vouchers to scholars to utilize in the campus cafeteria, but they do not currently provide student housing. While the California Assembly recently introduced AB 3207 - Community Colleges: Student Housing (Gibson) to establish student housing within the $\mathrm{CCC}$, there is no guarantee that the bill will 
be approved by the CA legislature nor does it guarantee that community college districts will move forward to provide such housing.

Recommendations from Foster Youth Scholars. The previous three themes were dedicated to better understanding the current experiences of foster youth scholars in community colleges. I also asked the scholar participants to provide recommendations for how colleges might be able to better support foster youth scholars. Their recommendations stemmed on being empathetic and providing structured support so that scholars could access the information they needed in a timely manner. One scholar stated I feel like just like in most other facets of life we kind of get over looked. We need a bigger space to come and hangout or get the things we need. We also need permanent staff because we don't need to have people keep coming in and out of our lives.

This scholar's sentiments of being "overlooked" and not necessarily having a place to go to is, unfortunately, very reflective of foster youth experiences throughout education. Even in research, there is very little published literature on the experiences of foster youth in community college. It is no wonder that institutions that thrive off of supporting evidence-based practices overlook foster youth because they do not appear in the "evidence" or the research. This lack of inclusion is what initially prompted me to focus my study on the experiences of foster youth in order to lift up their experiences in an effort to bring foster scholars to the forefront rather than being overlooked, yet again. 
Additionally, when asked what institutions can do to better support foster youth, another scholar suggested

Actually sit and talk to them show them that they [the colleges] are working with them and not gonna let them go threw the struggle by themselves

Even without having a dedicated space on campus for foster youth specifically, the suggestion to just sit down and talk to the scholars to build rapport and increase trust is also incredibly beneficial to supporting foster youth. Building rapport with scholars also addresses the previous scholar's concern with potential staffing turnover that the Next Up/Guardian Scholars Program may have experienced. LSC foster youth scholars would recommend having consistent staff of caring individuals and a dedicated space in which foster youth scholars can feel safe and comfortable.

\section{Little Streams Foster Youth Scholars Summary}

The foster youth scholars at LSC were motivated to attend college both based on external support and expectations of family and community members as well as an internal motivator to achieve their goals. The support that they received from the Next Up/Guardian Scholars Program and/or EOPS, foster youth scholars at LSC was found to be beneficial. Specifically, having access to counselors and the additional financial supports such as meal vouchers, book vouchers, and school supplies were campus supports that foster youth 
scholars appreciated the most. While the counselor support was helpful, some scholars also shared instances where their counselor recommendations were not in alignment with their educational goal which ended up extending the scholar's time to completion. The biggest recommendation that foster youth scholars at LSC provided was to provide support with empathy, to get to know the student in order to meet the student where they are. Additionally, the foster youth at LSC felt as though they were often overlooked on campus, especially since they did not have access to a dedicated space or place to go for resources.

\section{The Little Streams College Case Summary}

Again, the second research question in this study was focused on better understanding the educational experiences of foster youth in community colleges in an effort to more equitably implement Guided Pathways. When asked if they had previously been asked about ways in which the campus could better support foster youth, five scholars said they had been asked this question before. However, when asked if they had been asked about their opinion or experiences in relation to Guided Pathways or Campus Reform efforts, only one scholar said 'yes' - five responded 'no', and one was 'unsure'. Understanding that there are only 81 students, out of 15,00 that are technically classified as 
foster youth at LSC, it is not a surprise that they may have been "overlooked" in this area.

These truths aside, there are some aspects of the GP implementation plan at LSC that currently align with the recommendations made by the foster youth scholars. One such example was the development of the Access Center to provide support for students as they are entering the college. By staffing the Access Center with professionals, or paraprofessionals, who are able to sit down and talk with the student to better understand how they might be able to support or refer the student, could give foster youth scholars the empathy they need to feel comfortable navigating the campus. In addition to the Access Center, identifying additional space for foster youth students to build community, have their Next Up/Guardian Scholars Program meetings, and access their campus benefits would also be valuable for students. Finally, it would be beneficial to continue to host student forums at various times a day so that foster youth could attend and contribute to the ongoing conversations surrounding the Guided Pathways implementation. 


\section{Chapter 6: Case Study - Foggyville College}

Foggyville College (FC) is located in the suburbs of a major city in Northern California. Founded in 1969, FC is one of several colleges in a three college district. While most of the educational programming takes place on the FC campus, there is one satellite location that houses its entrepreneurship center open to community members as a co-working space. FC has a Vision to "inspire a global and diverse community of learners to achieve intellectual, cultural, social, economic and personal fulfillment." The FC values include: social justice, campus climate, open access, student success and equity, academic excellence, community partnership, participatory governance, and sustainability.

According to DataMart, FC enrolls approximately 10,000 students annually. In the 2018-2019 academic year, 68 percent of students were under the age of 25 , and 52 percent of students identified as female. The ethnic distribution of students at FC were $37.8 \%$ Hispanic, 22\%Asian, 19\%t White, 16\% Filipino, and 6\% Multi-Ethnic. In fall 2019, the term for which we have the most recent data, 66 students were identified as Foster Youth at FC.

\section{Foggyville College Guided Pathways Involvement}

Foggyville College was not a member of the California Guided Pathways Project. Instead, FC incorporated their Guided Pathways (GP) implementation 
within an entire campus redesign initiative. The campus redesign incorporates Guided Pathways, a Promise Scholars Program, and a focus on Transformative Teaching and Learning. This redesign was referred to as the Foggyville College Promise with the intent to help address and eliminate barriers to access (Promise Scholars Program), provide clear pathways for student achievement (Guided Pathways), and provide proper professional development for faculty and staff in order to support the students in achieving their goals (Transformative Teaching and Learning). The primary goal for the Foggyville College Promise was to serve as a guiding promise that the institution would help students get in, get through, and graduate...on time!

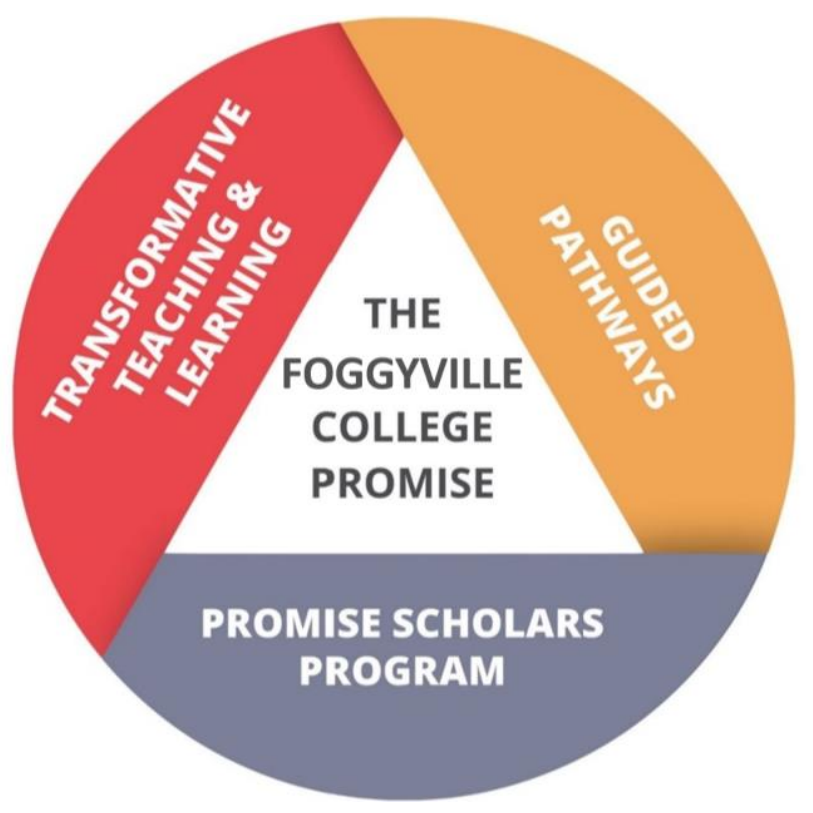

Figure 13. Foggyville College Redesign Framework

\section{Foggyville College Guided Pathways Practitioner Participants}


For this study, both direct and indirect participants were included. The direct participant consists of the Director of Guided Pathways and College Redesign, Christine, with whom I conducted an interview. Christine I identified as female and White. At the time we spoke, she had served in the director position for six months, but had spent the previous two years as a faculty colead working on the GP efforts. Prior to this administrative appointment Christine served as instructional faculty.

The indirect participants contributed to the development and publication of the key documents analyzed in this study. The documents analyzed include the Guided Pathways Scale of Adoption, Local Vision Goals Summary, and Student Equity and Achievement Plan (Table 7. Foggyville College List of Documents Analyzed). These indirect participants consist of the Vice President of Instruction, District Chancellor, President of Academic Senate, Dean of Institutional research, College President, Board of Trustees President, Dean of Student Equity, Vice President of Student Services, Chief Financial Officer, Dean of Counseling, and Student Equity Division Assistant. The documents analyzed in this study provided preliminary information that guided the questions asked in the interview with Christine. 
Table 7. Foggyville College List of Documents Analyzed

\begin{tabular}{|c|c|c|}
\hline $\begin{array}{l}\text { Document } \\
\text { Title }\end{array}$ & Contributing Authors & Purpose within this study \\
\hline $\begin{array}{l}\text { Guided } \\
\text { Pathways } \\
\text { Scale of } \\
\text { Adoption (18- } \\
\text { 19) }\end{array}$ & $\begin{array}{cl}\text { Foggyville College (FC) } \\
\text { - } & \text { Vice President } \\
\text { - } & \text { District Chancellor } \\
\text { - } & \text { President, Academic Senate }\end{array}$ & $\begin{array}{l}\text { This document was utilized to } \\
\text { gain an understanding of what } \\
\text { inquiry has already taken place } \\
\text { as well as what } \\
\text { recommendations have been } \\
\text { proposed. }\end{array}$ \\
\hline $\begin{array}{l}\text { Local Vision } \\
\text { Goals } \\
\text { Summary }\end{array}$ & $\begin{array}{cl}\text { FC } & \\
\text { - } & \text { Dean, Institutional Research } \\
\text { - } & \text { President, Academic Senate } \\
\text { - } & \text { College President } \\
\text { - } & \text { Board of Trustees President }\end{array}$ & $\begin{array}{l}\text { This document was utilized to } \\
\text { better understand the mission } \\
\text { and vision of each institution. } \\
\text { Additionally, it includes } \\
\text { information about } \\
\text { disproportionately impacted } \\
\text { students and the institution } \\
\text { goals to improve outcomes for } \\
\text { these groups. }\end{array}$ \\
\hline $\begin{array}{l}\text { Student } \\
\text { Equity \& } \\
\text { Achievement } \\
\text { Program Plan }\end{array}$ & \begin{tabular}{|ll} 
FC & \\
- & Dean, Student Equity \\
- & Vice President, Student Services \\
- & Chief Financial Officer \\
- & Dean, Counseling \\
- & Division Assistant, Student Equity \\
- & Vice President, Instruction \\
- & College President
\end{tabular} & $\begin{array}{l}\text { This document was utilized to } \\
\text { gain clarity on which student } \\
\text { groups were identified as } \\
\text { disproportionately impacted. } \\
\text { This document also provided } \\
\text { insights to proposed } \\
\text { interventions to support the } \\
\text { success of disproportionately } \\
\text { impacted students. }\end{array}$ \\
\hline
\end{tabular}

\section{Foggyville College Practitioners Themes}

Again, the first research question explores the intentional ways in which community college practitioners are addressing equity in the implementation of the Vision for Success, through the Guided Pathways framework. The three main themes that fall under this research question are 1) understanding equity, 2) equitable implementation of Guided Pathways, and 3) the inclusion of student voice in inquiry. 
Understanding Equity. Foggyville College established their Guided Pathways efforts within a larger campuswide redesign. This redesign was built from what FC refers to as their "Brutal Truths." These Brutal Truths illuminated the persistence and completion equity gaps between different student groups within the college. While each of the California Community Colleges are being asked to report on the equity gaps within their institution, referred to as the disproportionately impacted groups, Foggyville College did more than just report on these groups. Instead they interrogated the data in order to identify the gaps within the institution that are contributing to the gaps in student persistence and completion. The FC Student Equity and Achievement Plan states that the college redesign efforts,

in concert with the Comprehensive Diversity Framework and Student Equity Plan, places the responsibility for ensuring equity in outcomes squarely on the institution and its faculty, staff, managers, and administrators. In short, we are committed to designed [sic] a Student Ready Institution rather than expecting to for [sic] students to be College Ready.

FC displays critical consciousness in making explicit in the Student Equity Plan (SEP) the responsibility for the institutions to address issues of inequity in student outcomes provides a clear, unifying purpose for the campus redesign efforts. Additionally, the SEP stated that, the concept of student equity is not narrowly defined nor limited to the individual groups and activities contained in the plan. Instead, ensuring equity in student access, success, and achievement is considered 
fundamental to all programs and services. It is the guiding focus of the promise that [Foggyville] College makes to its communities and students: you will Get In, Get Through, and Graduate...On-Time, according to your individual educational goal.

The statement above displays the entire campus' commitment to justice by reconciling the notion that each member of the campus community is responsible for the equitable outcomes for students. It also endorses the idea that there may be additional activities and interventions outside of the SEP that the college will investigate in order to close equity gaps on campus. This acknowledged grace provides flexibility for the campus to identify and implement initiatives not yet developed as of the submission of the SEP.

Equitable Implementation of Guided Pathways. The GP efforts at FC are being led by a Director of Guided Pathways and College Redesign, Christine. Christine also works with a group of faculty co-leads who provide support to the various work and inquiry teams made of faculty, staff, administrators, and students. The inquiry groups are tasked with investigating both challenges within current practices as well as identifying potential solutions to these challenges. The proposed solutions are then presented to the campus administration who approves or denies the recommendation(s). Once a recommendation is approved, a work group is then tasked with identifying how to advance and implement the recommendation within the campus. The 
combined structure of the inquiry teams and work groups are referred to as the Design Team (Figure 14. Foggyville College Design Team Structure).

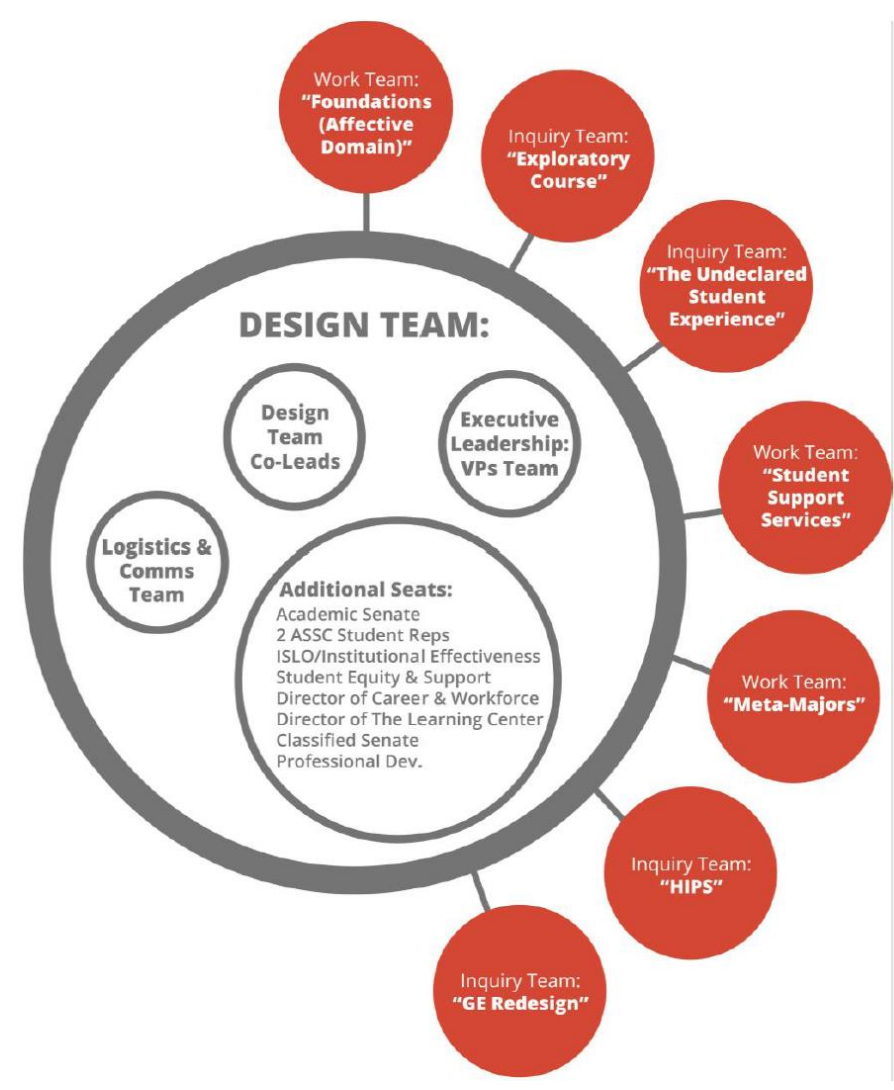

Figure 14. Foggyville College Design Team Structure

The Design Team image seen in Figure 14 has multiple layers. Within the main "Design Team" circle are smaller circles that identify primary groups that play a lead role in the Guided Pathways implementation. Included in these primary groups are the Design Team Co-Leads comprised of instructional faculty with release time to serve in this capacity; a logistics and communications team 
comprised of members from marketing, outreach, and research to provide insight on how GP work is being communicated primarily to external constituencies; and the executive leadership team which is comprised of the campus vice presidents. Additionally, there is space for members from across campus to serve on "additional seats" in an advisory board capacity. Outside of the main Design Team circle are conjoined circles that represent various inquiry teams and work teams. Each of these inquiry teams and work teams are comprised of various members of the campus community as well, though primarily served by faculty.

Having a broad and diverse constituency involved in the GP implementation allows for multiple lenses through which the work can be viewed. However, way in which decision are made at FC include a much less diverse approach. When asked about how decisions are made regarding what to implement at FC, Christine responded with "that has been a challenge, actually. People don't want to make decisions because decisions are political." She further explained that when working with campus administration I get pushback on like, well you just make the decision and tell us what to do. But then when I do that, there's like, Oh, well, you're not in a position to make that decision, kind of thing. So it's like it depends on. I get pushed back in both directions. And I get told you're just a director, like you don't have that kind of power. Yeah. So, yeah, politics. 
Again, while the intention to address systemic issues of inequities for students is at the forefront of the GP work at FC, there are still traditional systems in place that contradict the empowerment of the employees to make transformative decisions on campus that could benefit the students. Within the SEP, FC recognizes that equity is broadly defined, that student success is the responsibility of the entire campus, and that student goals are varied and diverse. These main ideas have been fundamental in driving the GP implementation efforts at FC and creating a baseline of understanding for the entire campus community. While speaking with Christine, she did address the difficulty in operationalizing the intention behind the SEP and real world practices. For example, the SEP reads,

[Foggyville] College's commitment to equity and social justice is actualized by grounding our work in being anti-racist, anti-sexist and in solidarity with queer communities. Rooting our work in these philosophies positions our institution in appropriate alignment to serve the most historically marginalized communities.

However, in speaking with Christine about what this looks like in practice, she stated that thus far the campus has really only reviewed the data for various student groups and acknowledged that disproportionate impact exists. She stated that,

We know the disparity and graduation rates amongst different ethnic and racial groups but we haven't really done anything to address that besides like conversations about learning communities and very academic 
conversations about things like high impact practices that have been shown to have a greater impact on disproportionately impacted groups.

While the larger campus community might be "on board" to address inequities in student success, this sentiment recognizes the complexity and difficulty in connecting the intentions to actual practice. Especially when attempting to change the culture and practices of an institution that has historically been rooted in systemic inequities.

Even when the commitment to justice is strong, addressing issues of equity within larger reform efforts is complicated. Nonetheless, Christine did have one recommendation for the ways in which colleges can support students, which is much less complicated. It starts with just being nice.

I think a lot of the work that needs to be done is around being nicer to students and like having human relationships and treating them with respect and we're treating them like humans. And so I think that there needs to be some professional development around that.

Christine's statement highlights the need for students to be humanized in educational settings. This idea is in alignment with the notion of being a "caring educator." In the McNair et. al, (2016) book entitled Becoming a Student-Ready College: A new culture of leadership for student success, the authors pen an entire chapter dedicated to the importance of being a "caring educator." The idea of being a caring educator is not connected to a specific role or title on 
campus, but rather connected to the role that each individual plays as it comes to student success. The ability to see oneself in the place of the student, to understand the systemic barriers that impact the student's experience, and the importance of approaching each interaction with students with care. Essentially, to have the capacity for empathy. Christine also shared that in the student focus groups conducted at FC students expressed the importance of having support on campus.

One of the questions that we asked them [was] if you had a team of people at [Foggyville] who could support you, who would be on that team? And it was so individual for each student because it was really about that personal connection and being able to see themselves in someone else. And so, we walked away feeling like, how do we, how do we institutionalize that?

FC found that when asked, students highlighted the importance of making a personal connection on campus based on their own experiences. Christine admitted that while it would be ideal to ensure that every student is able to make a strong personal connection with a faculty or staff member on campus, the idea of developing an intervention or system to do such is incredibly difficult. Inclusion of Student Voice in Inquiry. In my interview with Christine, she spoke of the importance of empathy within the GP work. She acknowledged the diversity of the FC student population beyond the traditional disproportionately impacted groups disaggregated by race and gender. She 
also mentioned working mothers and students that exited the school system prior to graduating from high school, and the importance of ensuring that their needs were being addressed with the Guided Pathways work. She stated that

I think one of the things is figuring out how to reach the students who are not as connected. And the only idea that I have for that is going into classrooms and talking to students there. Cuz it's really hard to ask students to do things outside of class. And we've been talking about that for a couple of semesters now and just haven't been able to make it work yet, but that's on the next steps list.

While FC may not have been able to engage with less traditional, less "engaged" students in the initial Guided Pathways efforts, it is reassuring that there is still the desire and plan to engage with more diverse student populations in future phases of the GP implementation. The ability to reflect on and identify which voices have been included in the student narrative and which students have not, is important. Equally important is having a plan to include diverse student, and employee, voices in the work as it continues.

I think just that constant, like, reminder to students that we really are here for them and we really are trying to make their lives better, because I don't think it always feels that way to them. Like, I think it sometimes feels like we're working against them. And so I think just like really being honest and acknowledging that helps with the buy in. 
Christine's acknowledgement of the mistrust that students may have with the institution especially since so many students have actually been harmed by education in the past. The desire to reconcile that harm in an effort to learn from students and drive institutional change is both courageous and displays the type of commitment to justice that is needed to move the needle.

\section{Foggyville College Practitioners Summary}

The first research question in this study was to identify the intentional ways in which community college practitioners are addressing equity in the implementation of the Vision for Success - through the Guided Pathways framework. Foggyville College's Brutal Truths that highlight disparities within student completion rates serve as a grounding framework upon which the campus can build change. Having the Brutal Truths as a guidepost alone, however, does not translate into actualized equity work. As Christine disclosed, it was difficult to connect specific initiatives or interventions related to improving disproportionate outcomes within the GP framework. Many of the recommendations, such as student success teams or thematic general education courses, were generic and to be experienced by all students. Additionally, it appears as though the primary voices involved in both inquiry and decision making were instructional faculty. Throughout both campus documentation and in the interview with Christine very little was mentioned 
about inclusion of student services or students in the decision making process. There is, however, a dedication towards providing proper professional development training for faculty and staff with an emphasis on equitable teaching practices. This commitment to invest in the development of all employees on campus supports the notion that improving equitable outcomes is the responsibility of all members of the campus community.

\section{Foggyville College Foster Youth Scholars}

As mentioned earlier in this chapter, Foggyville College (FC) enrolls approximately 10,000 students annually. In the Fall 2019 term, there were 66 students that the college identified as foster youth students. While 66 students of 10,000 only represents $0.66 \%$ of the student population it is important that educators take a vested interest in the success of all students within their institutions, no matter how small their presence might be - all students' success matters.

\section{Foggyville College Scholar Participants}

Scholars from Foggyville College participated in this study through an electronic interview and in-person paired interviews. I will first share the demographics of scholars that completed the electronic interview and then I will share the demographics of scholars that participated in the paired interviews. Nineteen scholars completed the electronic interview. For the electronic 
interview, three participants identified as male, three identified as female, and eight declined to state. As of the date in which they completed the survey, the participants had completed between one and 13 semesters in community college. Three scholars identified as Mexican-American, two scholars identified as Black, one scholar identified as Chinese, one scholar identified as South American, one scholar identified as Hawaiian, one scholar identified as Samoan, one scholar identified as White, and seven scholars declined to state their race or ethnicity.

For this study, I utilized network sampling to send the link to an electronic interview to the foster youth liaison at FC who coordinates the Guardian Scholars Program (GSP). The foster youth liaison then emailed out the link for scholars to complete. She also posted the link on the GSP Canvas page. The electronic interview asked participants open ended questions about their experiences in community college including accessing higher education, major and course selection, and identifying unique impacts for foster youth. The interview ended with a short survey to collect demographic data. Upon the completion of the interview, participants received a $\$ 10$ electronic gift card to thank them for their time. The data from the electronic interview was analyzed to provide a deeper understanding of the experiences of current and former foster youth in community college. 
I also utilized network sampling to recruit scholars to participate in the paired interviews. Seven scholars completed the paired interviews. Five scholars identified as female and two identified as male. Three scholars identified as White, one scholar identified as Black, two scholars identified as Mexican, and one identified as White-Latino. At the time of the interviews, the scholars had completed between one and 10 semesters in community college. The topics discussed in the paired interviews were built from the information shared in the electronic interviews. The questions were focused on accessing higher education, major and course selection, the identification of barriers for foster youth, and recommendations that foster youth scholars have for college practitioners.

\section{Foggyville College Foster Youth Scholar Themes}

The second research question explores the ways in which the educational experiences of former foster youth in community college can inform the equitable implementation of community college reform efforts - specifically, the Guided Pathways initiative. I analyzed the data collected in the electronic survey and in the paired interviews to develop the scholar themes. The four main themes that fall under this research question are: 1) understanding scholars' motivation in pursuing higher education; 2) understanding what's working for foster youth scholars; 3) exploring the areas of opportunity; and 4) 
hearing scholar recommendations. Again, I will not be editing the direct quotes provided by the foster youth scholars in an attempt to ensure that their true, authentic voice is being shared in this analysis.

\section{Understanding Scholars' Motivation in Pursuing Higher Education.}

Foster youth scholars at Foggyville College indicated that their motivators for attending college were often connected to external influences, which is similar to the findings from Somers et al. (2006). Two of the electronic interview respondents mentioned having external expectations of attending college from either a foster parent or society in general. One of the participants stated that they sought out college

To secure a better future for myself and to continue the cycle by showing my daughter that going to college is highly favored and hopefully she will continue the cycle.

Similarly, all seven of the paired interview participants also mentioned having external expectations that influenced their decision to attend college. One scholar, Laura stated

I decided to come to college because, so I still keep in contact with my family, they're always constantly asking me like, oh "What do you do for school?" and I don't want to like let them down, that's one. And then two I also want to want to be able to live a different life than my mom did, so. 
Laura's motivation to attend college was both prompted by family encouragement and expectations as well as the desire to change the trajectory of her current family situation, which is similar to students in research conducted by Tobolowsky, Scannapieco, Aguiniga, \& Madden (2019). Laura's aspirations to attend college to improve her family's socioeconomic status also supported by research. Researchers have reported that foster youth that complete community college have higher incomes and are less likely to rely on public benefits or be unemployed, compared to foster youth with only a high school diploma or GED (Okpych \& Courtney, 2014; Salazar, 2013).

In addition to external influencers that motivate scholars to pursue college, several FC foster youth also shared internal motivating factors that led them to higher education. Six of the electronic interview participants and five of the paired interview participants suggested that their decision to attend college was either based on achieving a personal goal or preparing for a desired career.

Electronic Interview Question: Why did you decide to attend college?

Answer: I wanted to take my education to next level in my life to enjoy a solid career and be able to take care of my friends family.

Paired Interviews - Tia: I took a good four years off. I took a huge gap. Then I came back to school. And personally the only reason I came back to do school's because our social norm claims that we need people to do so. That's, that's the social norm status. 
As evidenced by the responses of both the electronic interview scholar and the scholar that participated in the paired interview, the internal and external motivators were not mutually exclusive. The internal motivator of wanting to achieve a goal or advance their career, was still deeply connected to an external motivator of benefiting their family or community.

Finally when attempting to understand why foster youth scholars elected to attend FC specifically five scholars from the electronic interview and five from the paired interviews identified convenience and familiarity as primary factors. The convenience of FC was connected to location and being close to where the scholar lived.

Question:How and why did you select the college that you are currently attending?

Electronic Interview Scholar Answer: It's local and has classes I could take/have schedule flexibilities.

Electronic Interview Scholar Answer: I chose this college because it was the closest community college to where i stay.

Alternatively, though, a few scholars also noted that while FC was not the community college closest to where they lived, FC was appealing based on recommendations from social workers or family members that highlighted the programs and set an expectation of support that a foster youth scholar might be able to receive at $\mathrm{FC}$ that they could not receive at their more local institution. 
Familiarity was based on having a previous connection to FC through a sibling or family member's previous attendance at FC or having participated in a concurrent enrollment program at FC which allowed the taking of college classes while still in high school.

Understanding What Is Working for Foster Youth Scholars. Similar to the external factors that encouraged the scholar's enrollment into college, several foster youth scholars also attributed their persistence in school to established support programs. Both Guardian Scholars Program (GSP) and Extended Opportunities, Programs, \& Services (EOPS) were highlighted as programs that scholars feel have supported their success by two scholars from the electronic interview and by all of the scholars in the paired interview. At FC, both GSP and EOPS work closely together where EOPS provides counseling support and GSP offers support in addressing scholars' basic needs and connecting to the larger campus. From the electronic interview, one scholar shared that

Guardian Scholar- helps with keeping you on track, providing counseling, provides meal vouchers, transportation vouchers, etc.

From one of the paired interviews, Alina shared

It's nice because like GSP literally has a place for, like people to come like chill, and you know, where it doesn't feel like, this like, cold atmosphere like even picking like [Susan - the GSP coordinator] was like such an awesome idea for 
them because she's super open, and like, so it's kind of like the people who you know make it and through TRiO [another student support program] it works to like you have unlimited access to tutoring. So you ever have any questions, it's answered to you very quickly.

Scholars value having access to GSP which has provided scholars with both physical space for scholars to create community as well as a centralized location for scholars to seek out information and assistance, similar to students in the study conducted by Hass, Allen, \& Amoah (2014). Scholars also attributed GSP with their ability to access courses through priority registration. Additionally, the joint counseling requirements of GSP, EOPS, and TRiO (which is not an abbreviation) require scholars to meet with counselors multiple times throughout the semester in order to provide proactive support for scholars throughout their collegiate experience. When asked if they ever had trouble accessing courses, Jeff, a scholar from one of the paired interviews stated, cuz I'm with EOPS and GSPS, and DRC and they really helped me like get into classes but also you have to maintain a point, you know, a requirement to be enrolled in your programs. Right. Yeah, I haven't had any problems yet.

Similar to the majority of GSP scholars, Jeff is also in EOPS. Additionally, like many foster youth as attested to in Pecora et. al., 2006), both Jeff and Karrie, another paired interview scholar, receive support from the Disability Resource Center (DRC) on campus. Whether through GSP, EOPS, or DRC, scholars 
expressed gratitude for having student support programs that provided priority registration, academic guidance, connections to campus, and general financial support. Being connected to these support programs also provided scholars with leverage as it came to working with faculty members on campus.

In addition to support programs, scholars also share the impactful experiences they had with faculty members on campus. Adam, a participant in one of the paired interviews shared that it was through a discussion with a faculty member that he was introduced to GSP.

\section{Adam}

So I was told about the program by a professor, because I was, I had some stuff going on, I was going to drop out like a year or so ago. And then he informed me of these resources that were available. And I had never even heard of them despite like trying to find them on the school website or something like that. I just didn't know it was a community system.

\section{Lauren Ford}

Yeah. Did you, did, was that in like a one on one conversation? Or was it on the syllabus or -

\section{Adam}

in a one on one conversation. And so just like what I was saying earlier, there's not really any real information available about these programs, like nothing like on the syllabus to let people know about it, nothing.

Adam's willingness to open up to his faculty member allowed that faculty to direct Adam to campus supports that encouraged his persistence at FC. Unfortunately, as evidenced by the low college completion rates of foster youth, 
many scholars rarely have such a pivotal interaction with members of their campus community. In addition to referring scholars to campus resources, foster youth scholars also shared moments when faculty supported them in the classroom as well. Norma, a scholar that participated in a paired interview reflected on a time when she felt supported by a faculty member.

Even though the maximum capacity was reached the teacher let me in because of the fact that I had her for the last two semesters. So, that like making the connection with teachers definitely helped me a lot. And also the priority registration really does help.

Faculty member's awareness of support programs such as GSP can provide referrals to scholars that need just-in-time assistance that experts in student services can provide. Beyond that, when faculty members are able to show empathy to vulnerable students such as foster youth, scholars feel supported and motivated by that faculty member's belief in them. In both the electronic interview and the paired interviews, foster youth scholars shared that they identified the classes they wanted to take based on referrals from other foster youth scholars in GSP or from trusted family members. Faculty members that display empathy, support, and encouragement to foster youth become members of a trusted cadre of campus professionals for foster youth scholars, and GSP overall. 
Equally as impactful as supportive and empathetic faculty members, are faculty members that display impatience or indifference with a student's foster youth status and all that comes attached to such a status. During our conversation, Norma also shared a moment in which she did not feel supported by a faculty member. When asked what advice she would give to colleges to better support foster youth scholars she suggested

I feel like understanding, understanding is a big thing. Because I definitely have had some professors, where they're like well this was due this, this and this day, you usually do. And usually you expect professors to be like oh no it's fine you usually turn things in so it's fine l'll make an exception. But I've had a few where it's like you didn't meet the deadline. So you're just going to affect the final grade. So, just being understanding in general, to be able to not not feel judged.

Norma referred to having to miss school from time to time to deal with county issues related to her foster youth status. This is not uncommon, as $A B 12$ provides students in foster care to continue care through their 21st birthday. As such, this expanded time in care also requires consistent check-up/check-ins with county officials. Just like most businesses, county offices are open traditional business hours, Monday through Friday, $8 \mathrm{am}$ to $5 \mathrm{pm}$ - the same hours that the majority of full-time students are in class. In Okpych \& Courtney (2017) the researchers found that students often had to miss school three times a semester due to reasons associated with being in foster care. To add, foster 
youth scholars may not be able to select the time to meet with their social worker around their school schedule, as it could be out of their control; and yet meeting with their social worker regularly is still a requirement. Therefore, additional empathy from faculty members as it comes to the attendance policy or assignment submissions would alleviate some barriers that foster youth scholars face as they attempt to persist in college.

Exploring the Areas of Opportunity. While foster youth scholars at FC expressed feelings of support from some faculty members and through GSP, there were still areas in which scholars felt their needs were not being met. Some of these opportunities were connected to scholars' basic needs, such as financial and housing insecurities. Feeling a sense of connectedness was another overwhelming opportunity that scholars shared.

When discussing reasons why foster youth scholars stop out of college, several scholars mentioned the challenge in balancing school and life at the same time. In the electronic interview, one scholar plainly stated

It is hard to balance school and provide for yourself at the same time. Working a jon [sic - job] and attending school regularly is my biggest challenge.

While the desire to attend college is there, the more pressing need to support themselves financially can interfere with their ability to persist in school. Similar to previous research, many scholars that participated in this study were working 
while also attending college (Cooper, Mery, \& Rassen, 2008; Kinarsky, 2017). Though not asked explicitly whether or not scholars worked, four of scholars from the electronic interview and six of scholars from the paired interviews shared that they were working while attending FC. In fact, two of the scholars from the paired interview had to leave the interview a few minutes early in order to make it to work on time. One such scholar was Norma. Norma shared that she strategically attempted to balance her class schedule with equal amounts of "easy" and "difficult" classes in order to ensure her success in the classes while also needing to work. She stated

for example with this semester I also have communication requirements. But it's more laid back, because I know as my last semester, I get, I have to work to be able to pay off bills and stuff. So, with the schedule that I have I'm able to work more hours and kind of like balance things without having to go overboard.

Norma's balanced schedule, still at a full 18 units, allowed her to manage courseload expectations so that she could still work to support herself. GSP and EOPS at FC provide foster youth scholars with book vouchers up to $\$ 300$ each semester to purchase books in the campus bookstore, access to technology such as laptops and calculators if needed, weekly food vouchers so that scholars can eat on campus, as well as school and testing supplies. Additionally, foster youth scholars that complete the financial aid application are 
eligible for the California College Promise Grant (formerly Board of Governors Fee Waiver) that covers enrollment fees, both the PELL and the CHAFEE grant - both federal grants that when combined could offer up to an additional $\$ 12,000$ a year. While these supports are incredibly beneficial for scholars they are not able to cover the full cost of attendance which includes housing and utilities, transportation, and meals at home. In fact, Alina alluded to the challenges in filling out the financial aid application needed to even receive these benefits.

Alina worked full-time the year before she enrolled in college. Once she started taking classes, she cut her hours down to part-time to allow herself more time to focus on her classes. However, the financial aid application was based on the earnings that she received while working full-time, even though her financial status was set to change. She had to complete additional extenuating circumstances forms in order to have her file reviewed and her financial aid adjusted. The additional forms that she had to fill out were incredibly stressful and confusing, but she felt compelled to fill them out in order to receive the financial support she needed to continue attending FC. Laura also shared frustration in maneuvering through the financial aid system, especially as a foster youth. 
And then, and then also not get not having that support, like if you're the first one in your family to go to college, like, when I first came here, like I didn't even like I didn't even know there was a CHAFEE grant, I didn't know I was eligible for that. There was no GSP program. There wasn't like like, I was doing this all. I couldn't ask my mom like hey, you know like, or like my guardian, my legal guardian at the time, like, Hey, can you help me fill out this application or like, you know, and then he's getting mad at me for asking for his taxes and just, you know, it's just all these unfamiliar things that could just like scare you or just like discourage you from, you know, like achieving or like wanting what you like, envision, because I think in the back of our mind like we all want to be successful. We all want it. We all want it but like it's, it's hard getting there especially if you don't have all the tools or resources.

Norma, who was in the same paired interview session as Laura also shared the challenge of attempting to complete the financial aid application as a foster youth - especially in trying to identify who exactly the guardian was that needed to be included on her financial aid forms. Foster youth can complete the financial aid application as independent students which does not require them to include guardian information, but does require them to "verify" their independent status with court documentation identifying them as a foster youth. For some scholars, retrieving this information could be difficult. For other youth that simply just do not live with their parents, like my mother and sister when they were younger, such paperwork may not exist. Having to go through so many hoops, alone, was a challenge that many foster youth scholars shared. Laura did share, however, that her biggest champion and supporter at FC when 
she first started college was a woman named Jaclyn who worked in the financial aid office. Laura mentioned that Jaclyn helped her navigate the financial aid process and reached out to her throughout the semester to checkin and support Laura's success. Unfortunately, Jaclyn is no longer employed at FC and none of the other scholars in the paired interviews had the opportunity to work with her or anyone else as deeply connected to the financial aid process. However, Laura is now a student worker in the financial aid office and attributes her success in this role to the support that she received from Jaclyn. Housing insecurity was also another area of opportunity that scholars discussed. When asked why they chose to attend college, one scholar from the electronic interview stated

It's expensive in the Bay Area and you need a degree to survive.

For this particular scholar, and several others in this region, both financial security and housing security are intersecting challenges. During the paired interviews, several scholars identified issues with consistent housing as a potential barrier to foster youth scholars' persistence. Tia, shared information about a community based organization that provides housing for transitional aged youth - young people transitioning out of their foster care or court ordered care placements - between 18-24 years old. 
I know there's this thing called, like a thing called HIP Housing, which is available for 18 to 24 year olds, most foster youth don't know about that. It's free housing in [Bay Area] that's pretty its, a big, it's a big deal. I don't even know about it. I wish I could have it right now. I really wish I could have it. Like a lot of people are like sleeping in their home in their cars or like they're forced to be in situations where they don't want to be. Like, we have Huckleberry Finn, which is like a shelter here in [Bay Area] supposedly, like, there's not really enough shelters or places where people can find maybe that support group outside of school as well.

The District in which FC is a member provides limited housing for faculty and staff - limited both in the number of units and the length of stay a faculty and staff member can reside in the housing. However, the District does not provide housing for students. In the paired interview with Jeff and Alina, we discussed the lack of student housing within the District. Alina stated that there were talks of building student housing for international students. A position that Jeff felt was unfair - understanding that international students pay more to attend colleges in the U.S. which helps to financially support programs and services on campus, but also addressing the fact that many local students have housing issues as well. Alina recommended that foster youth also be considered in the discussion around student housing, even suggesting that scholars might be able to work on campus in exchange for rent.

I'm not talking about like getting someone to live for free. Obviously that's never going to work. You're never going to get anything for free. 
Like to do work study or, is that, what it is? Like work on campus, like pay rent and everything too, but it's just like going to be easier for us to continue education, because as I said like that all begins from finance. And a lot of people give up, just because they need the basic necessities. Right?

Alina shared her own personal experience of dealing with the stress of housing insecurity. A former roommate moved out of their apartment and she was not able to afford her rent alone. She decided to buy a van and has been living in her van, near campus, ever since. She also stated that she was really proud of her van and loved living in it so as not to elicit any pity from Jeff and $\mathrm{I}$. However, Alina's homelessness, self-selected or not, mirrors the $25 \%-27 \%$ of former foster youth that experience at least one bout of homelessness after emancipation (Courtney et al., 2004; Goldrick-Rab, Richardson, \& Hernandez, 2017). The reality of homelessness adds yet another layer of challenge to foster youth scholars' ability to successfully complete their education.

Finally, even if scholars are financially and housing stable, they may still struggle with feeling a sense of belonging on campus. One scholar from the electronic interviews cited "Ioneliness" as a potential reason as to why foster youth scholars might stop out of college. Additionally, Tia a scholar from one of the paired interviews reflected on her experience at FC and shared 
There's no community, there's no one really that has your back. Like, there's not like family for life or something like that. There's no one telling you like, hey, like, if you keep going, we're going to keep making sure that you help them, like the friends that you need and the community you need to push through. You guys start here and you feel like you're doing great in the beginning and then all of a sudden, you're like, Okay, this is kind of boring. Like, what am I doing here? Like, there's no sense of time, like, pressure, in community college, no pressure.

Tia's experience highlighted the idea that there is often a lot of support at the onboarding, matriculation phase, with a lot of outreach and follow up from the college. However, once school starts that level of support flattens and students are then left on their own which may decrease motivation in continuing to pursue their education goal - especially as other, more pressing needs related to finances, arise. So even with GSP, EOPS, and other support programs, foster youth scholars at FC still lack an overall sense of community and support within the institution.

Recommendations from Foster Youth Scholars. The previous three themes were dedicated to better understanding the current experiences of foster youth scholars in community colleges. I also asked the scholar participants to provide recommendations for how colleges might be able to better support foster youth scholars. Their recommendations stemmed on being empathetic and providing structured support so that scholars could build community within the institution. With regards to empathy, Laura shared, 
I think talking to each foster youth, like everyone has a different story. And they all have a story. I think, like, understanding where they came from and what's their story will not like, not only help, you know, you, like, help them out but kind of like, I don't know, but I guess, I don't know. I don't know maybe like like introducing them to all the resources like that they could take advantage of, like, recommending professors.

Taking time to get to know scholars as individuals, to meet them where they are, in order to provide timely and relevant resources and referrals is important. Not all foster youth scholars have the same experience or the same needs. In fact, not all foster youth scholars want to be identified as foster youth. Both Norma and Laura shared that they previously felt shame and embarrassment regarding their foster youth status, concerned primarily with how they would be perceived by peers and practitioners. This is consistent with the findings from Sanchez (2004) and Kinarsky (2017) where foster youth were hesitant to disclose their foster youth for fear of the stigmatization associated with being labeled as a foster youth. They also shared that they have both since grown past that feeling of embarrassment and shame though for different reasons. Laura realized the amount of resources and support she could receive once she disclosed her foster youth status. Norma saw her disclosure as an opportunity to dispel myths about foster youth and become an agent for change. Both Laura and Norma were able to share the resources and information gained from GSP and EOPS with other scholars on campus. Though this was an informal 
network that they created, there is still the need for a more visible support structure for foster youth scholars at FC.

While FC does have GSP, EOPS, and TRiO, which all offer supports for traditionally underserved students - GSP and EOPS for foster youth, specifically - there is still a challenge with scholars being aware of such programs. In the electronic interview, only three scholars specifically identified GSP and/or EOPS as a program that supported foster youth on their campus. In the paired interview Adam stated that he searched the website for information to support foster youth but could not find it. It was not until he spoke with one of his instructors that he was introduced to GSP. Laura's story of how Jaclyn in the financial aid office reached out to her upon her enrollment and then maintained contact with her throughout her time at the college is one way in which structured and lasting support could take place.

Additionally, in Adam and Tia's paired interview, the scholars brainstormed different ways for the campus to connect scholars to valuable information regarding campus resources and events. They shared that they missed morning announcements in high school because it was a way to know what was going on on campus; finding information would not just be by happenstance such as learning about a campus event just because they happened to walk into the right room or building. They also shared that the college's current 
student portal, SchoolSMART, was more of an online directory rather than an information center. They recommended that it be updated to include a calendar of events, announcements, and other pertinent information related to different student types.

Tia

if [SchoolSMART] was reconstructed

Lauren Ford

What would that look like? if you want to draw there are markers and papers.

Tia

you need more of a hook. You need something to cap to capture a student's like, I don't know, eye, to go into [ShoolSMART]. Because right now you, like, you go into [SchoolSMART] first. It's like a pain in the butt pain. You put in your [ID] number and then you go in and your, snap it says like, student records. It says all these frickin things. You don't know what's going on with what to click on first, sort of like, Oh shit, like I'm just not even going to look at it. That's pretty much how I -

Adam

yeah, it's a long list of different sections.

Tia

If it was more like icons, icons like that you will like images, images, simple, easy, simple. And to the point, like, hey, registration is in two days boom boom, there's like a little bit of an icon going like go ahead and click on this link right here for register your classes, right here. Yeah, like more kind of techie like more kind of like-

Adam

user friendly approach. 
Tia 22:47

Yeah, we're all technologically advanced but yet [SchoolSMART] looks like shit. Like I'm like we're all doing so well. Then we're trying to make school more interesting and people to even register for classes but registering for classes, is so hard to pick in the first place, what can we expect?

Without multiple avenues to information, be it peers, support systems, or through the student portal, foster youth scholars, and many other students for that matter, may not feel connected to the campus. This lack of connectedness can result in an overwhelming feeling of needing to navigate college alone. Geiger, Hanrahan, Cheung, \& Lietz (2016) expressed the need to have updated information on the college website and within . Compounded with additional stressors of being financially insecure and the requirements of adhering to county and state regulations to maintain their foster youth benefits, it is no surprise that foster youth scholars often struggle to persist and complete their college goals.

However, not all is lost. As with many stories where the odds are stacked up against a person, there are still silver linings. Such a silver lining is evidenced by this scholars' response to their experience entering Foggyville College:

When I first attended to [foggyville] i was nervous. I was nervous because I didn't know if was smart enough to attend a college. However 
with hard work and the proper tool I succeeded. I love my experience here.

\section{Foggyville College Foster Youth Scholars Summary}

Foster youth at FC were motivated to attend college for a variety of reasons. Some were motivated and encouraged by their family members, foster parents, or influencers at their schools such as a counselor or social worker. While other scholars were motivated by the determination to overcome their past experiences or start a new career. Many foster youth scholars identified the Guardian Scholars Program and EOPS as invaluable support programs - appreciating both the resources provided by the programs and the access to counseling. Priority registration was beneficial for students to gain access into their classes on their education plans without fear of being closed out of a particular course. This early access to courses eventually paid off as they were able to build rapport with essential faculty members who were familiar with the challenges that foster youth scholars often face and were able to approach them with empathy. However these feelings of empathy were most often just provided by faculty that the student already had a relationship with - it did not extend across the campus and as such, the request for empathy was most prevalent throughout the recommendations by FC foster youth scholars. Additionally, issues related to the cost of living, and therefore cost of attendance, were also challenges that foster youth scholars addressed. The 
GSP provided book vouchers, meal vouchers, and school supplies for foster youth students and yet many of them still needed to work in order to pay for living expenses. Because the District that FC is located in provides housing for faculty and staff, foster youth scholars were also curious about their opportunity to access District supported housing as well, especially since many foster youth scholars are housing insecure. The most prevalent recommendations, however, was just to get to know the students as individuals in order to provide the proper support at the right time, show empathy and understanding when working with all students, and provide better visibility to campus supports such as Guardian Scholars Programs so that students can start receiving support as soon as they get to campus.

\section{The Foggyville College Case Summary}

The second research question in this study was focused on better understanding the educational experiences of foster youth in community colleges in an effort to more equitably implement Guided Pathways. In the electronic interview, when asked if they had previously been asked about ways in which the campus could better support foster youth, two scholars replied 'yes', while 12 responded 'no'. Similarly, when asked if they had been asked about their opinion or experiences in relation to Guided Pathways or Campus Reform efforts, zero scholars replied 'yes.' Instead, four responded 'no' and 11 
replied 'not sure'. In the paired interviews I also asked all of the participants if they had heard of Guided Pathways or about campus reform efforts, and none of the scholars said that they had. The fact that the foster youth scholars in this study were not aware of the campus wide reform efforts could be a testament to the lack of student inclusion that has taken place at FC within the GP implementation. The only students included in the Design Team, the decision making body to support the GP implementation were from the Associated Students, or student government. These students are already highly engaged and may not represent the diversity of experiences found within the entire student body population. It would benefit FC to conduct more intentional inquiry to ensure that all of the disproportionately impacted student groups experiences are reflected in the inquiry process and therefore in the decisions that are made.

The most promising aspect of the FC Guided Pathways implementation is the intentional approach to transformative teaching and learning. The idea of ensuring that all faculty and staff across the campus are provided with professional development rooted in equity based practices could provide employees with the skillset needed to work from a lens of equity rather than based in transactions. Additionally, the prospect of thematic general education courses could benefit foster youth scholars by contextualizing core courses in 
an effort to make the materials more meaningful. Laura mentioned that the first time she felt empowered in school was when she took a Chicano Studies course and saw herself, and her culture, reflected in the material. Though, this particular approach is not beneficially unique to foster youth scholars, the notion that it could be meaningful for all new students is reassuring - especially when one of the thematic pathways is "social justice." 


\section{Chapter 7: Cross Case Analysis}

The previous chapters served as individual case studies for each campus in an attempt to answer the research questions. This chapter will serve as a cross case study where I evaluate each campus' findings across each case, or campus. I will address both research questions by identifying findings from both practitioner and foster youth scholar participants. I will begin with the first research question by highlighting themes from the practitioner findings. Then I will address the second research question by highlighting themes from the findings of the former foster youth scholars. The chapter will conclude with an overall summary of the cross-case analysis.

RQ1:What are the intentional ways in which community college practitioners are addressing equity in the implementation of the Vision for Success through the Guided Pathways framework? In order to answer the first research question across all three cases, I will utilize the same themes identified for the individual college practitioner cases. These three themes were: 1) understanding equity, 2) equitable implementation of Guided Pathways, and 3) the inclusion of student voice in inquiry.

Understanding equity. All three colleges included in this study are currently implementing Guided Pathways on their campus. While each college has their unique approach to GP implementation, there are some stark 
similarities. Each campus has a grounding framework rooted in addressing issues of equity. For Bode College (BC), the Student Equity and Achievement Plan (SEP) provides the foundation for the campus' equity based reform efforts. For Little Streams College (LSC) the Organizational Change Paradigm serves as the campus' equity rooted framework. Finally, Foggyville College (FC) has their Brutal Truths that prompted the Foggyville College Promise - a pledge to students evolved from a framework of a common understanding of the need for equity based reform. Each campus framework acknowledges the historical inequities that persist throughout the institution and places a call to action for faculty and staff to identify ways in which such inequities are to be addressed. The ways in which each campus has chosen to address such issues of equity has varied. The most varied approach has been in their decision making structures.

Equitable implementation of Guided Pathways. Each campus has a vast, multi-stakeholder implementation team. Each campus' Guided Pathways team is comprised of administrators, faculty, and classified professionals. Bode College and Little Streams College also include paid student assistants on their Guided Pathways teams, while Foggyville College had seats available for members of student government to serve in a committee capacity. Though all campuses acknowledge providing faculty with release time, or overload, to work 
on Guided Pathways reform efforts, only Bode College mentioned extending the same acknowledgement of value for classified professionals by providing overtime for any Guided Pathways work. Being able to identify ways in which equity can be addressed for students can often begin with acknowledging issues of inequity within the workforce. Bode College offering to pay classified professionals for their involvement and leadership within Guided Pathways ensures that all areas of campus are involved and bought-in to the reform work that is taking place.

Beyond the staffing and decision making structures that lead the Guided Pathways efforts is an intention to implement innovative interventions that will close equity gaps. Though the equity based frameworks provided by each campus are important to ground the work, none of the interventions mentioned were particularly grounded in improving equity for any specific set of students. Instead, the recommendations from each campus focused on updating the orientation and developing student support/success teams. Just placing the orientation online or updating a few slides to better highlight the services on campus may not be impactful enough to make a true difference. Bode College's use of modules that students receive based on their student type is an attempt to provide students with relevant, specific, and timely information to help clarify information that they need to begin their college journey. 
Additionally, the support and success teams could be beneficial depending on how students are grouped with their team of faculty and staff. However, since the California Community Colleges are open access institutions there will not really be a way to monitor and manage caseloads of special populations. For example, if the support/success teams can only serve a caseload of 200 students, and all 200 students are a member of a specific disproportionately impacted group, the 201st student within that group will now be added to a different caseload. These students that exceed the caseload maximum may start to be added to other existing caseloads or new caseloads of all students that exceeded the maximum, essentially creating a generic pool of students with unique needs. Not unlike the current practice within the CCCs. Each of the colleges included in this study were currently trying to identify their student support/success team structure - perhaps to address this potential issue - so it will be interesting to see the impact of these support/success teams in the future.

Inclusion of student voice in inquiry. All three Guided Pathways campus leads acknowledged the desire increase to outreach and inclusion of student voice within the Guided Pathways implementation. As previously mentioned, both Bode College and Little Streams College hired student assistants to provide support to the work teams as well as serve in a student 
voice capacity. Foggyville College had recently submitted a request for student assistants, though had not hired them as of the start of this study. Even with hired student assistants their roles and involvement within the GP implementation differed at each campus. At LSC the student assistants served in a more clerical role providing administrative support for the GP work teams and personal insights on the recommendations made. This can put a lot of pressure on two students to represent the entire student body. Alternatively at BC the student assistants served as members of the GP work teams and conducted campus surveys to gather feedback on recommendations from the GP work teams. The way in which BC utilizes their student assistants highlights an effort to ensure that diverse student voices are included in the GP reform efforts.

Beyond the student assistants, each college mentioned the use of student focus groups. Bode College focus groups were conducted by CCEAL and were focused on gathering insights from various student types and groups from across campus. Foggyville College held focus groups with local high school seniors and current students to learn more about their utilization of the website as well as gather insights on proposed names of the guided pathways. Additionally, Foggyville held focus groups with the student government to gain insights on the college experiences of their members as well as provide 
information to the members regarding the reform efforts. One outcome of this was the more student government members expressed interest in supporting and serving on the Design Team. Finally, the town hall at Little Streams College was initiated and conducted by the student government. The student led town hall provided students the opportunity to share their stories about their experiences at LSC and provide recommendations to the administrators on how to incorporate changes within the Guided Pathways reform efforts.

Bode College was the only institution in this study to explicitly mention foster youth intentionally being included in the student focus groups. While foster youth students from Little Streams and Foggville may have participated in the focus groups they were not mentioned by the Guided Pathways lead nor in the supporting documents such as the Guided Pathways Scale of Adoption or Student Equity and Achievement Plan, even though foster youth are listed as a disproportionately impacted group on all three campus' Local Vision Goals document. Therefore, my second research question that inquires about the experiences of foster youth is a great opportunity to glean such valuable insights.

RQ2: How can the educational experiences of former foster youth inform the equitable implementation of community college reforms through the Guided Pathways framework? 
In order to answer the second research question across all three cases, I will utilize the same themes identified for the student college practitioner cases. These four themes were: 1) understanding scholars' motivation in pursuing higher education; 2) understanding what's working for foster youth scholars; 3) exploring the areas of opportunity; and 4) hearing scholar recommendations. As a reminder, I was unable to receive responses from foster youth scholars at Bode College. Therefore, this cross-case analysis will only include findings from Little Streams College and Foggyville College.

\section{Understanding scholars' motivation in pursuing higher education.}

Similar to many students that pursue higher education, especially community college, foster youth scholars do so based on both internal and external motivating factors. Many scholars referred to family members, teachers or counselors, social workers, and foster parents as external influencers that encouraged students to pursue college. Many provided referrals to the institution the student was attending based on personal experience or connections with the campus Guardian Scholars Program. Internal motivators included a desire to achieve an academic goal (getting a degree), increasing economic or career mobility, and to change the trajectory of their personal, and family, story. Similar to the findings by Tobolowsky, Scannapieco, Aguiniga, \& Madden (2019), several scholars stated that they wanted to live a better life 
than their parents or they wanted to provide a better life for their children, and they sought out college to open the door to do so.

Understanding what's working for foster youth scholars. At both Little Streams College and Foggyville College, foster youth scholars appreciated having access to support programs such as Next Up/Guardian Scholars Program (GSP). Few, if any, scholars mentioned not being able to access classes because through GSP they had access to priority registration. The only time in which a scholar mentioned not being to access a class that they were planning to take was when they did not take advantage of their priority registration. In addition, the financial and school support that the GSP offers is also valued by the students. The weekly meal vouchers, book vouchers, school supplies, and access to emergency funds were all highlighted as support that foster youth scholars value. Finally, beyond the tangible supports, scholars also valued being able to access counseling through GSP, which often had lower wait times than general counseling, and provided them an opportunity to build relationships with their GSP faculty and staff. These relationships extended beyond GSP and was reflected in the greater campus community as an informal network of trusted faculty and staff. Students at Foggyville College were also appreciative of the physical space that GSP has 
on campus as it offered both a reprieve and safe space for foster youth scholars to receive information and access help when needed.

Exploring the areas of opportunity. While scholars at Foggyville College were grateful to have a dedicated space on campus, scholars at Little Streams College did not. A dedicated space, with permanent staffing, were recommendations from Little Streams scholars as a way to help support foster youth success. Just having space where scholars feel valued and not "overlooked" can promote a sense of belonging and encourage student engagement. For a student population with the lowest historical completion rates, a dedicated space could actually bolster completion rates.

Additionally, scholars also shared that financial and housing insecurity have been significant challenges that threaten persistence and completion. The foster youth scholars that were included in this study were all from different parts of Northern California, which, in general, has a high cost of living no matter the city. While AB12 allows foster youth to remain in foster care, and thus the educational benefits, until they are 21 , not all foster youth have a residence that welcomes that extension. As a result they have to be able to financially provide for themselves in order to secure housing. With such a great responsibility starting at a younger age, school may easily be eliminated from the priority list as scholars have to focus on survival. While colleges may not be 
able to provide subsidized housing for foster youth scholars, though there is currently legislation in the works to do so, there is a request for faculty, staff, and administrators to display empathy when working with foster youth because they are often juggling so many responsibilities.

Foster youth scholar recommendations. The most prevalent recommendation from foster youth scholars was empathy. To understand that foster youth face additional responsibilities outside of just being a student. They have to work, have family obligations, and may still be required to checkin with county officials to maintain their foster youth benefits. The county checkins can often disrupt class attendance and so strict attendance policies may impact scholars' abilities to persist in their courses. Faculty that have displayed empathy towards foster youth scholars are often included on the informal foster youth network of trusted campus supporters. Scholars will take multiple courses with those faculty and recommend their peers to take courses taught by those faculty as well. Leading with empathy creates a safe space for students to really learn and thrive so that they can meet their educational goals. The second recommendation that foster youth scholars made was to provide students with timely and accurate information about the resources on campus. Many scholars, even in this study, did not acknowledge that there was a support program on their campus dedicated to supporting foster youth - even 
though the request for participation was sent through the campus foster youth program. Without clear information to distinguish GSP from other support programs on campus, many foster youth scholars may not be aware that such support exists. Some ways in which campuses could provide this information is through faculty syllabi, through the instructional/course portal, or the student record portal - where students register for classes. Having an announcement feature on the instructional/course portal or student record portal can reach students across campus with intentionality without having to hope that the student happened to either discover the resources on their own or speak to the right faculty or staff member who knew to direct them to GSP.

\section{Cross Case Analysis Summary}

The purpose of this study was to better understand the ways in which college practitioners were implementing equity based reform efforts on their campus, through the Guided Pathways framework. Learning from former foster youth scholars provided an opportunity to hear from students that traditionally have the lowest college completion rates of any other group of students. In evaluating the findings from each of the three campuses, and across the three campuses, there are both similarities in the approach to equitable Guided Pathways implementation, and experiences of foster youth scholars, and there are some stark differences. With regards to the Guided Pathways 
implementation, all three colleges have frameworks grounded in equity. However, simply being grounded in equity does not always translate to operationalizing equity through innovative practices. For example, ensuring that the website and orientation materials were available in Spanish for a Hispanic Serving Institution (HSI) is not necessarily innovative, yet this is one of the ways in which Bode College is attempting to implement equitable practices. Many of the reform efforts being recommended across the three colleges within this study could be referred to as just good practice. Which begs the question, why weren't we doing this before? Though there are potential disconnect between having equity based frameworks and intentions to support equity, and the way in which equity is being operationalized, I don't believe that these campuses were just providing a sort of "equity lip service." Instead, I believe that they have every intention and desire to close equity gaps on their campus, but are, at the point of this research, still in the process of figuring it out. Because many of the interventions appeared to focus on the larger student body population I hope that once the general restructuring of the campus is truly underway, there will be a second wave of initiatives focused solely on the most marginalized populations.

It is, however, encouraging to learn that the campuses have empowered a variety of constituencies to participate in the campus reform efforts. Whether 
serving on a work team or participating in a focus group/town hall, the collaborative effort to include a multitude of voices and experiences in the inquiry and decision making process are promising. The inclusion of diverse participants ensures that simple recommendations such as Spanish materials at an HSI do not go overlooked based on an assumption that the college is already meeting a need. Though the inclusion of diverse campus participants is wonderful, there is a recognition that not all campus constituency voices, such as foster youth, are being heard.

Foster youth scholars have had historically low completion rates for a reason. Beyond the reality that their life circumstances may not have prepared them mentally, socially, or economically to enter college after high school, there is also a reality in which the college campuses have not done enough to welcome and support foster youth scholars throughout their higher education journey. Generic orientations that don't provide specific information about the on campus supports such as Guardian Scholars, or the lack of personnel to help guide scholars through the complicated financial aid system, and faculty that are not empathetic to the complex realities that come with being a foster youth scholars, can all attribute to a foster youth scholar's departure from higher education. While foster youth, as all students, are individuals with intersecting identities, the reality is that the one identifier of "foster youth" has historically 
impacted students in their ability to navigate into and through the higher educational system. As open access institutions, and often the only higher education institution in which a former foster youth in California is eligible to attend, California Community Colleges have a responsibility to ensure that institutional practices and procedures are not creating barriers to student success. In the following chapter I will provide recommendations for educational leaders to consider as they implement Guided Pathways on their campus. The experiences of foster youth scholars will guide my recommendations in order to address issues of equity and attempt to close the equity gap. 


\section{Chapter 8: Summary, Discussion, \& Recommendations \\ Summary}

The California Community College (CCC) system enrolls over 2.1 million students annually (CCLC, 2018). While enrollment and access has been consistently high for decades, completion rates have been relatively low. The statewide two year graduation rate for students earning Associate Degrees is 13\% (PPIC, 2019). The graduation rate increases to 31\% after three years, and to $48 \%$ after six years. For students from vulnerable, or minoritized, populations those averages decrease significantly. This gap in completion rates for minoritized students is often referred to as the "equity gap."

One such population that often falls into this "equity gap" are foster youth. Over $70 \%$ of foster youth in high school express a desire to attend college, however only about $10 \%$ actually do (Salazar, 2012). While the two year completion rate for overall CCC students is just $13 \%$, the completion rate for foster youth, within any time period, is around four percent (Rassen, Cooper, \& Mery, 2010). While foster youth are often categorized as a marginalized population with marginalized populations (National Working Group on Foster Care and Education, 2018), simply having an identity as a foster youth has shown to decrease the probability of continued enrollment in college than any other disadvantaged, or minoritized, group (Frerer, Davis, \& Henke, 2013). 
In an effort to address, and improve, CCC completion rates, CCC Chancellor Eloy Ortiz announced a strategic plan entitled the "Vision for

Success: Strengthening the California Community Colleges to Meet California's Needs." Within the Vision for Success, the Chancellor identified the need to ensure improvements in the way CCCs serve and support the most vulnerable students with the lowest completion rates. The Vision for Success report led to the establishment of new legislation and education codes to help colleges reform and restructure their institutions to better address inequities and close the equity gap. One major component of the Vision for Success is the Guided Pathways framework. The goal of Guided Pathways (GP) is to streamline the student experience so that students are essentially "guided" through their community college experience from onboarding to completion. GP provides colleges with the opportunity to develop structured academic plans for all majors and degree paths, partnerships with local high schools to align curriculum and provide early college exposure opportunities, and student support programs that provide on-time support for students to encourage persistence.

\section{Discussion of Related Findings}

The purpose of this qualitative, cross-case study, was to explore the ways in which CCCs were operationalizing the Vision for Success. Specifically, 
how they were addressing equity within the implementation of the Guided Pathways framework. I had two research questions to guide this study. RQ1: What are the intentional ways in which community college leaders are addressing equity in the implementation of the Vision for Success, through the Guided Pathways framework?

RQ2: How can the educational experiences of former foster youth inform the equitable implementation of $\mathrm{CC}$ reforms?

To answer these questions I conducted a qualitative cross-case study of three community colleges in Northern California: Bode College, Little Streams College, and Foggyville College. These institutions were selected because of their early commitment to implement Guided Pathways. While Foggville College began their exploration of Guided Pathways early on in 2016, Little Streams College and Bode College were members of the California Guided Pathways Project - a 20 college consortium that received professional development surrounding the implementation of GP. Additionally, each campus had an established campus support program for current and former foster youth and listed foster youth as a disproportionately impacted student population on their Local Vision Goals and in their Student Equity and Achievement Plan.

To answer the first research question I conducted a document analysis of each campus' Local Vision Goals, Student Equity Plan (SEP), and Guided 
Pathways Scale of Adoption. I also interviewed the lead Guided Pathways practitioner at each campus. Both the documents analyzed and through the interview with the campus GP lead, each campus established a strong commitment to identify and eliminate equity gaps within their institution. Through the development of multi-stakeholder implementation teams, each campus identified the importance of campuswide buy-in to support the reform efforts. Two campuses also included students within their GP implementation team as student assistants. The students provided relevant insights and feedback on recommendations.

Each campus shared examples of the way in which they were hoping to address issues of equity through their GP implementation. All of the campuses mentioned updating their orientations and onboarding process to better support students. Only one campus mentioned updating orientation so that students receive modules that highlight supports based on their identity or student type. All of the campuses also mentioned the intention to develop student support/success teams, comprised of staff and faculty, to provide timely support for students. Though none of the campuses had yet established their student support/success teams, there was not a clear mention of how these teams would be developed, who would serve on them, or how students might be assigned to them. 
Findings related to this research question underscored the reality that it is incredibly difficult to develop specific interventions to address the unique needs of students. All of the campuses acknowledged the historical inequities that persist in the community colleges as well as their campus' strong dedication to eliminate equity gaps. It didn't appear as though CCs in this study had identified any particular interventions to support specific disproportionately impacted (DI) students. Instead, the interventions and recommendations were more generalized as practices to support all students more intentionally. The purpose of the Vision for Success was to increase the completion rates for DI students, however if none of the interventions are attached to a specific DI population, then I am still curious as to how equity gaps will actually lessen. Furthermore, the Vision for Success is comprised of multiple different initiatives, Guided Pathways being one of many. It could be that there were different interventions proposed on each campus outside of the Guided Pathways work that would better address the needs of DI student populations. Or, it could be that campuses are suffering from "initiative fatigue" - the idea that too many things are happening at once and the buy-in and excitement for the initiative has begun to wane. In speaking with Christine at Foggyville, she alluded to the impact that initiative fatigue has had on the campus especially as it comes to buy in across the campus. 
To answer the second research question I conducted electronic interviews and in-person, paired interviews with foster youth scholars attending Little Streams College and Foggyville College. Scholars that participated in this study shared that they appreciated having the support of the Next Up/Guardian Scholars Program (GSP) and additional programs such as EOPS. The program offers access to academic counseling, priority registration, meal vouchers, transportation vouchers, school supplies, calculators, and more. While having access to GSP and EOPS was beneficial to scholar's ability to access the institutions, they still lacked a sense of community and belonging on campus. Indeed, scholars from both the electronic interview and the paired interviews felt as though they were often overlooked on their campus. Scholars also shared the challenges in accessing information regarding campus resources and activities which added to the lack of campus community. Even finding out about GSP or EOPS seemed to be happenstance. Though there is some information on each college's website about the Next Up/Guardian Scholars Programs, scholars in this study expressed difficulty in finding information about foster youth support programs on campus. Instead, some scholars were referred by their social worker or a faculty member after displaying difficulties in adjusting to college. 
Scholars also expressed a need for more empathy from their campuses. Scholars shared stories of faculty rigidity impacting their academic confidence in college. Scholars may have to make difficult choices to decide between attending class and meeting with their social worker in order to maintain their county benefits. In addition, while foster youth may receive additional financial aid to support their attendance in college, there is a tremendous amount of paperwork that needs to be submitted in order to access these funds. Without empathetic guidance and support the process can be very overwhelming and frustrating for scholars. Having empathetic faculty and staff on campus creates a safe space for scholars to learn, ask questions, and feel invested in the campus community - because they feel as though the campus is invested in them.

\section{Recommendations for Leadership}

Many of the recommended interventions and reform efforts that the campuses in this study proposed started by understanding the experiences and needs of the larger campus populations - what all students are experiencing. These efforts are then taken broadly to update the entire general student experience. My recommendations, however, start with understanding the experiences and needs of the most vulnerable students, identifying what reforms and interventions might be developed, and then expanding those 
efforts to the larger student population. Within Disability Services this is often referred to as Universal Design Learning. Wherein pedagogy and learning environments are created to be accessible to the widest range of users possible by being adaptive and flexible (Rose, Harbour, Johnston, Daley, \& Abarbanell, 2006). The fundamental idea behind UDL is that when you take into consideration the accessibility needs for students that have "non-traditional needs" in the overall design of a course, program, or service, that course, program, or service, now becomes accessible to a greater number of students. It includes both students that could have accessed the course, program, or service without any changes as well as the students who could not have accessed the course, program, or service had there been no changes. Through the use of UDL, schools and higher education, become more accessible to a greater number of students. With this in mind, the recommendations that I provide below focus on identifying the needs of the most vulnerable students, such as foster youth, as a baseline to start the development of equitable reform efforts.

\section{Intentionally include your vulnerable students in GP: Not just the} easy to access students. While all of the campuses in this study conducted student focus groups or town halls to query students about their educational experiences or thoughts on GP recommendations, only one campus mentioned 
holding special sessions for different student types. Many students that attended these sessions were involved in student government and the sessions were held during the day. As such, it is not surprising that almost all scholar respondents stated that they had never heard of Guided Pathways nor had been asked about their opinion on campus reform efforts. Inquiry activities such as these are not bad, however if these are the only opportunities to engage student voice, the voices that will be engaged will be skewed towards the experiences of students that have already identified how to navigate the system (Cook-Slather, 2006). An as example, though all students may go through the matriculation and registration process, the process could be experienced differently based on the student type. Without being able to identify these slight differences by student type the recommendations that are currently being made may continue to leave vulnerable students behind. As Mansfield (2013) stated, historically marginalized students are often the subject of much reform but rarely actors in shaping the reform efforts. Holding focus groups for foster youth, student parents, part-time students, distance education students, student veterans, and any other recognized DI student group might highlight barriers that institutions did not realize were there.

Feeling Welcomed: Create space for your vulnerable students both within GP, specifically, and on campus, generally. To build off of the 
recommendation to include vulnerable students in GP, it would also be beneficial to make physical space for students on campus as well. Scholars in this study at Foggyville College spoke highly of having a physical space to go to to pick up snacks, meet with GSP program staff, and rest in between campus. Having the space allowed them to meet other foster youth scholars and develop a sense of community. Such space could also provide an opportunity for foster youth scholars to access, or at least be introduced to, additional campus resources. These findings support those reported by Hass, Allen, \& Amoah (2014) who suggested that environments that provide safe havens for students contribute to their self efficacy in higher education. Due to the Foster Youth Success Initiative, each campus has a foster youth liaison who is primarily housed in the financial aid office. Imagine if that financial aid liaison could come into the foster youth scholars office to assist with financial aid application completion, or answer questions regarding taxes, dependency status, and CHAFEE grants. Not unlike the participants in research conducted by Sanchez (2004), both Laura and Norma expressed previous feelings of embarrassment in being identified as a foster youth within the larger campus community, so a traditional financial aid workshop open to the general public may not provide the environment where foster youth scholars can feel comfortable to ask questions related to the challenges of completing financial aid while in the foster care 
program. However, having a space where foster youth students can gather on campus provides a sense of safety, welcome, and belonging.

\section{Accessing Information: Update campus website's search}

functionality so that the most relevant findings appear. Several scholars in this study mentioned that it was hard to find relevant information about campus supports and services on their campus website. In fact, some scholars even stated that their campus did not have a program for foster youth. Geiger, Hanrahan, Cheung, \& Lietz (2016), recommend having an updated website with staff contact information, student stories, and key messages as a way to recruit foster youth to the campus support program. While many campuses are updating their websites to display their new academic pathways, now is a great time to also update the student services pages and their search features. If students were to type "foster youth" into the website search bar, what results pop up? Better yet, which results pop up without having to scroll or go beyond the first page? Would getting to the "right" results require an understanding of the campus culture and language - including all of our higher education acronyms? Ensuring that both college websites, including search features, and departmental websites are updated will help foster youth scholars access information in a timely and supportive manner. 
The importance of accessing timely information is not reserved just for students, but is equally important for campus faculty, classified professionals, and administrators. David, the GP Dean, mentioned the establishment of Early Alert system at LSC. Such systems allow for faculty and classified professionals to work together and develop plans to support individual student retention and completion. Having campuswide technology to support faculty and staff collaboration could also contributed to a more streamlined approach for student success.

Case Management: Student Support/Success Teams should include members of the community/county to provide holistic support. Foster youth in this study shared their feelings of food, housing, and economic security. While they were grateful of the campus programs available that could provide some relief, such as the food pantry or working on campus, there are still larger needs beyond what a campus might be able to provide. Tia highlighted a county housing support program for foster youth but also confessed that she did not know much about it, but wished that she did. It might be beneficial for the student support/success teams currently being developed through the GP framework, include members of the community or county that might have additional expertise in supporting special populations. Indeed, Whitman (2018) and Cooper, Rassen, and Mery (2010), suggest that 
students could benefit from partnerships between both campus-based programs and off-campus services, such as mental health or county services, as a holistic approach to student services. Through a Memorandum of Understanding (MOU) a social worker, or representative that works with Transitional Aged Youth, could participate as a member of the support/success team could provide streamlined support for foster youth within the institution. Such a recommendation was also made in Batsche et. al (2014) where the researchers suggested that providing training for both case managers on community college resources and community college personnel on the foster care system could enhance the college-knowledge for all parties involved. Additionally, Franco and Durdella (2018) suggested that providing information to foster parents, supervisors of independent living programs, and social workers can better support foster youth in their transition to college. Similarly with populations such as veterans, having a representative from the Veterans Administration as a member of the student success team could be a tremendous benefit for student veterans. Such collaboration also builds up rapport with influential community agencies who can support the development of a collegiate pipeline for students that have struggled to access higher education in the past. 
Training: Provide Trauma Informed Care and Healing Centered Care training for all members of the campus workforce. The recommendations above are all focused on technical transformations. Updating processes, technology, and developing relationships. While technical transformations will be necessary, equally as important are the transformations within the individuals who lead and work in our institutions. Many faculty are content matter experts. Many staff and classified professionals are expert technicians. Though it is imperative for faculty and staff to continue to be experts in the job that they were hired to do, institutions can also provide trauma informed and healing centered professional development for all campus employees. I would highly recommend that such training be provided for faculty and staff that are members of student support/success teams, especially. Many colleges are already starting to institute equity based trainings, such as unconscious bias training. Trauma Informed and Healing Centered Care trainings can only add to the professional development of educators as we work to better serve all students.

Around $70 \%$ of adults in the U.S. have experienced some type of trauma in their lives (Whiteside McDonnell, n.d.). Individuals from low-income households and communities of color - especially African American and Latinx - are more likely to experience some form of trauma in their lives than wealthy 
or White households (Ridgard, Laracy, DuPaul, Shapiro, \& Power, 2015). When individuals experience trauma it negatively impacts their sense of self, trust in others, and beliefs about the world (Institute on Trauma and TraumaInformed Care [ITTIC], n.d.). When students experience educational trauma, they can form a mistrust in educators and educational systems. Trauma informed care is an approach to providing services and supports for individuals by recognizing and acknowledging the whole person (ITTIC, n.d.). Trauma informed care has five grounding principles: safety, choice, collaboration, trustworthiness, and empowerment. These five grounding principles develop a framework for educators to reduce the likelihood of retraumatizing students. Dwarsky and Pérez, suggest that educators who work with foster youth "need to understand and be prepared to address the unique challenges encountered by foster youth" (2010, pp. 25). Ridgard et. al., suggest that providing trauma informed care training to school employees can help to change the culture, policies, and procedures that traditionally govern the school (2015). When all employees have trauma informed care training, they will be able to recognize signs of trauma, respond appropriately to the student, and engage without retraumatizing the student. Having this understanding of trauma can provide faculty and staff with one set of tools needed to support students that have experienced trauma. The other set of tools comes with healing centered care. 
Trauma informed care training provides educators with tools to identify trauma and respond to displays of trauma immediately (i.e. a student yelling at the admissions counter because they are frustrated after a series of miscommunications). However, one critique of trauma informed care is that it can be deficit based and educators could then take on a savior complex seeking to "fix" all of the students that have experienced trauma rather than empower them. Instead of grounding in deficits, healing centered care is grounded in self-affirmation and empowerment of individuals and communities (Ginwright, 2018). Tobolowsky et. al's study found that even child protective workers, many of whom are trained in trauma informed practices, can sometimes automatically place a negative connotation on foster youth simply because they are in the foster care system (2019). Healing Centered Care shifts the focus from the trauma of the past to the strengths of the individual and how they can be agents of change within their communities. Culture is a large part of healing centered practices as it can ground individuals with a sense of purpose, self-perception, and meaning - all individual aspects that are stripped when one experiences trauma. Healing is a communal practice that is shaped in communities with shared identities. With this in mind, it would be beneficial for individuals on student support/success teams, especially those that are 
intended to work with vulnerable populations, to undergo Healing Centered Care training in addition to Trauma Informed Care training.

\section{Recommendations for Policymakers}

The California Community Colleges Chancellor's Office (CCCCO) launched the Vision for Success with the help of a number of experts from across the state. However, in looking at the expert list it did not appear as though any experts from organizations that support foster youth, or any other organization/group that supports vulnerable populations were included in the development of the Vision for Success. For future systemwide mandates, the CCCCO could collaborate with the Foster Youth Success Initiative liaisons and foster youth advocacy groups to ensure that the experiences of foster youth are being included at the onset of the decision making. Alternatively, providing an opportunity for foster youth students to serve on an advisory board would also capture helpful information to inform systemwide decisions.

In 2015, California College Pathways, with sponsorship from the John Burton Foundation for Children without Homes, published a report entitled No Time to Lose: A Policy Agenda to Support College Success for Foster Youth. In the report they acknowledged that California has established several laws to support the educational aspirations of foster youth in the K-12 system. They advocate that policy makers should also focus on supporting foster youth in the 
CA public postsecondary education systems. While some of the recommendations that they proposed in the report have since been enacted, there are still areas of opportunity that are outstanding. One such proposal was with regard to the increase of financial aid.

Many students in this study expressed gratitude for the financial aid that they received. However, they also expressed the need to work in order to "survive" in California; one student shared that she lived in her van. It would be incredibly beneficial for legislators to review the current state aid allocations for the Cal Grant and Chaffee grant and provide adjustments for foster youth that have dependents and are living on their own. It would be especially helpful to take cost of living by region into consideration when determining the allocation as certain parts of the state are more expensive to live in than others. Additionally, legislators could provide opportunities for colleges to either construct student housing or enter agreements with local housing facilities to provide housing for foster youth and homeless students. As Alina recommended, students could utilize their work-study or CalWORKs approval to work within the residential facilities as paraprofessional student staff and off-set housing costs. 


\section{Recommendations for Future Research}

There are two major recommendation strands for future research that extend from this study on the equitable implementation of Guided Pathways (GP) in CCC. The first is to continue to conduct research on GP implementation. The second is to continue to conduct research to understand the experiences of foster youth attending community colleges.

Research on Guided Pathways implementation. As of the writing of this dissertation, spring 2020, Guided Pathways is still a relatively new concept in the California Community Colleges. So new that very few colleges have fully implemented GP on their campus, or completed their campus redesign efforts. As such, more research will need to be conducted to better understand the actual impact of GP on overall student completion, the impact of GP on closing equity gaps, the impact of different GP structures on student completion, the inclusion of student voice within GP implementation, and the approach to GP implementation with a focus on leadership and decision making, as examples. Additionally, while this study was focused on the voices of foster youth, similar studies could be conducted to better understand the experiences of other vulnerable student populations within the CCC in respect to GP implementation.

Experiences of foster youth in community colleges. Though it's been recorded that many foster youth begin their educational journey at 
community colleges, there is relatively nothing published highlighting these experiences. Without these published accounts, foster youth at community colleges will continue to feel overlooked as practitioners rely on "evidence" from research to guide their work. In fact, there were several times during my conversations with foster youth scholars where they thanked me for even wanting to ask them questions and learn more about their experiences; attesting to that constant feeling of being overlooked. Therefore, there is a tremendous amount of opportunity to continue research on the experience of foster youth within community colleges. Specifically within the Guided Pathways realm, additional research could evaluate the impact of foster youth programs such as Next Up/Guardian Scholars Program, on scholar outcomes; the impact of Guided Pathways on community college access and completion for foster youth; the impact of early college programs and dual enrollment on access to community colleges for foster youth; the impact of $A B 705$ and updated placement requirements on foster youth college persistence and completion; or the impact of student support/success teams in community colleges on foster youth completion.

Small sample sizes of foster youth may continue to be a challenge for future research. However, there may be opportunities to increase sample sizes through the use of mixed-method especially when evaluating the impact of GP 
for foster youth across the entire CCC system which includes 115 colleges. Additionally, the future studies might disaggregate foster youth students by race, gender, student parents, working while enrolled, or placement type, in order to better understand the impact of foster youth intersectionality on access, persistence, and enrollment.

\section{Final Reflection}

I finished this dissertation in the midst of the Spring 2020 COVID-19 Pandemic. As of the writing of this chapter I am entering my fourth week of a shelter-in-place ordered for the Bay Area with no determined lift date. While the shelter-in-place has interrupted my daily schedule, my focus, and at times motivation to write my dissertation, that has been the extent to my disruptions. I am incredibly grateful and blessed to have secure employment where I continue to advocate for community college students from the comfort of my desk or couch in my humble apartment. I share that to say, I am fully aware that the scholars that I spoke with for the purpose of this study are likely having a significantly different experience. Many of the scholars spoke about needing to prioritize work in order to support themselves. They also highlighted the importance of the on campus support of the Next Up/Guardian Scholars Program and campus food pantries where they can access food weekly. One scholar even expressed the reality of living in her van. 
As we transitioned our campuses to support online learning, I immediately thought of Alina, Laura, Adam, Jeff, Tia, Norma, Karrie and all of the students that completed the electronic interviews. If scholars were feeling overlooked before, how are they faring now? If our campuses are physically closed, where is Alina able to study and attend classes online? Can Karrie and Jeff access their disability resource center accommodations? Do our scholars, including Laura and Norma who both stated that they use the food pantry on campus, have access to food? Are they still working? If they are, is it safe? While I understand that our colleges are not able to serve all needs for all students all the time, tremendous shifts in delivery of service, which was the result of the COVID-19 Pandemic, exacerbate the inequities that already existed.

I find myself in leadership meetings where we are trying to meet students' needs, reminding my colleagues that while our intentions to provide support for students is noble, we have to take into consideration our most vulnerable students when identifying the process to do so. Sure, we can mail out grocery store gift-cards to students that have mentioned that they are food insecure, but the reality is not all students have an address. Or the address that they have isn't safe to send mail. Or it's changed three times since they first registered for classes. I do recognize that our foster youth, and homeless, 
scholars are small populations on college campuses. However, it is during times such as these when our smallest, most vulnerable populations that are being hit the hardest. And the reality is that unless we really want to move the needle, we have to take these scholars into consideration as we make decisions to improve student success.

I know, read: hope, that our current pandemic will pass and we will be back at our institutions sooner than later. However, I hope that things do not go back to normal. Because "back to normal" was already not working for so many of our students - especially our foster youth. I hope that in spite of this incredible disruption to our higher education institutions, college leadership, faculty, and classified professionals can take this time to rethink the way in which education has to be. Because, again, what it has been is not working. Guided Pathways gave us an opportunity to rethink academic plans and pathways from onboarding to graduation. COVID gave us an opportunity to rethink what college looks like, where college takes place, and who has the privilege to access college - and why/how such privilege exists in the first place. Within this past month I have witnessed colleges become more innovative and committed to equity than ever before. The weekly announcements from the CCC Chancellor's Office highlighting campuses hosting drive-through food pick-ups for community members, setting up 
systems to ensure that all students have access to computers and internet free of charge, establishment of free online telehealth services, including mental health support, and setting up phone trees where each student, faculty, and staff member is checked on to ensure that they are safe, healthy, and to let them know the campuses are still "here" to support them.

In the second week of the shelter-in-place order, my sister sent me a series of instagram posts by @_cuban_link (not an endorsement) who addressed many of our new found realities.

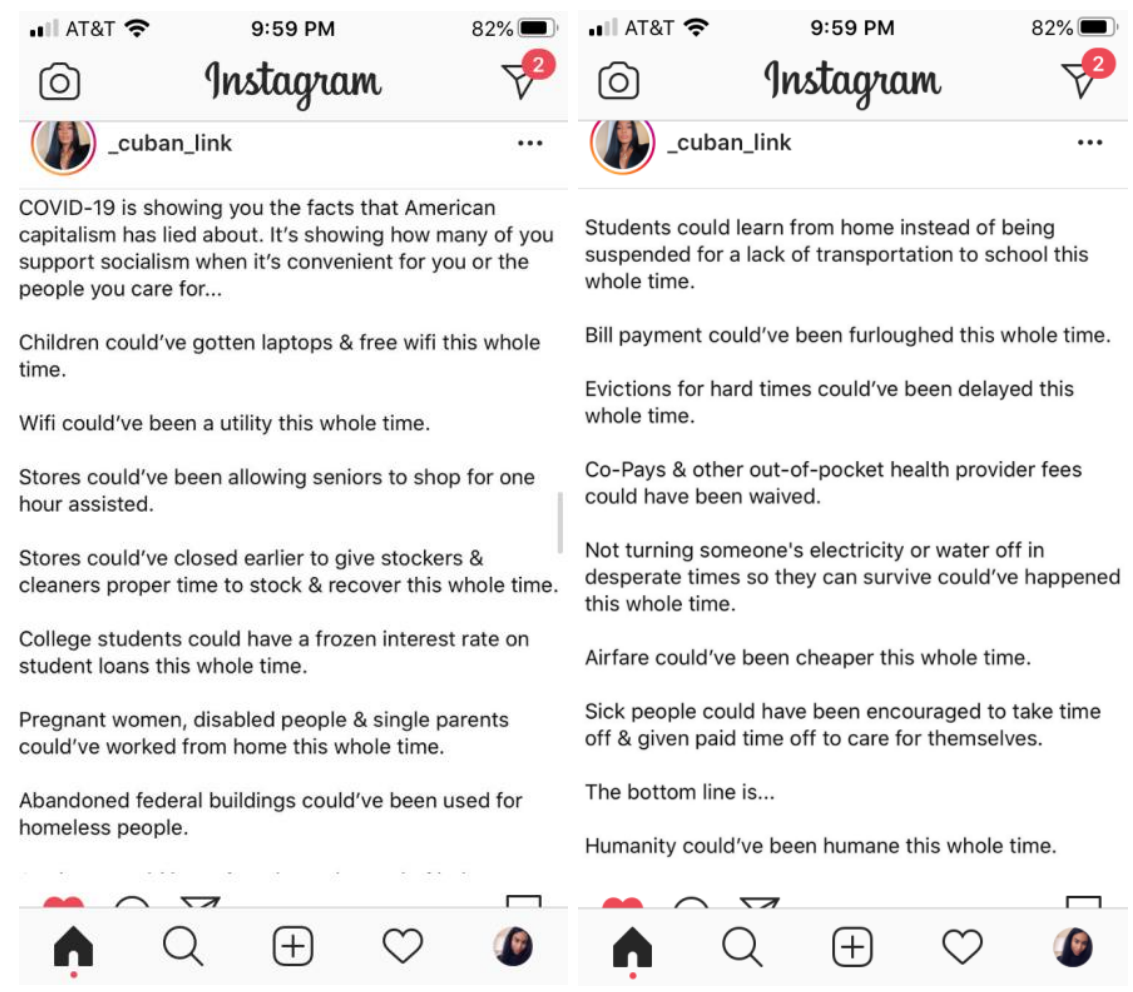

Figure 15. @_cuban_link Instagram Post Re:COVID-19 
While her blame of these new realities on capitalism is not the focus of this particular study, I do think that she makes valid points. Maybe we could have provided free laptops and wifi for each student in our institution, maybe we could have repurposed abandoned buildings to provide shelter for our unhoused and homeless, maybe students could have learned from home instead of being dismissed from school. Maybe a part of the Guided Pathways framework includes these questions as well. And if it does, with a little humanity and empathy, then maybe that needle will actually move. 


\section{References}

Academic Senate for California Community Colleges. (2014). Multiple measures in assessment: The requirements and challenges of multiple measures in California Community Colleges. Retrieved from: https://www.asccc.org/papers/multiple-measures-assessmentrequirements-and-challenges-multiple-measures-california.

Alliance for Children's Rights. (2013). Know before you go: Graduation under AB 167/216. Retrieved from: http://kids-alliance.org/wpcontent/uploads/2013/07/Graduation-Under-AB-2014-Web.pdf.

American Association of Community Colleges. (2017). Fast facts 2017.

Washington, DC. https://www.aacc.nche.edu/wpcontent/uploads/2017/09/AACCFactSheet2017.pdf.

Bailey, T., Jaggars, S., \& Jenkins, D. (2015). Redesigning America's Community Colleges: A Clearer Path to Student Success. Cambridge: Harvard University Press.

Basic Skills Initiative. (2007). Basic Skills as a foundation for student success in California Community Colleges. Retrieved from: http://www.cccbsi.org/Websites/basicskills/Images/BasicSkills_booklet -2.pdf. 
Batsche, C., Hart, S., Ort, R., Armstrong, M., Strozier, A., Hummer, V. (2014). Child and Family Social Work, 19, 174-184.

Bowen, G. (2009). Document analysis as a qualitative research method. Qualitative Research Journal, 9(2), 27-40.

California Chafee Grant for Foster Youth. (n.d.). https://www.chafee.csac.ca.gov/. California Community Colleges. (2019). CalWORKs Program Guide. Retrieved from: https://calworksassociation.org/wpcontent/uploads/2019/10/Cal-WORKs-Program-Guide.pdf. California Community Colleges Chancellor's Office. (2006). Foster youth success initiative student success orientation framework: Helping students achieve their dreams. Sacramento, CA: Author. Retrieved from https://extranet.cccco.edu/Portals/ 1/SSSP/FYSI/FYSI Student Success Framewok.pdf California Community College Chancellor's Office. (2011). The California Community Colleges launch task force to boost completion rates over next decade [Press Release]. Retrieved from: http://californiacommunitycolleges.cccco.edu/Portals/0/DocDownloads /PressReleases/Announcement\%20of\%20Student\%20Success\%20T ask\%20Force\%20FINAL\%202\%20\%281-18-11\%29.pdf. 
California Community College Chancellor's Office. (2012). Gov. Brown signs Student Success Act of 2012 into law, ushering in improvements at California Community Colleges [Press Release]. Retrieved from: http://extranet.cccco.edu/Portals/1/SSSP/Matriculation/SB1456Studen tSuccessActOf2012/PressReleaseSB1456StudentSuccessActOf2012 SignedGov.pdf.

California Community Colleges Chancellor's Office. (2017a). Vision for Success: Strengthening the California Community Colleges to Meet California's Needs, 1-57. Retrieved from http://californiacommunitycolleges.cccco.edu/Portals/O/Reports/vision-forsuccess.pdf.

California Community Colleges Chancellor's Office. (2017b). AB 19 (Santiago) - California College Promise Chapter 735, Statues of 2017 Summary. Retrieved from: http://californiacommunitycolleges.cccco.edu/Portals/0/GovRelations/ enacted-bills/ab-19-summary.pdf.

California Community Colleges Chancellor's Office. (2017c). AB 705 (Irwin) - Seymour-Campbell Student Success Act of 2012: Assessment. Chapter 745, Statues of 2017 Summary. Retrieved from: 
http://www.californiacommunitycolleges.cccco.edu/Portals/0/GovRelat ions/Enacted-Bills/ab-705-summary.pdf.

California Community Colleges Chancellor's Office Management Information Systems Data Mart. (2019). Special Population/Group Student Count Parameter Selection Area. Retrieved from: https://datamart.cccco.edu/Services/Special_Pop_Count.aspx.

California Community Colleges Chancellor's Office, Student Success Metrics. (2019). Student Type - All Students. Retrieved from: https://www.calpassplus.org/LaunchBoard/Student-Success-Metrics.aspx. California Student Aid Commission. (n.d.). California Chafee Grant for Foster Youth: Free Money for Foster Youth for College or Career Training. Retrieved from: https://www.chafee.csac.ca.gov/.

Carnevale, A. P., Smith, N., \& Strohl, J. (2013). Recovery: Job Growth and Education Requirements through 2020. Washington, DC. Retrieved from https://1gyhoq479ufd3yna29x7ubjn-wpengine.netdna-ssl.com/wpcontent/uploads/2014/11/Recovery2020.FR_.Web_.pdf.

Charmaz, K. (2014). Constructing grounded theory (2nd ed.). Thousand Oaks, CA: Sage.

Cook-Sather, A. (2006). Sound, presence, and power: "Student voice" in educational research and reform. Curriculum Inquiry, 36, 356-390. 
Cooks, J. (class lecture fall 2017).

Cooper, D., Mery, P., \& Rassen, E. (2008). Serving former foster youth in California community colleges: Successes, challenges, and recommendations.

Berkeley, CA: Center for Student Success Research and Planning Group for California Community Colleges.

Courtney, M. E., Dworsky, A., Brown, A., Love, K., \& Vorhies, V. (2011). Midwest Evaluation of the Adult Functioning of Former Foster Youth : Outcomes at Age 26. Chapin Hall, Chicago, IL.

Courtney, M.E., Terao, S., \& Bost, N. (2004). Midwest Evaluation of the Adult Functioning of Former Foster Youth: Conditions of the Youth Preparing to Leave State Care. Chicago:Chapin Hall Center for Children at the University of Chicago.

Creswell, J. W. (2004). Research design, 425-448.

Dadgar, M., Smith-Arillaga, E., Buck, D., Sinclair, B., Fischerhall, C., \& Brown, K. (2017).Bringing Student Voices to Guided Pathways Inquiry and Design. Oakland, CA: Career Ladders Project. Retrieved from: https://cccgp.cccco.edu/Portals/0/Bringing-Student-Voices-to-GuidedPathways-Inquiry-and-Design.pdf. 
Dworsky, A., \& Pérez, A. (2010). Helping former foster youth graduate from college through campus support programs. Children and Youth Services Review, 32(2), 255-263.

EAB. (2016). How meta-majors guide students toward on-time graduation.

Retrieved from: https://eab.com/insights/daily-briefing/student-success/howmeta-majors-guide-students-toward-on-time-graduation/.

Foundation for California Community Colleges. (2016). California Guided Pathways Project. Retrieved from: https://www.caguidedpathways.org/

Franco, J., Durdella, N., (2018). The influence of social and family backgrounds on college transition experiences of foster youth. New Directions for Community Colleges, 181, 69-80.

Frerer, K., Davis Sosenko, L., Henke, R. R. (2013). At greater risk: California foster youth and the path from high school to college. San Francisco, CA: Stuart Foundation.

Fullan, M. (1994). Coordinating top-down and bottom-up strategies for educational reform. In R. J. Anson (Eds), Systemic Reform: Perspective and Improvement (pp. 7-23). Washington, D.C.: Office of Educational Research and Improvement.

Gerring, J. (2007). Case study research: Principles and practices. New York: Cambridge University Press. 
Gibson, F. (2007). Conducting focus groups with children and young people: strategies for success. Journal of research in nursing, 12(5), 473-483.

Geiger, J. M. \& Beltran, S. J. (2017). Outcomes and experiences of foster care alumni in postsecondary education: A review of the literature. Children and Youth Services Review, 79, 186-197.

Geiger, J. M., Hanrahan, J. E., Cheung, J. R., Lietz, C. A. (2016). Developing an on-campus recruitment and retention program for foster care alumni. Children and Youth Services Review, 61, 271-280.

Ginwright, S. (2018). The future of healing: Shifting from trauma informed care to healing centered engagement. Medium. https://medium.com/@ginwright/the-future-ofhealing-shifting-from-trauma-informed-care-to-healing-centeredengagement-634f557ce69c.

Goldrick-Rab, S., Richardson, J., \& Hernandez, A. (2017). Hungry and homeless in college: Results from a national study of basic needs insecurity in higher education. Madison: WI: Wisconsin HOPE Lab. Retrieved from http://wihopelab.com/publications/Hungry-and-Homeless-in-CollegeReport.pdf. 
Grigorieff, M. (2016). Dispossessing Educational Equity: A Critical Exploration of California's Community College Student Success Act. Journal of Critical Education Policy Studies, 14(1),144-167.

Groves, R. M., Singer, E., \& Corning, A. (2000). Leverage-saliency theory of survey participation: Description and an illustration. Public Opinion Quarterly, 64(3), 299-308.

Gunn-Wright, R. (Guest speaker). (2019, March 28). The Ezra Klein Show [Audio podcast]. Retrieved from: https://megaphone.link/VMP6171901858.

Harbour, C. P., \& Smith, D. A. (2016). The completion agenda, community colleges, and civic capacity. Community College Journal of Research and Practice, 40(2), 100-112. https://doi.org/10.1080/10668926.2014.996923

Harris, M. S., Jackson, L. J., O’Brien, K., \& Pecora, P. J. (2009).

Disproportionality in education and employment outcomes of adult foster care alumni. Children and Youth Services Review, 31, 1150-1159.

Haskins, J. (2016, July 26). How meta majors guide students toward ontime graduation. Retrieved from: https://www.eab.com/dailybriefing/2016/07/26/how-meta-majors-guide-students-toward-on-timegraduation. 
Hass, M., Qllen, Q., Amoah, M. (2014). Turning points and resilience of academically successful foster youth. Children and Youth Services Review, 44, 387-392.

Head, E. (2009). The ethics and implications of paying participants in qualitative research. International Journal of Social Research Methodology, 12(4), 335344.

Horn, L. J., \& Carroll, C. D. (1997). Confronting the odds: Students at risk and the pipeline to higher education. Washington, DC: U.S. Department of Education.

IEPI Guided Pathways. (2018). Collecting student voices for guided pathways inquiry and design: Why do it, how it works, and what it looks like in action. Sacramento, CA: California Community Colleges Chancellor's Office. Retrieved from: http://cccgp.cccco.edu/Portals/0/Student-Voices-Inquiry-Guide-FinalMar13.pdf.

Institute on Trauma and Trauma-Informed Care [ITTIC] (n.d.). What is trauma-informed care? Retrieved from: http://socialwork.buffalo.edu/social-research/institutescenters/institute-on-trauma-and-trauma-informed-care/what-is-traumainformed-care.html. 
Isenberg, S. (2018). Case Study: NOVA software platform designed/developed by productOps to increase student success rates. Santa Cruz Tech Beat. Retrieved from:

http://www.santacruztechbeat.com/2018/11/27/case-study-novasoftware-platform-designed-developed-by-productops-to-increasestudent-success-rates/.

Jenkins, D., Lahr, H., Fink, J., \& Ganga, E. (2018). What we are learning about guided pathways. Retrieved from: https://ccrc.tc.columbia.edu/publications/what-we-are-learningguided-pathways.html.

Karp, M. J. M., \& Bork, R. J. H. (2012). “They Never Told Me What to Expect, So I Didn't Know What to Do": Defining and Clarifying the Role of a Community College Student. Community College Research Center Columbia University, (116)47.

Kelly, B., Margolis, M., McCormack, L., LeBaron, P. A., \& Chowdhury, D. (2017). Field Methods, 29(4), 333-350.

Kinarsky, A. (2017). Fostering success: Understanding the experience of foster youth undergraduates. Children and Youth Services Review, $81,220-228$. 
Knifong, D. (n.d.). Listening to Students: Project summary and process. Retrieved from: https://www.csus.edu/saseep/ListeningSurvey/Project\%20Summary\% 20and\%20Process.pdf.

Kohoutek, J. (2013). Three decades of implementation research in higher education: Limitations and prospects of theory development. Higher Education Quarterly, 67(1), 56-79.

Legislative Analyst's Office. (2016, February 5). Overview of community college basic skills programs. Retrieved from: https://lao.ca.gov/handouts/education/2016/Basic-SkillsPrograms-020516.pdf.

Lipsky, M. (1980). Street level bureaucracy: Dilemmas of the individual in public services. New York, NY: Russell Sage Foundation.

Lodge, C. (2005). From hearing voices to engaging in dialogue: Problematising student participation in school improvement. Journal of Educational Change, 6(2), 125-146.

Mansfield, K. C. (2014). How listening to student voices informs and strengthens social justice research and practice. Educational Administration Quarterly, 50(3), 392-430. 
McNair, T. B., Albertine, S., Cooper, M.A., McDonald, N., \& , Major Jr., T. (2016). Becoming a student-ready college : A new culture of leadership for student success. Retrieved from https://ebookcentral.proquest.com

Merdinger, J. M., Hines, A. M., Osterling, K. L., \& Wyatt, P. (2005). Pathways to college for Former Foster Youth: Understanding factors that contribute to educational success. Child Welfare, 84(6), 867-896.

Merriam, S. B. (1998). Qualitative Research and Case Study Applications in Education. Revised and Expanded from Case Study Research in Education. San Francisco, CA: Jossey-Bass Publishers.

Mitra, D. (2004). The significance of students: Can increasing "student voice" in schools lead to gains in youth development? Teachers College Record, 106(4), 651-688.

Morris, C. (2017). From foster care to higher ed. Diverse Issues in Higher Education, 34(19).

Museus, S., Lee, N., Calhoun, K., Sánchez-Parkinson, L., \& Ting, M. (2017). The Social Action, Leadership, and Transformation (SALT) Model. Retrieved from https://www.indiana.edu/ cece/wordpress/wpcontent/uploads/2018/01/Museus-et-al-2017-SALT-Model-Brief.pdf. National Working Group on Foster Care and Education. (2018). Fostering success in education: National factsheet on the educational outcomes of 
children in foster care. Retrieved from: http://fosteringchamps.org/wpcontent/uploads/2018/04/NationalEducationDatasheet2018-2.pdf.

Okpych, N. J., \& Courtney, M. E. (2014). Does education pay for youth formerly in foster care? Comparison of employment outcomes with a national sample. Children and Youth Services Review, 43, 18-28. https://doi.org/10.1016/j.childyouth.2014.04.013.

Pecora, P. J. (2012). Maximizing educational achievement of youth in foster care and alumni: Factors associated with success. Children and Youth Services Review, 34, 1121-1129. https://doi.org/10.1016/j.childyouth.2012.01.044.

Pecora, P. J., Kessler, R. C.,Williams, J., O'Brien, K., Downs, A. C., English, D., White, C. R., Hiripi, E., Wiggins, T., \& Holmes, K. (2005). Improving family foster care: Findings from the Northwest Foster Care Alumni Study. Seattle, WA: Casey Family Programs www. Casey.org.

Pecora, P. J., Williams, J., Kessler, R. C., Hiripi, E., O'Brien, K., Emerson, J., Herrick, M. A., Torres, D. (2006). Assessing the educational achievements of adults who were formerly placed in family foster care. Child \& Family Social Work, 11, 220-231.

Piel, M. H., \& Lacasse, J. M. (2017). Responsive engagement in mental health services for foster youth transitioning to adulthood. Journal of Family Social Work, 20(4), 340-356. https://doi.org/10.1080/10522158.2017.1348115 
Pingel, S., Parker, E., \& Sisneros, L. (2016). Free Community College: An approach to increase adult student success in postsecondary education. Education Commission of the States. Retrieved from: https://www.ecs.org/wp-content/uploads/Free-Community-College-Anapproach-to-increase-adult-student-success-in-postsecondary-education.pdf.

Rassen, E., Cooper, D. M., \& Mery, P. (2010). Serving Special Populations: A Study of Former Foster Youth at California Community Colleges. Journal of Applied Research in the Community College, 17(2), 24-34. Retrieved from http://newforums.metapress.com/index/W4427374G7X7847L.pdf.

Raucher, D., Tran, C., Lemley, A. (2015). No time to lose: A policy agenda to support college success for foster youth. California College Pathways Project. Retrieved from: http://www.cacollegepathways.org/wpcontent/uploads/2015/12/no_time_to_lose_-_final_single_page_0.pdf.

Ridgard, T. J., Laracy, S. D., DuPaul, G. J., Shapiro, E. S., \& Power, T. J. (2015). Trauma-informed care in schools: A social justice imperative. Bethesda: National Association of School Psychologists. Retrieved from http://jpllnet.sfsu.edu/login?url=https://search-proquestcom.jpllnet.sfsu.edu/docview/1731542953?accountid=13802 
Rios, S. J., \& Rocco, T. S. (2014). From Foster Care to College: Barriers and Supports on the Road to Postsecondary Education. Emerging Adulthood, 2(3), 227-237. https://doi.org/10.1177/2167696814526715.

Rose, D. H., Harbour, W. S., Johnston, C. S., Daley, S. G., Abarbanell, L. (2006). Universal design for learning in postsecondary education: Reflections on principles and their application. Journal of Postsecondary Education and Disability, 19(2), 135-151.

Sabatier, P. A. and Mazmanian, D. A. (1980) The implementation of public policy: a Framework of analysis. Policy Studies Journal, 8(4/2), p. 538-560.

Salazar, A. M. (2012). Supporting college success in foster care alumni: Salient factors related to postsecondary retention. Child Welfare, 91(5), 139-167.

Salazar, A. M. (2013). The value of a college degree for foster care alumni: Comparisons with general population samples. Social Work (United States), 58(2), 139-150. https://doi.org/10.1093/sw/swt014.

Saldaña, J. (2014-07-01). Coding and Analysis Strategies. In The Oxford Handbook of Qualitative Research. : Oxford University Press, P. Leavy Eds. Retrieved from https://www.oxfordhandbooks.com/view/10.1093/oxfordhb/9780199811755. 001.0001/oxfordhb-9780199811755-e-001. 
Sanchez, R. (2004). Youth perspectives on permanency. Retrieved from: http://www.familyfinding.org/assets/files/YouthPerspectives.pdf.

Seidman, I. (2013) Interviewing as Qualitative Research: A Guide for Researchers in Education and the Social Sciences. Teachers College Press, New York.

Shields, C. M. (2010). Transformative leadership: Working for equity in diverse contexts. Educational Administration Quarterly, 46(4), 558-589. https://doi.org/10.1177/0013161X10375609.

Singer, E. \& Bossarte, R. M. (2006). Incentives for survey participation: When are they "coercive"? American Journal of Preventative Medicine, 35(5), 411-418.

St. John, E. P. (2012). Academic capital formation: An emergent theory. In R. Winkle- Wagner, E. P. St. John, \& P. Bowman (Eds.), Expanding postsecondary opportunity for underrepresented students: Theory and practice of academic capital formation (pp. 3-28). New York, NY: AMS Press, Inc.

Strolin-Goltzman, J., Woodhouse, V., Suter, J., \& Werrbach, M. (2016). A mixed method study on educational well-being and resilience among youth in foster care. Children and Youth ServiceReview, 70, 30-36. https://doi.org/10.1016/j.childyouth.2016.08.014.

Sarubbi, M., Parker, E., \& Sponsler, B. (2016). Strengthening policies for foster youth postsecondary attainment. Denver, CO: Education Commission of the 
States. Retrieved from https://www.ecs.org/strengthening-policies-for-fosteryouth- postsecondary-attainment/.

Theoharis, G. (2007). Social Justice Educational Leaders and Resistance: Toward a Theory of Social Justice Leadership. Educational Administration Quarterly, 43(2), 221-258. https://doi.org/10.1177/0013161X06293717.

Troia, J., Woodward, S., Bussiere, A., \& Ramiu, M. (2006). Frequenty asked questions \& answers about AB 490. California Foster youth Education Task Force. Retrieved from: http://www.cfyetf.org/uploads/AB\%20490\%20FAQs06.pdf.

Tobolowsky, B. F., Scannapieco, M., Aguiniga, D. M., Madden, E. E. (2019). Former foster youth experiences with higher education: Opportunities and challenges. Children and Youth Services Review, 104, 1-11. https://doi.org/10.1016/j.childyouth.2019.05.039.

Webster, D., Lee, S., Dawson, W., Magruder, J., Exel, M., Cuccaro-Alamin, S., Putnam-Hornstein, E., Wiegmann, W., Saika, G., Chambers, J., Min, S., Randhawa, P., Hammond, I., Sandoval, A., Yee, H., Benton, C., White, J., Lee, H., \& Morris, N. (2019). CCWIP reports. Retrieved 3/26/2019, from University of California at Berkeley California Child Welfare Indicators Project website. URL: <http://cssr.berkeley.edu/ucb_childwelfare>. 
Wilson, A., Onwuegbuzie, A., \& Manning, L. (2016). Using Paired Depth Interviews to Collect Qualitative Data. The Qualitative Report, 21(9), 1549-1573.

Yin, R., \& Campbell, D. (2018). Case study research and applications: Design and methods (Sixth ed.). Thousand Oaks, California: SAGE Publications.

Whiteside McDonell, E., (n.d.). Advancing trauma informed research education \& practice [Infographic]. Retrieved from: https://www.barry.edu/center-forhuman-rights-social-justice/advancing-trauma-research.html.

Whitman, K. (2018). Personal perspectives on providing services to foster youth. New Directions for Community Colleges, 181, 81-90. doi: 10.1002/cc.20294.

Yosso, T. J. (2005). Whose culture has capital? A critical race theory discussion of community cultural wealth. Race Ethnicity and Education. https://doi.org/10.1080/1361332052000341006. 


\section{Appendix A}

\section{Practitioner Interview Questions}

1. What is your college's current Guided Pathways structure? nd what is your role in it? Structure along the 4 pillars of GP. Each pillar has a different workgroup. Each workgroup has a tri-chair focus which includes a classified, faculty, and manager.

2. What is your college's current Guided Pathways structure? There is mention of aligning GP with participatory governance structure - are any students included in this process?

3. Why did [your college] sign up to participate in the CA Guided Pathways Project?

4. How did you get campus buy-in during your approach to Guided Pathways?

5. How do decisions get made within the Guided Pathways work?

6. What are the different workgroups, how do they work together, and who are on the workgroups? Are there any students? Who are the students?

7. In looking at the Spring 2018-Summer 2019 Guided Pathways assessment on NOVA, I had a few questions and was hoping that you might be able to provide some answers. Questions varied by campus

8. In looking at the 2018 Local Vision Goals on NOVA, I had a few questions and was hoping that you might be able to provide some answers. Questions varied by campus 
9. In looking at the 2018 Student Equity and Achievement Plan on NOVA, I had a few questions and was hoping that you might be able to provide some answers. Questions varied by campus 


\title{
Appendix B
}

\author{
Practitioner Interview E-Mail Invitation
}

Dear (name),

My name is Lauren Ford and I am a graduate student at San Francisco State University. My research is based on the reform efforts that are currently taking place within the California Community College system, specifically within the Vision for Success. You have received this email because you are listed as a member of your campus Guided Pathways team.

I am interested in learning about the ways in which community college practitioners are approaching Guided Pathways implementation. I'm specifically interested in learning more about your inquiry process and the recommended interventions that your campus is proposing in an effort to implement Guided Pathways and address issues of equity.

I would love to schedule an interview with you to discuss the Guided Pathways implementation at (enter college name). The interview will take place via zoom and could last up to an hour. Here is a link to schedule the interview at a time that works best for you between October 14 - November 1, 2019.

This study was approved by the Institutional Review Board (IRB). If you have any questions, please feel free to contact me directly.

Thank you, in advance, for your support.

\author{
Lauren Ford \\ Doctoral Candidate - Educational Leadership \\ San Francisco State University \\ Iford2@mail.sfsu.edu / ford.lauren.n@gmail.com \\ 513.290 .0394 \\ Meeting URL: https://www.meetingbird.com/m/Hkgtoy-tS
}




\title{
Appendix C
}

\author{
Foster Youth Scholar E-Mail Invitation to Participate
}

Dear [Foster Youth Liaison],

My name is Lauren Ford and I am a graduate student at San Francisco State University. My research is based on the reform efforts that are currently taking place within the California Community College system, specifically within the Vision for Success.

I am interested in learning about the experiences of former foster youth in community college. I am reaching out to you today because I would like to ask former foster youth at [Your] College about their experiences as a college student. You are listed as the foster youth success initiative liaison on your campus and I was hoping that you might share the survey link below with the students in your Guardian Scholars Program.

Below is a link to an online interview. Each question is open ended. Feel free to type as much or as little information as you'd like. As a token of my appreciation for participating, each student that completes the online interview will receive a \$10 electronic gift card to a store of their choice.

\section{CLICK HERE TO ACCESS THE SURVEY}

This research as been approved by the Institutional Review Board (IRB). If you have any questions, please feel free to contact me directly.

Thank you, in advance, for your support.

\author{
Lauren Ford \\ Doctoral Candidate - Educational Leadership
}


San Francisco State University

Iford2@mail.sfsu.edu / ford.lauren.n@gmail.com

513.290.0394 


\title{
Appendix D
}

\author{
Scholar Electronic Interview Questions
}

\section{Implied Consent to Participate in Research}

Data collected from this confidential survey will be used for completion of a doctoral degree in educational leadership at San Francisco State University. The information gathered will be used for research on community college reform efforts and the experience of former foster youth in community colleges.

The interview questions will be about your experience as a former foster youth in community college.

You have been invited to participate because you are involved in your campus program that supports current or former foster youth.

You must be 18 years of age or older to participate. There are no risks to you in participating in this online, written interview. If you are eligible to complete the full interview, you will receive a $\$ 10$ electronic gift card via email. You may choose to participate or not. You may answer only the questions you feel comfortable answering, and you may stop at any time. If you do not wish to participate, you may simply exit this online interview, with no penalty to yourself. If you do participate, completion and return of the survey indicates your consent to the above conditions. Your decision whether or not to participate in this research will have no influence on your present or future status at San Francisco State University nor at your current college.

The survey should take approximately 30 minutes to complete. Any questions or concerns should be directed to the principal investigator, Lauren Ford, at Iford2@mail.sfsu.edu or the research advisor, Lecturer Laurie Scolari, at Iscolari@sfsu.edu.

1. Are you currently or have you ever been in court-ordered foster care? $(\mathrm{Y} / \mathrm{N})$

2. Why did you decide to attend college?

3. How and why did you select the college that you are currently attending? 
4. What was your experience like when you first decided to enroll at the college that you are currently attending?

(If you were successful in enrolling when you first decided to attend college, what do you think contributed to your success? If you were not successful, what do you think were barriers that prevented you from being successful?)

5. Did you have a major selected when you first enrolled in college?

a. Yes (Skip to Q. 6)

b. No, but I have one now (Skip to Q. 7)

c. No, I am still selecting one (Skip to Q. 8)

6. If yes, how did you go about making the decision to select the major that you did?

7. If no, but you have since selected a major, how did you go about selecting your major?

8. If no, and you still have not selected a major, how do you think you will go about selecting your major?

9. Is there anything that your college did do, or could do, to help you or your peers decide on a major early on?

10. How do you decide which classes to take?

11. Have you ever had to stop attending classes or drop out completely prior to finishing your educational goal? $(\mathrm{Y} / \mathrm{N})$

12. Have any other foster youth you know ever had to stop attending classes or drop out completely prior to finishing their educational goal? ( $Y / N)$

13. Why do you think that students, especially former foster youth, stop attending classes or drop out of school?

14. Are you aware of any programs or supports on campus that are dedicated to helping former foster youth be successful in college? If so, what are they and what types of support do they provide?

15. What kinds of things can the college do to help former foster youth students overcome barriers and stay in school?

16. When do you expect to complete your educational goal? (What semester and what year?

17. How do you know when you are expected to complete your educational program?

18. Has your college ever asked you about your opinion, as a former foster youth, on how the college can help students be more successful at your college? ( $\mathrm{Y}=$ Skip to $\mathrm{Q} .19 / \mathrm{N}=$ Skip to $\mathrm{Q} .20)$

19. If yes, how were you involved and how did they ask you about your opinion?

20. Has your college ever asked you about your opinion or experiences as a former foster youth with any Guided Pathways or College Reform efforts, specifically? ( $\mathrm{Y}=$ Skip to Q21. / N = Skip to D1 / Unsure= Skip to D1.) 
The following questions are demographic questions only. They are just being asked so that the researcher knows a little more about who has completed this online interview. Your personal information will not be shared back with your institution. Your personal information will also be removed from your answers in order to allow your responses to be anonymous.

21. Age you turned on your most recent birthday?

22. How many semesters in college have you completed?

23. What is your current educational goal?

a. Obtain an associate degree and transfer to a 4-year institution

b. Transfer to a 4-year institution without an associate degree

c. Obtain a 2-year associate degree without transfer

d. Obtain a 2-year technical degree without transfer

e. Earn a career technical certificate without transfer

f. Discover/Formulate career interests, plans, goals

g. Prepare for a new career (acquire job skills)

h. Advance in current job/career (update job skills)

i. Maintain certificate or license

j. Educational development

k. Improve basic skills

I. Complete credits for high school diploma or GED

$m$. Undecided on goal

n. To move from noncredit coursework to credit coursework

o. 4-year college student taking courses to meet 4-year college requirements

24. What is your race or ethnicity? (Feel free to check one or more option)

a. Mexican, Mexican-American, Chicano

b. Click to write Choice 2

c. Central American

d. South American

e. Hispanic: Other

f. Asian: Indian

g. Asian: Chinese

h. Asian: Japanese

i. Asian: Korean

j. Asian: Laotian

k. Asian: Cambodian

I. Asian: Vietnamese

m. Asian: Hmong 
n. Asian: Other - A person having origins in any of the original peoples of the Far East, Southeast Asia, or the Indian Subcontinent

o. Black or African-American: A person having origins in any of the black racial groups of Africa.

p. American Indian/Alaskan Native - A person having origins in any of the original peoples of North and South America (including Central America) who maintains cultural identification through tribal affiliation or community attachments

q. American Indian

r. Pacific Islander: Guamanian

s. Pacific Islander: Filipino

t. Pacific Islander: Hawaiian

u. Pacific Islander: Samoan

v. Pacific Islander: Other - A person having origins in any of the original peoples of Hawaii, Guam, Samoa, or other Pacific Islands

w. White: A person having origins in any of the original peoples of Europe, the Middle East, or North America

$x$. Decline to State

25 . What is your gender?

a. Female

b. Male

c. Transgender

d. Other

e. Decline to State

26. What is the name of the community college you currently attend?

Thank you for submitting your responses to this survey. As a thank you, I'd like to send you a \$10 gift card via email. In order to receive your gift card, please enter your preferred email address below:

If you would like to be contacted to participate in a follow up focus group to share more about your experiences as a former foster youth in community college, please include your name and email address below: 


\title{
Appendix E
}

\author{
Scholar Focus Group Recruitment Flyer
}

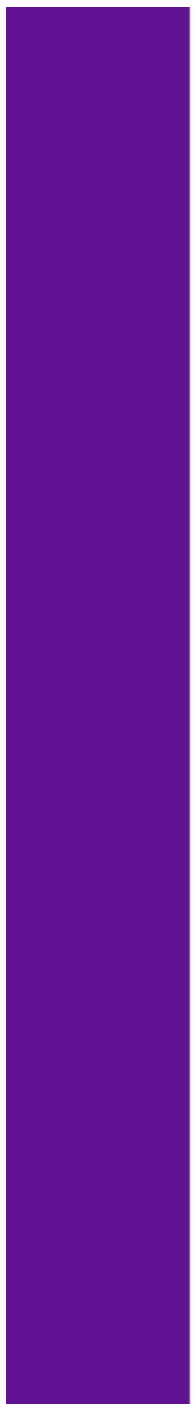

\section{Participants Needed!}

to participate in a Student Focus Group as a part of a research project related to:

Better understanding the experiences of former foster youth in college and applying this information to community college reforms

\section{When}

Tues., December 3, 12:30pm - 2:00pm

$$
\text { OR }
$$

Weds., December 4, 12:30pm - 2:00pm

Where

Foggyville Building $X, X X X$

Eligibility:

- Current or former foster youth

- Current students at Fogyville College

This focus group will be in a collaborative learning environment and will take approximately 90 minutes of your time. All participants will receive a free lunch and a \$10 e-gift card as a thank you for your time.

All feedback and information obtained will remain entirely anonymous, confidential, and secure.

Sign Up here:

For more information, contact:

Lauren Ford

Iford2@mail.sfsu.edu

513.290 .0394 


\title{
Appendix F
}

\author{
Scholar Focus Group Informed Consent Form
}

\section{San Francisco State University Informed Consent to Participate in Research}

Research Title: Community College Reform: Placing Foster Youth at the Center of a More Equitable Vision for Success

\begin{abstract}
A. PURPOSE AND BACKGROUND
The purpose of this research is on community college reform efforts and the experience of former foster youth in community colleges. The researcher, Lauren Ford, is a graduate student at San Francisco State University conducting research for a doctorate in educational leadership. You are being asked to participate in this study because you are a student in your community college's campus program to support current or former foster youth.
\end{abstract}

\section{B. PROCEDURES}

If you agree to participate in this research, the following will occur:

- you will participate in a focus group lasting approximately ninety minutes about your experience as a former foster youth in community college.

- the interview will be audio recorded to ensure accuracy in reporting your statements.

- total time commitment will be ninety minutes.

\section{RISKS}

There are no presumed risk to you for participating in this research project. No names or identities will be used in any published reports of the research. Only the researcher will have access to the research data. 


\section{CONFIDENTIALITY}

The research data will be kept in a secure location and only the researcher will have access to the data. All research data will be stored in an encrypted document on a password protected computer. Audio or video recordings will be destroyed at the end of the study.

\section{E. DIRECT BENEFITS}

There will be no direct benefits to the participant.

\section{F. COSTS}

There will be no cost to you for participating in this research.

\section{G. COMPENSATION}

Student participants will receive a $\$ 10$ electronic gift card after completing the interview. The gift cards will be sent electronically through Tango Card services. The $\$ 10$ incentive will be automatically sent to participants upon the completion of the focus group. Tango can integrate into Qualtrics in order to automatically send a $\$ 10$ electronic gift card via Tango Card Services for participants to redeem.

\section{H. ALTERNATIVES}

The alternative is not to participate in the research.

\section{I.. QUESTIONS}

If you have any questions about the study, you may contact the researcher, Lauren Ford by email at 1ford2@mail.sfsu.edu or you may contact the researcher's advisor, Professor Laurie Scolari at lscolari@sfsu.edu.

Questions about your rights as a study participant, or comments or complaints about the study, may also be addressed to the Human and Animal Protections at 415: 338-1093 or protocol@sfsu.edu.

\section{J. CONSENT}

You have been given a copy of this consent form to keep.

PARTICIPATION IN THIS RESEARCH IS VOLUNTARY. You are free to decline to participate in this research, or to withdraw your participation at any point, without penalty. Your decision whether or not to participate in this research will have no influence on your present or future status at San Francisco State University. 
Signature

$$
\text { Research Participant }
$$

Signature

$$
\text { Researcher }
$$

Date:

Date:

Please scan the code below or enter the URL below in order to complete the demographic survey and receive your $\$ 10$ gift card.

Scan QR code

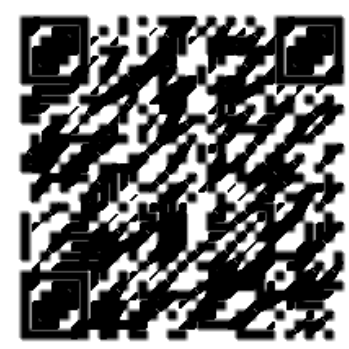

OR

Go to this URL:

https://bit.ly/2r6xC_ 


\title{
Appendix G
}

\author{
Scholar Paired Interview Questions
}

Introduction

1. Let's go around, introduce yourself, and please just tell us a little bit about why you decided to go to college.

Choosing a major

2. How many of you have chosen a major already? How many of you feel you have not made a decision about your choice of major yet? (Look for a show of hands, say the number out loud for the recorder)

3. Let's begin with those of you who have decided on a major already. How did you go about making that decision?

Probes:

- How long did it take you to choose a major?

- Have you changed your major along the way? (Look for a show of hands from people who changed their major multiple times)

- What was helpful in exploring what your interests were?

4. For those who have not decided on a major, how do you think you will go about making the decision?

Probes:

- How much do you know about your areas of interest? What other information do you need to make a decision?

5. What do you think the college could do to help you and other students decide on a major early on?

Choosing classes

6. How do you decide which courses to take?

Probes:

- Do you know which courses you need to take next semester? If not, how will you find out?

- Where can you get the most helpful information on which courses to take every semester?

- What has been your experience in choosing courses? Can you usually register for the courses you need?

- Are you able to get the advising/counseling that you need? 
- What do you think works well when it comes to choosing your courses every semester?

- What do you think could improve?

Closing

7. Do you know anyone who has had to stop or drop out before finishing their program? Why do you think that happens?

8. What kinds of things can the college do to help students overcome their biggest challenges and stay in school? 